\title{
Hybrid Wing Body Shielding Studies Using an Ultrasonic Configurable Fan Artificial Noise Source Generating Simple Modes
}

Daniel L. Sutliff and Clifford A. Brown

Glenn Research Center, Cleveland, Ohio

Bruce E. Walker

Channel Islands Acoustics, Camarillo, California 


\section{NASA STI Program . . . in Profile}

Since its founding, NASA has been dedicated to the advancement of aeronautics and space science. The NASA Scientific and Technical Information (STI) program plays a key part in helping NASA maintain this important role.

The NASA STI Program operates under the auspices of the Agency Chief Information Officer. It collects, organizes, provides for archiving, and disseminates NASA's STI. The NASA STI program provides access to the NASA Aeronautics and Space Database and its public interface, the NASA Technical Reports Server, thus providing one of the largest collections of aeronautical and space science STI in the world. Results are published in both non-NASA channels and by NASA in the NASA STI Report Series, which includes the following report types:

- TECHNICAL PUBLICATION. Reports of completed research or a major significant phase of research that present the results of NASA programs and include extensive data or theoretical analysis. Includes compilations of significant scientific and technical data and information deemed to be of continuing reference value. NASA counterpart of peer-reviewed formal professional papers but has less stringent limitations on manuscript length and extent of graphic presentations.

- TECHNICAL MEMORANDUM. Scientific and technical findings that are preliminary or of specialized interest, e.g., quick release reports, working papers, and bibliographies that contain minimal annotation. Does not contain extensive analysis.

- CONTRACTOR REPORT. Scientific and technical findings by NASA-sponsored contractors and grantees.
- CONFERENCE PUBLICATION. Collected papers from scientific and technical conferences, symposia, seminars, or other meetings sponsored or cosponsored by NASA.

- SPECIAL PUBLICATION. Scientific, technical, or historical information from NASA programs, projects, and missions, often concerned with subjects having substantial public interest.

- TECHNICAL TRANSLATION. Englishlanguage translations of foreign scientific and technical material pertinent to NASA's mission.

Specialized services also include creating custom thesauri, building customized databases, organizing and publishing research results.

For more information about the NASA STI program, see the following:

- Access the NASA STI program home page at http://www.sti.nasa.gov

- E-mail your question to help@sti.nasa.gov

- Fax your question to the NASA STI Information Desk at 443-757-5803

- Phone the NASA STI Information Desk at 443-757-5802

- Write to: STI Information Desk NASA Center for AeroSpace Information 7115 Standard Drive Hanover, MD 21076-1320 


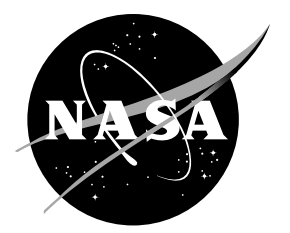

\section{Hybrid Wing Body Shielding Studies Using an Ultrasonic Configurable Fan Artificial Noise Source Generating Simple Modes}

Daniel L. Sutliff and Clifford A. Brown

Glenn Research Center, Cleveland, Ohio

Bruce E. Walker

Channel Islands Acoustics, Camarillo, California

Prepared for the

18th Aeroacoustics Conference

cosponsored by the American Institute of Aeronautics and Astronautics and the Confederation of European Aerospace Societies

Colorado Springs, Colorado, June 4-6, 2012

National Aeronautics and

Space Administration

Glenn Research Center

Cleveland, Ohio 44135 


\section{Acknowledgments}

The authors world like to acknowledge the efforts of D. Podboy, L. Smith, R. Loew, B. Groening, E. Mysliwiec, and J. Mirecki of TFOME for their support in model assembly and ATL testing. C. Garcia (also TFOME) wrote the A/D and D/A algorithms used for signature generation and in-duct verification. This work was supported by the NASA Vehicle Systems Integration program/ Environmentally Responsible Aircraft project and the Fundamental Aeronautics/Subsonic Fixed Wing program.

Trade names and trademarks are used in this report for identification only. Their usage does not constitute an official endorsement, either expressed or implied, by the National Aeronautics and Space Administration.

This work was sponsored by the Fundamental Aeronautics Program at the NASA Glenn Research Center.

Level of Review: This material has been technically reviewed by technical management.

Available from

NASA Center for Aerospace Information 7115 Standard Drive

Hanover, MD 21076-1320
National Technical Information Service 5301 Shawnee Road Alexandria, VA 22312 


\title{
Hybrid Wing Body Shielding Studies Using an Ultrasonic Configurable Fan Artificial Noise Source Generating Simple Modes
}

\author{
Daniel L. Sutliff and Clifford A. Brown \\ National Aeronautics and Space Administration \\ Glenn Research Center \\ Cleveland, Ohio 44135 \\ Bruce E. Walker \\ Channel Islands Acoustics \\ Camarillo, California 93010
}

\begin{abstract}
An Ultrasonic Configurable Fan Artificial Noise Source (UCFANS) was designed, built, and tested in support of the Langley Research Center's 14- by 22-Foot wind tunnel test of the Hybrid Wing Body (HWB) full three-dimensional 5.8 percent scale model. The UCFANS is a 5.8 percent rapid prototype scale model of a high-bypass turbofan engine that can generate the tonal signature of candidate engines using artificial sources (no flow). The purpose of the test was to provide an estimate of the acoustic shielding benefits possible from mounting the engine on the upper surface of an HWB aircraft and to provide a database for shielding code validation. A range of frequencies, and a parametric study of modes were generated from exhaust and inlet nacelle configurations. Radiated acoustic data were acquired from a traversing linear array of 13 microphones, spanning $36 \mathrm{in.} \mathrm{Two} \mathrm{planes} \mathrm{perpendicular} \mathrm{to} \mathrm{the} \mathrm{axis} \mathrm{of} \mathrm{the}$ nacelle (in its $0^{\circ}$ orientation) and three planes parallel were acquired from the array sweep. In each plane the linear array traversed five sweeps, for a total span of $160 \mathrm{in}$. acquired. The resolution of the sweep is variable, so that points closer to the model are taken at a higher resolution. Contour plots of Sound Pressure Level, and integrated Power Levels are presented in this paper; as well as the in-duct modal structure.
\end{abstract}

\subsection{Introduction}

The Subsonic Fixed Wing (SFW) and Environmentally Responsible Aircraft (ERA) Projects of NASA Aeronautics Research Mission Directorate Fundamental Aeronautics Program established the research goals (Ref. 1) to develop innovative Hybrid Wing Body configurations that meet the NASA N+2 goals by enabling noise prediction methods for subsonic fixed wing aircraft fleet in 2020. The Ultrasonic Configurable Fan Artificial Noise Source (UCFANS) investigation was conducted as part of a larger effort to develop a hybrid wing body subsonic transport configuration with noise prediction methods to meet the NASA SFW and ERA N+2 noise goal of $-42 \mathrm{~dB}$ cum relative to FAR 36 Stage 4 while achieving a -25 percent fuel burned compared to current transports.

Shielding of engine noise by airframe components is a significant consideration in the design of nextgeneration transport aircraft to meet these goals. Fan tones and broadband noise are important components of engine noise. Tones in particular tend to be characterized by discrete radiated modes with distinctive radiation patterns. Modeling aircraft noise accurately will depend partially on knowledge of the effect of nearby barriers on these radiation patterns. The purpose of this paper is the documentation of a scale-mode test nacelle to validate code predictions of shielding and scattering of modal radiation from realistic representations of turbofan inlets and exhausts when located near finite barrier surfaces. 
The test described in this paper is in support of the NASA Hybrid Wing Body (HWB) 5.8 percent scale model test at Langley Research Center's 14- by 22-Foot wind tunnel (Ref. 2). The HWB test will be conducted to determine the noise characteristics of an HWB aircraft and in particular to determine the acoustic shielding benefits from mounting the engines on the upper surface of the airframe. Jet engine noise as well as the broadband component of turbomachinery noise will be simulated. The purpose of the UCFANS test is to provide complimentary data on the shielding of the tonal component of turbomachinery noise. The data will be used to estimate shielding from the HWB configuration and to provide a database for shielding code validation.

The UCFANS is a 5.8 percent scale model of a turbofan nacelle and fan duct. It was designed, built, and tested for measuring acoustic shielding by prospective airframe components of modal fan tone radiation in an anechoic chamber. Artificial (no flow) noise sources are used in the model to reproduce the noise characteristics of a turbofan engine without the complexity of scaling down the fan. The artificial sources also offer additional control over the mode and frequency at each point to give a more precise database for prediction code development and validation. Model fabrication was accomplished using rapid-prototype technology at NASA Glenn Research Center.

An array of 36 wide-bandwidth electrostatic actuators was installed in a dual annulus within the fan duct and driven with modally phased tone signals between 7 and $40 \mathrm{kHz}$. Three rows of 24 widebandwidth microphones were installed in the duct between the actuator array and the configurable inlet/exhaust exit plane to measure the modal tone generation. Modal excitation and analysis at up to nine simultaneous frequencies was accomplished by multiplexing. Note that this arrangement allows fine control over tone frequency and azimuthal mode but only limited control over radial modes.

Spectral components of the in-duct microphone data corresponding to reference excitation frequencies were spatially filtered to recover complex amplitudes of circumferential mode orders for each of the three rings. For each circumferential mode, radial components were estimated by steering vector matrix inversion for the three rings. Far-field radiation was measured using a three-dimensional traversing microphone rake. Corresponding far-field data was converted to "lossless" (spherical spreading only) levels at the locations of the microphones based on temperature and humidity data recorded for each data set.

\subsection{Facility}

The Acoustical Testing Laboratory (Ref. 3) (ATL) consists of a 23- by 27- by 20-ft (height) convertible hemi/anechoic chamber and separate sound-attenuating test support enclosure. Absorptive 34-in. fiberglass wedges in the test chamber provide an anechoic environment down to $100 \mathrm{~Hz}$. A springisolated floor system affords vibration isolation above $3 \mathrm{~Hz}$. These criteria, along with very low design background levels, enable the acquisition of accurate and repeatable acoustical measurements on test articles that produce very little noise. Removable floor wedges allow the test chamber to operate in either a hemi-anechoic or anechoic configuration, depending on the size of the test article and the specific test being conducted (the UCFANS test was conducted in the anechoic configuration). The test support enclosure functions as a control room during normal operations.

A traverse system that can travel in the three dimensions of the chamber was utilized for acquiring acoustic data for this test. The traverse travel was limited to motion in planes, (e.g., a horizontal or a vertical plane, but no arcs). The traverse system drove a linear array of $13,1 / 4 \mathrm{in}$. condensor style microphones spaced 3 in. apart (36 in. span).

\subsection{Test Articles}

The UCFANS test article was based on the 5.8 percent scale model of the candidate nacelle of the N2A-EXTE HWB model. This turbofan engine is an ultra-high bypass fan (Ref. 4) class. This scale factor resulted in a duct diameter of approximately 6-in., a nacelle length of approximately 1-ft, and a frequency 
range of $\sim 5$ to $50 \mathrm{kHz}$. The cut-on circumferential mode generation for the prototype turbofan, based on rotor blade and stator vane count, is $m=10$ at 2 BPF and $m=-8$ at 3 BPF. These modes, while not used in this test were the basis for choosing the actuator count. The model was manufactured at the NASA Glenn Research Center using rapid prototyping methods.

The 'wing' used to determine the shielded radiation was a two-dimensional $1 / 4$ in. thick aluminum plate. The trailing and leading edge was manufactured to match the contours of the HWB N2A model, but the plan form was not.

\subsection{Actuators}

The frequency range from blade passing frequency (BPF) at approach to $3 \mathrm{BPF}$ at takeoff is from just under $8 \mathrm{kHz}$ to just above $57 \mathrm{kHz}$ at the 5.8 percent model scale. To accomplish this and to allow some control over radial mode content, ultrasonic electrostatic actuators were used. These actuators have a nominal frequency response of $95 \mathrm{~dB}$ SPL at $10 \mathrm{~cm}$ for a $9.9 \mathrm{~V}_{\text {peak to peak }} 5 \mathrm{kHz}$ input signal, $\pm 11 \mathrm{~dB}$ from 4 to $110 \mathrm{kHz}$. Dedicated amplifier/power supply assemblies drove the actuators. Figure 1 shows the dimensions of an isolated driver in the standard monopole configuration (Figure 1(a)). The drivers were modified (by removing the 'can' mounted on the backside) so as to provide a dipole source (Figure 1b).

The actuators (two standard monopole versions and 4 dipole configurations) were evaluated individually for free-field characteristics by placing them in the ATL (see Figure 2) and measuring the response to a $100 \mathrm{kHz}$ MLS input signal at a $1 \mathrm{~m}$ radius at $15^{\circ}$ increments. MLS (Ref. 5) (or Maximum Length Sequence, sometimes referred to as Gallois Sequence) is a binary pulse-width modulated signal whose circular autocorrelation function is $\delta(0)$. The length of the sequence is $2^{N-1}$, where $N=18$ was used in this study. At a $100 \mathrm{kHz}$ clock rate, this provides a $2.6 \mathrm{sec}$ burst of deterministic "noise" that contains all frequencies to above $50 \mathrm{kHz}$ but which has a crest factor of 1, as opposed to Gaussian noise, which has an effective crest factor of over 3. Cross-correlating the excitation signal with a received signal provides the impulse response of the system being measured. A typical frequency response plot is shown in Figure 3(a) and a typical directivity plot in Figure 3(b). The responses were found to be consistent.

Each actuator and in-duct microphone was bench-tested for complex frequency response and equalization tables created to minimize the effect of actuator non-uniformity on modal radiation and of microphone non-uniformity on modal analysis. Actuators were driven from a dedicated D/A system using pre-recorded 37-channel multi-frequency signals (one for each actuator and one reference) WAV file. Induct microphone data were recorded on a separate dedicated A/D system, resulting in a 73-channel (one for each microphones and reference) TDMS file (a National Instruments file format). Far-field data was recorded on a dedicated facility A/D system, resulting in a 16-channel file (one fixed microphone, 13 traversing microphones, one reference and one timing signal). For each position of the far-field microphone traverse, three combinations of tone excitation and a 3-sec burst of 36-channel statistically independent random noise were recorded to provide differing radial mode mixes and to compare data being taken in a separate test using pneumatic broadband noise generation.

\subsection{Internal Microphones}

The acoustic signature was measured in-duct, for modal content verification, by omni-directional electric condenser microphones (Figure 4(a)). These microphones are typically used in the audible range (20 to $16,000 \mathrm{~Hz}$ ) but have been utilized for ultrasonic wildlife studies (Ref. 6). These microphones were also evaluated for frequency response and compared to the response of a $1 / 4 \mathrm{in}$. B\&K 4939 style microphone (Figure 4(b)). Microphones whose response was relatively inconsistent were not used. 


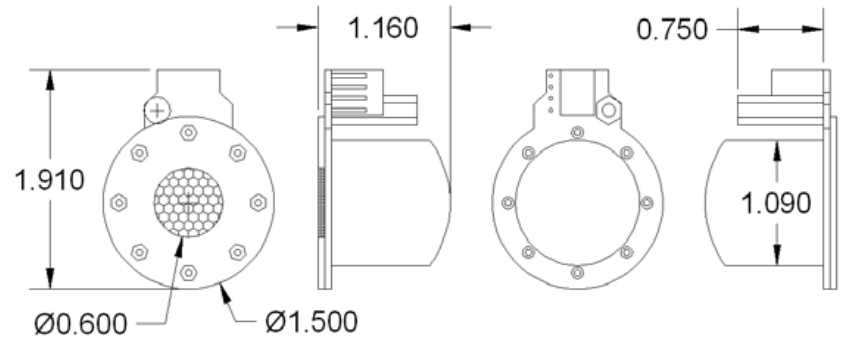

(a)
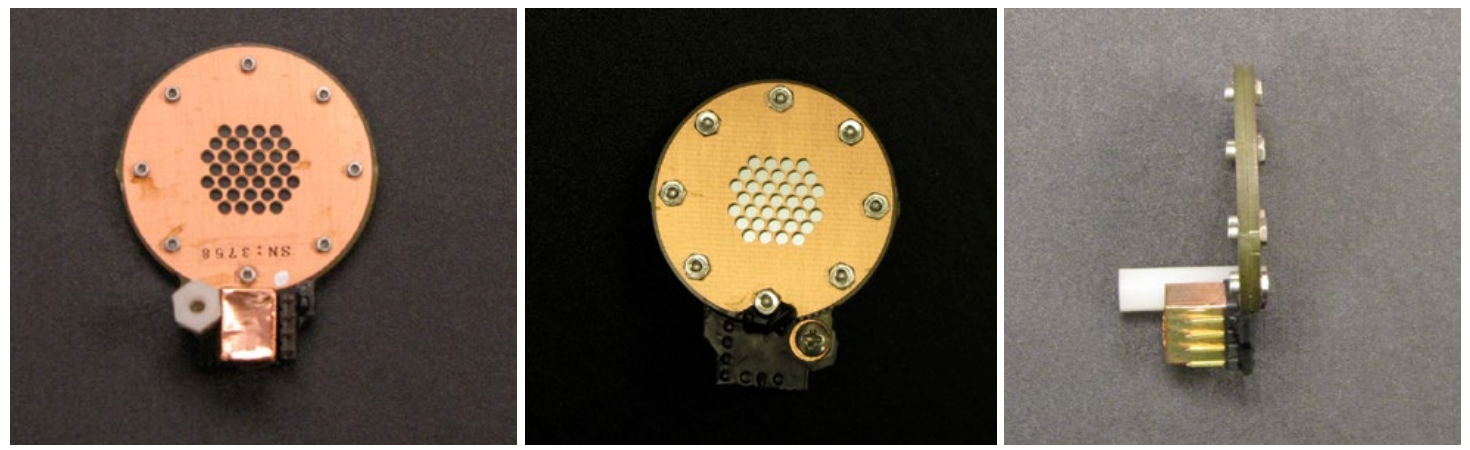

(b)

Figure 1.-(a) Dimensions of Electrostatic Actuator in Monopole Configuration. (b) Photographs of Electrostatic Actuator in Dipole Configuration.

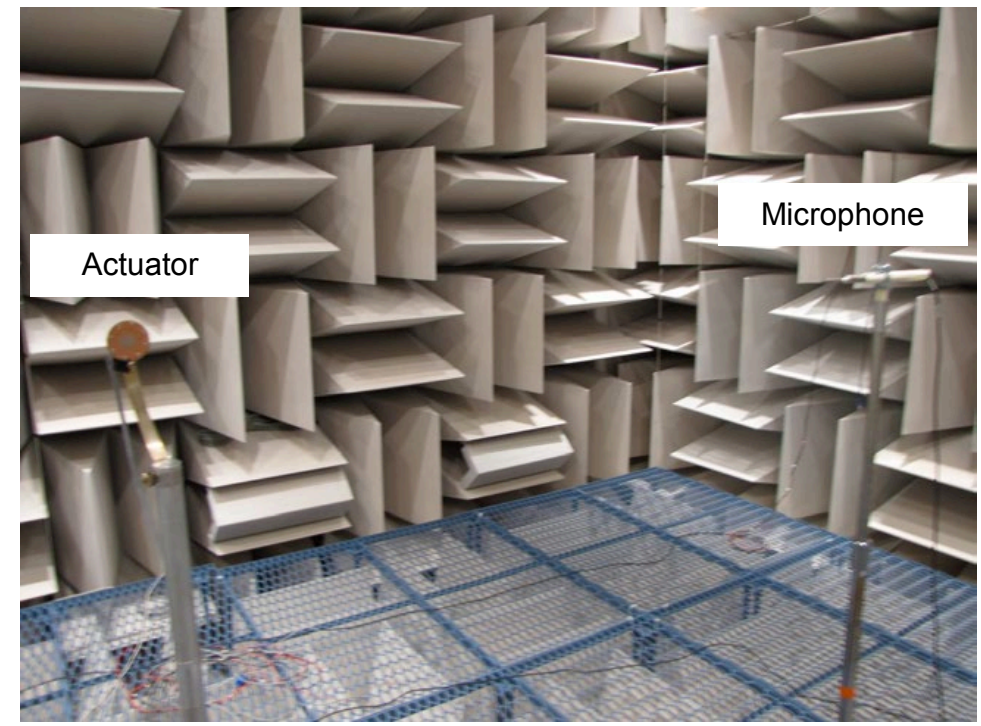

Figure 2.-Isolated Actuator Test Setup in ATL. 


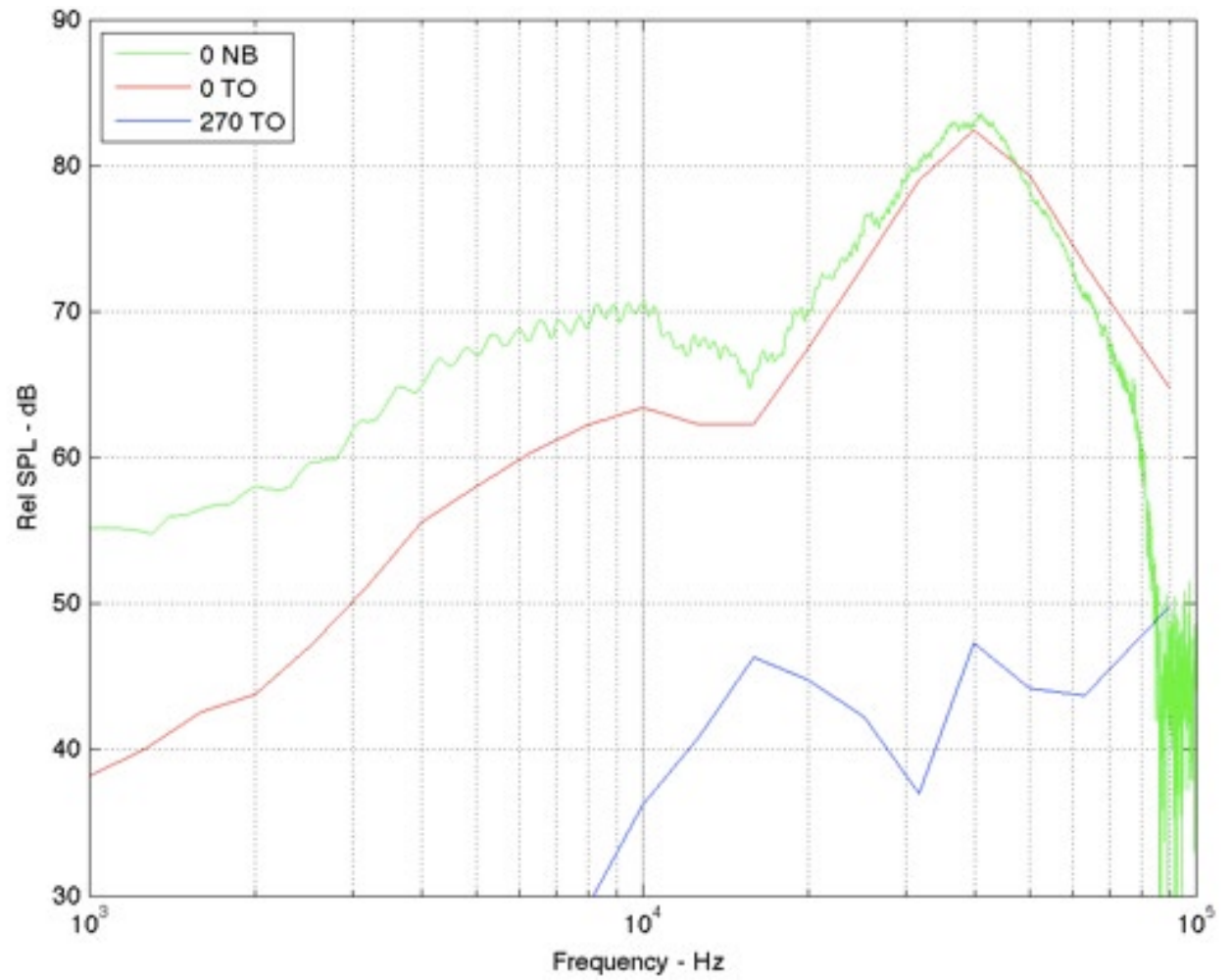

(a)
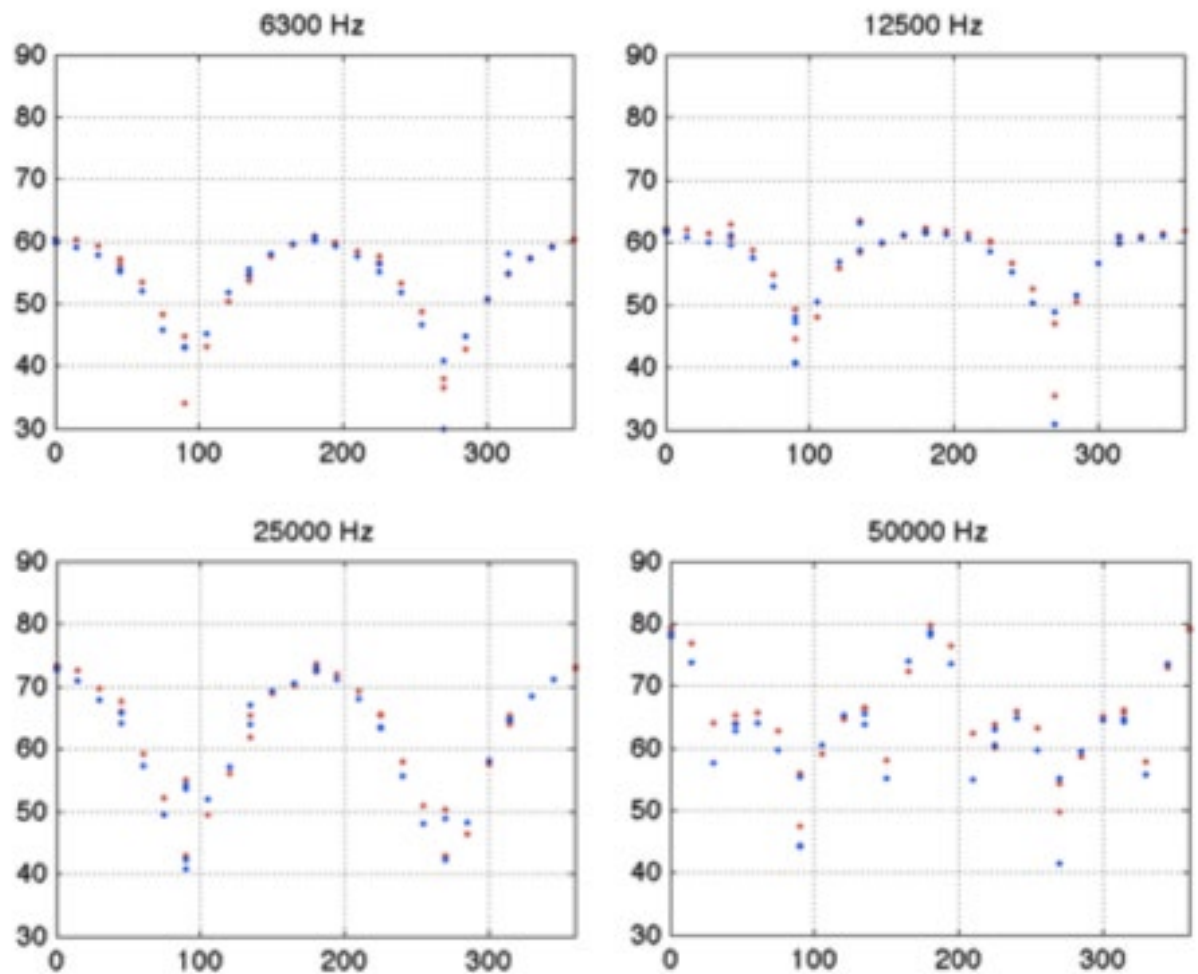

(b)

Figure 3.-(a) Typical Narrow Band (NB) and Third Octave (TO) Frequency Response of Isolated Actuator (Dipole Configuration) at $0^{\circ}$ and $270^{\circ}$ from Principal Radiation Axis. (b) Typical Directivity Response (dB versus Angle) of Isolated Actuator (Dipole Configuration). 
Dimensions in $\mathrm{mm}$ (not to scale)

WM-64C/64K

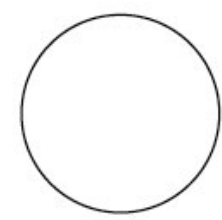

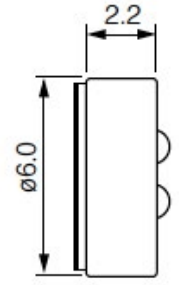

(a)
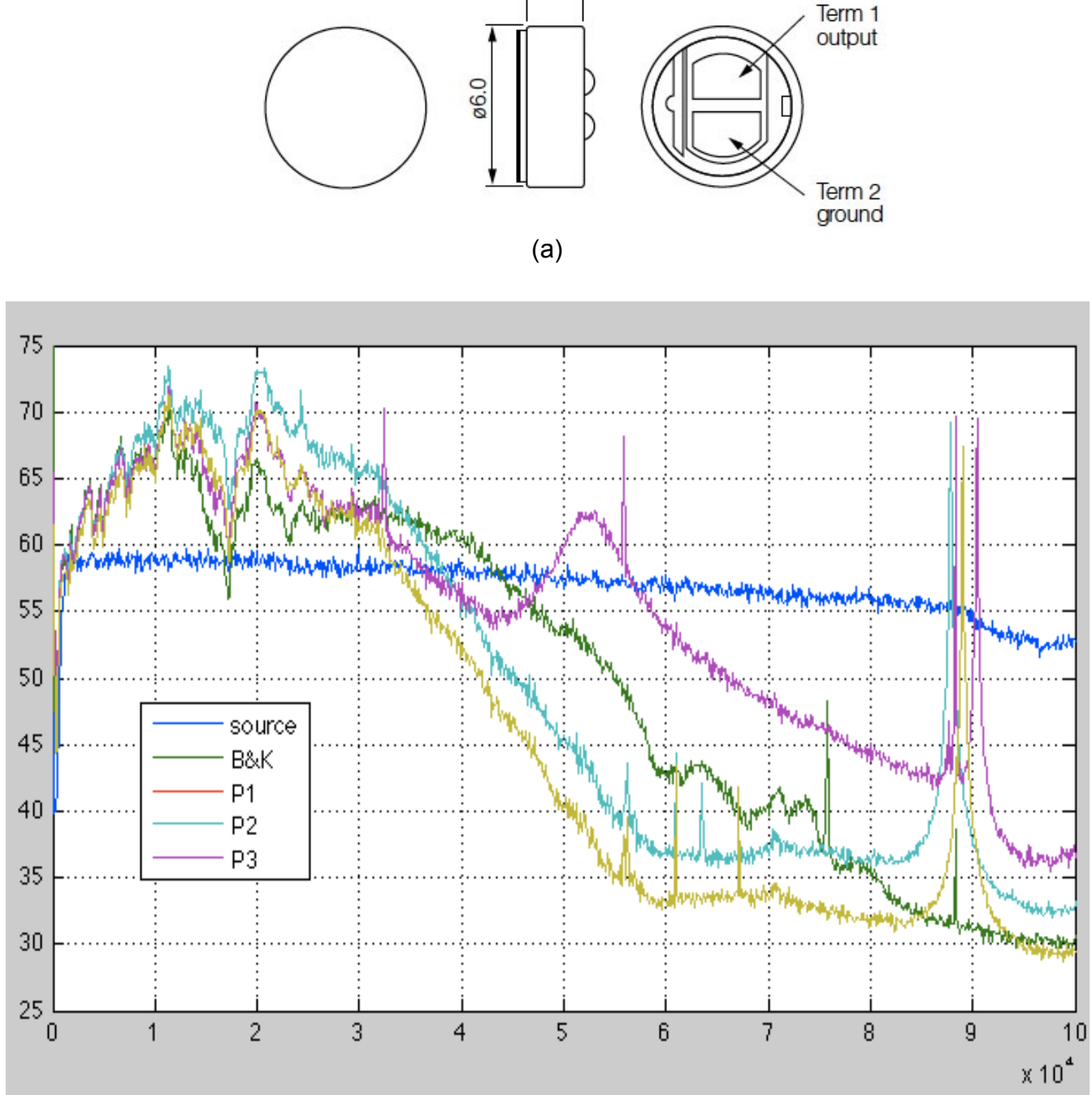

(b)

Figure 4.-(a) Dimensions of Electret Microphone. (b) Sample Isolated Electret Microphone Frequency Response Curves Compared to $1 / 4$ in. B\&K 4939 Style Microphone.

\subsection{Assembly}

Figure 5 shows a CAD drawing of the model. Areas critical to far-field acoustic radiation from the duct, such as inlet lip and duct exit dimensions were held to high fidelity, while areas not so critical to acoustics (e.g., internal flow path) were relaxed. The rapid prototype model was cast in five sections so that any section could be removed, replaced, or redesigned. In particular the exhaust lip and tail cone can be removed and replaced with the inlet lip and spinner to switch the model from an exhaust to an inlet radiation model. In these cases, the opposite end of the model is blocked off, and absorptive material placed in the cavity to minimize internal reflections. The remainder of the model is unchanged. The cabling for the internal drivers was routed through the center section. While this arrangement meant that the complete internal and external lines did not completely match the target nacelle, this area is not 
primarily relevant to duct/far-field radiation, and furthermore the prime objective of the test was to obtain the differences between the shielded and unshielded cases. The flexibility in this arrangement (i.e., no rewiring actuators or moving the model), more than outweighed any minor effect on the radiation. An appropriately scaled pylon was place between the nacelle and wing to simulate the mounted geometry on the HWB.

The actuators were mounted in an annular ring, whose dimensions matched the hub-to-tip ratio of the candidate engine nacelle. The inner path was kept constant to the spinner to minimize mode change due to area. Two rows of 18 actuators each were mounted circumferentially, one from the hub, and the second row from the 'tip'. These rows were offset radially in the same axial plane, but interlocking (Figure 5). The actuator count and distribution allowed for circumferential modes up to $m=8$, and two radial modes to be controlled. Higher modes can be generated but effects like aliasing and under specification become factors. Figure 6 shows photographs of the actuators installed.

The microphones were flush mounted internally in 3 axially distributed rows, 24 microphones each, equally spaced in the circumferential direction (Figure 7). This distribution allows for measurement of up to $m=11$, and $n=2$, without aliasing. Compensation curves for all microphones were obtained in-situ.

Figure 8(a) shows the fully assembled UCFANS nacelle and Figure 8(b) shows the nacelle mounted in the ATL.

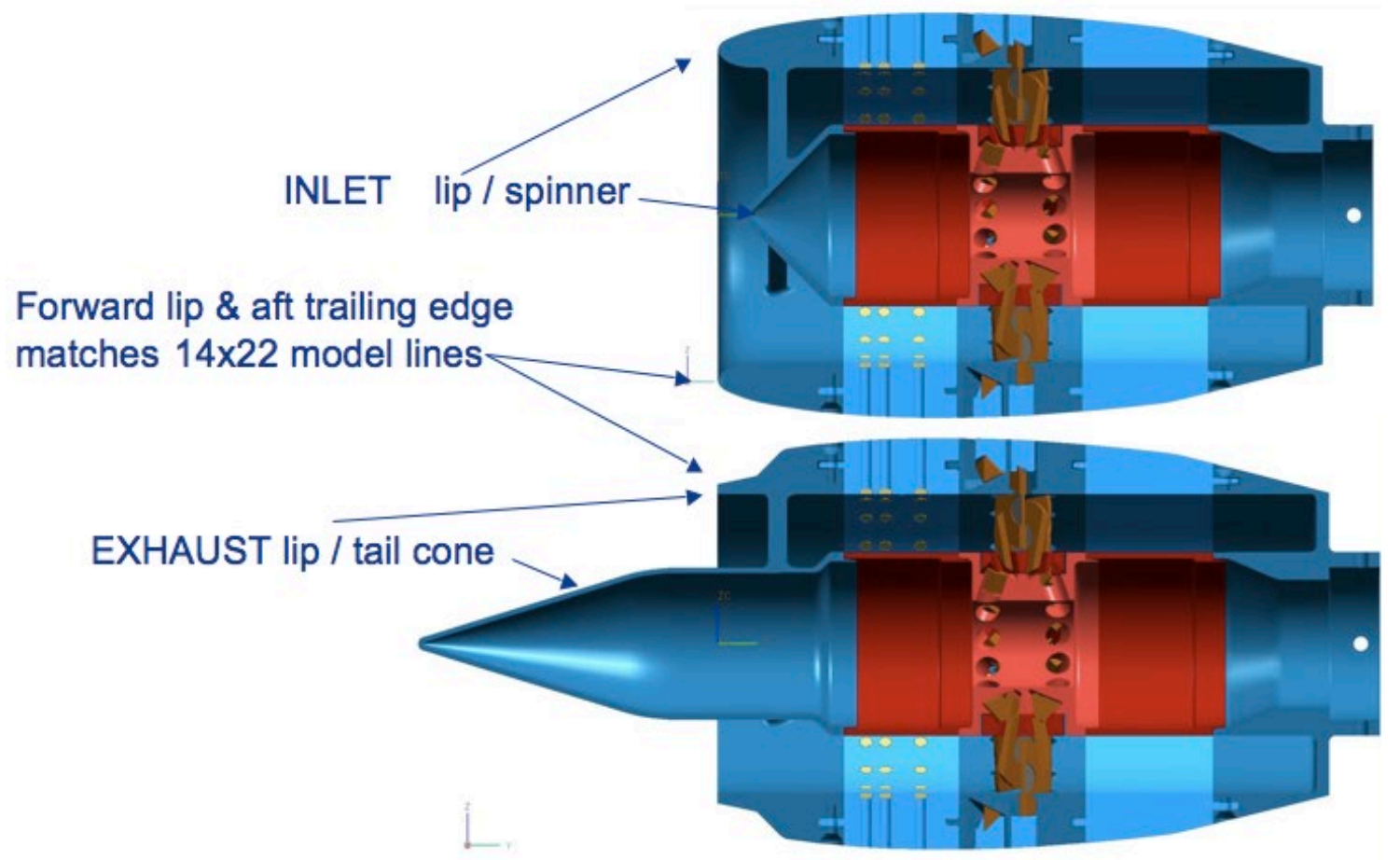

Figure 5.-CAD Drawings of Nacelle in Inlet and Exhaust configurations. 

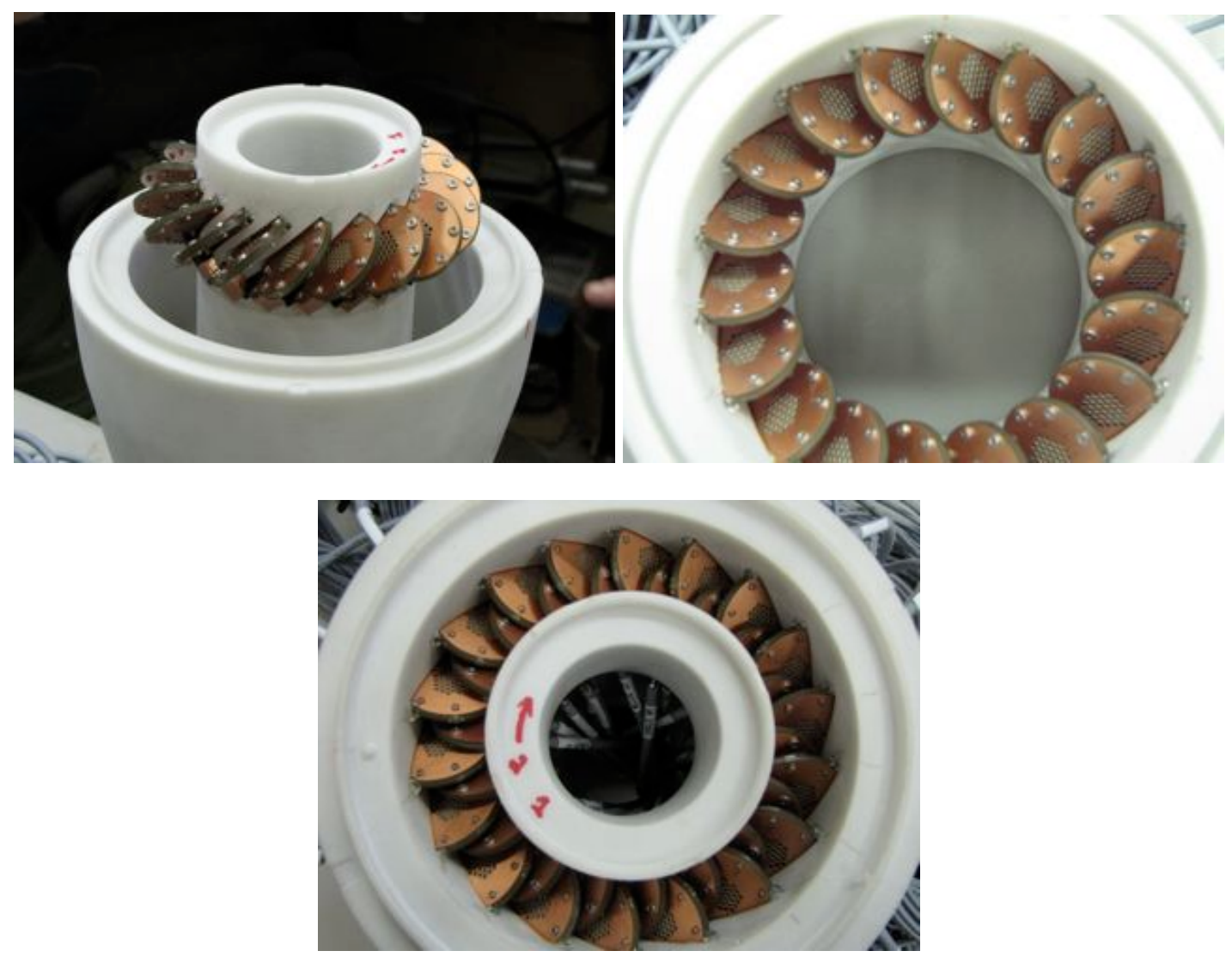

Figure 6.-Actuators Installed in Rapid Prototype Model.

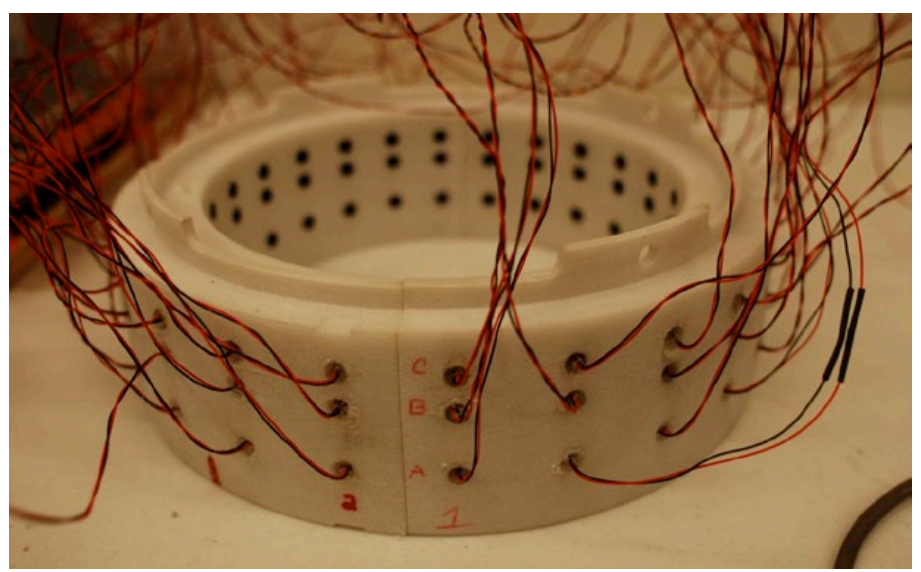

Figure 7.-Electret Microphones Installed in Rapid Prototype Model. 


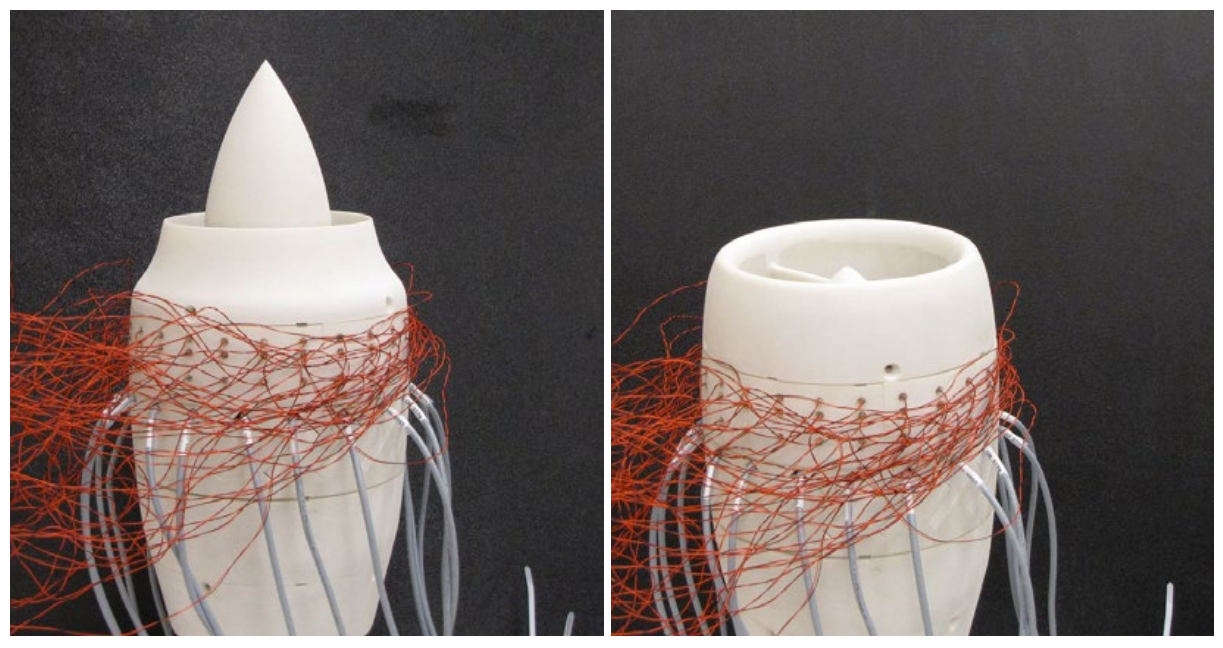

(a)

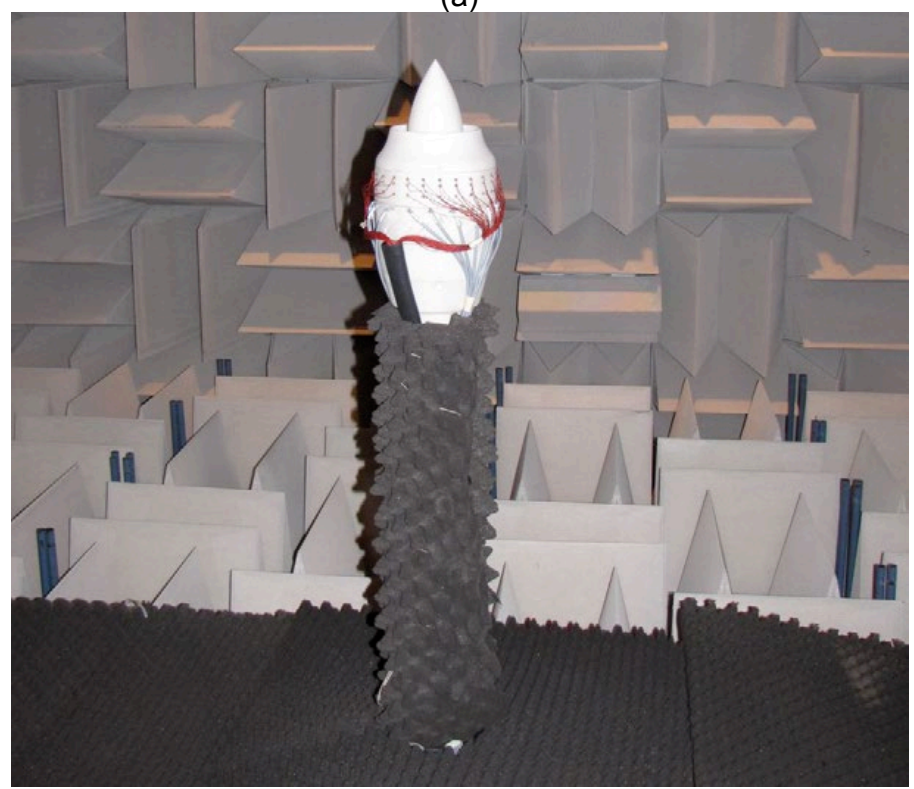

(b)

Figure 8.-(a) Assembled Rapid Prototype Model in Exhaust, and Inlet Configurations (not dressed). (b) UCFANS in Exhaust Configurations Installed in ATL.

\subsection{Shield Hardware}

The wing, or shield, was an aluminum plate $68.5 \mathrm{in}$. high that spanned the entire width of the acoustic chamber. It was decided to trade-off the three-dimensional plan form effects present on the HWB to concentrate on the diffraction effects of the edge. For the UCFANS in the exhaust configuration, a sharp trailing edge based on the HWB N2A-EXTE model was used. The trailing edge was made of solid rapid prototype material and was mounted on, and blended to, the aluminum plate (see Figure 9(a)). For the UCFANS in the inlet condition, the edge is represented by more of the hybrid wing fuselage and was made of fiberglass. The leading edge fits over the trailing edge so that the edges may be reused as illustrated in Figure 9(b).

\subsection{In-Duct Signature Generation and Validation}

See Figure 10 for a block diagram of the signature generation and in-duct measurement. 

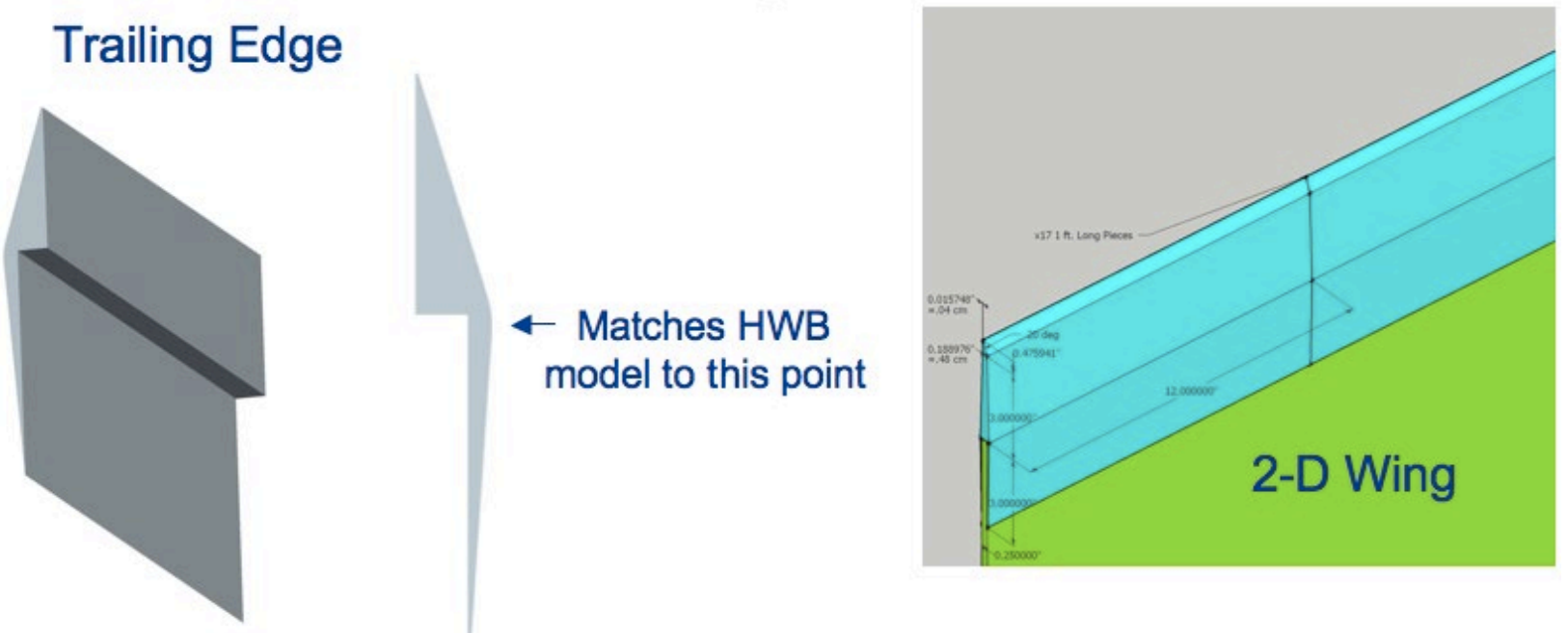

(a)

\section{Leading Edge}

$\leftarrow$ Matches HWB model to this point

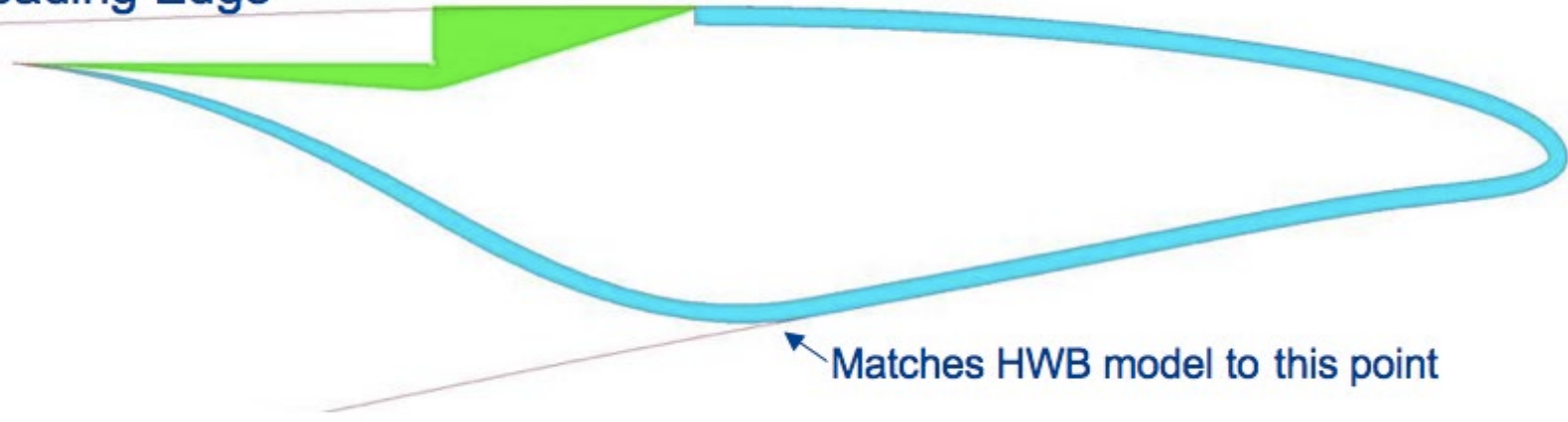

(b)

Figure 9.-(a) Trailing Edges Representation. (b) Leading Edge Representation. 


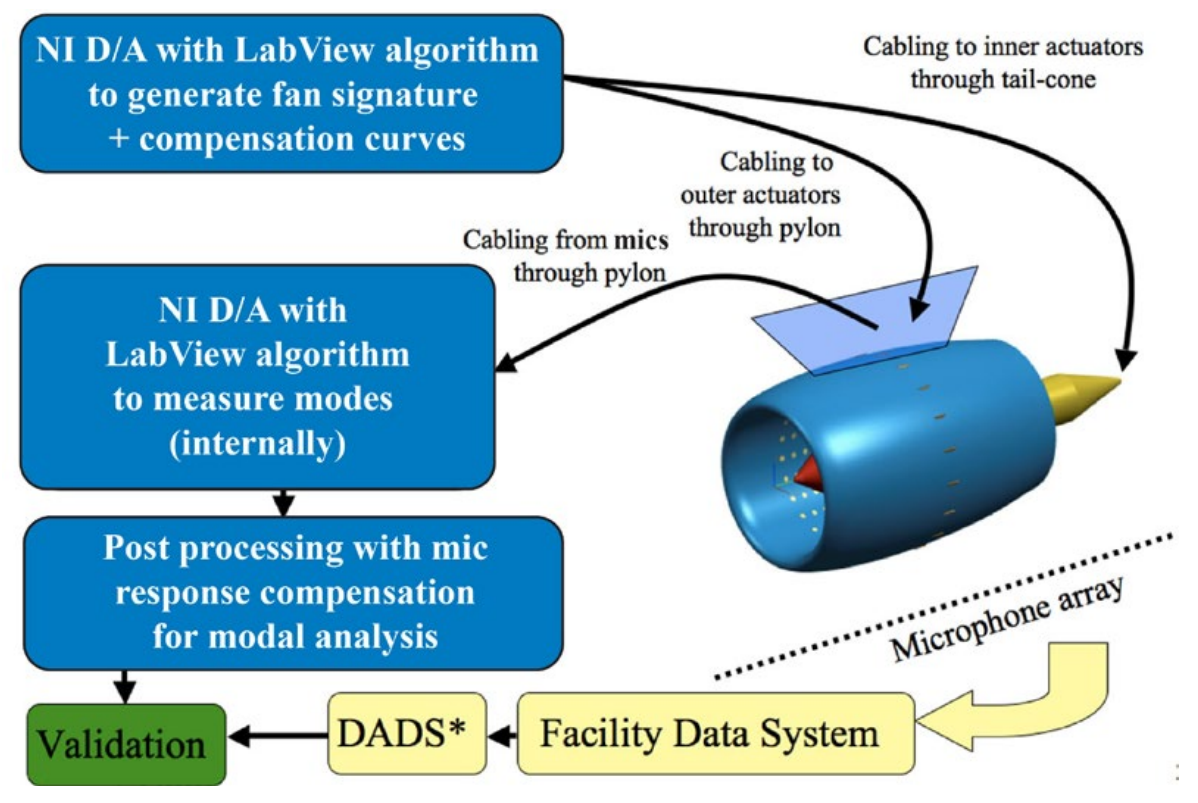

Figure 10.-Block Diagram for UCFANS Signature Generation and Measurement. (“Digital Acoustic Data System).

\subsubsection{Signature Generation}

The signature to generate the modal content was pre-calculated using the desired modes and frequencies, and stored. Each actuator in the array was driven by a composite signal of seven excitation frequencies, equalized for variations in individual actuator amplitude and phase response, and phased to match the circumferential wave numbers of the modes to be radiated. A GUI program was used to create the algorithm to read in the pre-stored signal. These 36 signatures, plus a reference signal were output by a $200 \mathrm{kS} / \mathrm{s}$ sample rate D/A chassis, allowing the full desired frequency range to be well below the Nyquist frequency. In addition to the 36-actuator drive channels, a reference channel consisting of the unity amplitude cosine wave of all excitation frequencies which was output directly to the data recorder. Because the test frequencies were limited to integer values up to $60 \mathrm{kHz}$, the excitation signals were multiples of 1-sec duration.

An additional matrix of 36 each, $3 \mathrm{sec}(600,000$ points) Gaussian noise signals was generated and stored in a file and applied to the test fixture actuators as an additional file. Care was taken to ensure that although the signals are statistically independent among the actuators, the radiated signal is coherent from test point to test point, allowing cross correlation and coherence computation between data taken at different traverse stops or even on different test days.

To minimize test time, three unique blocks of the seven frequencies plus one the broadband signature (Gaussian distribution) were generated, sequentially. The two sets of radial drivers could be pre-set with a desired amplitude and/or phase relation, as a group. To achieve differing radial mode combinations, three consecutive, 2-sec signal bursts were applied with differing drive levels to the inner and outer actuators rows. Since the signal is known, parsing the frequency content from each block separately was conceptually straight-forward. Effectively, this allowed for 22 separate conditions to be acquired in a short time frame. Figure 11(a) depicts the sequential block concept and Figure 11(b) the FFT of a representative block. 


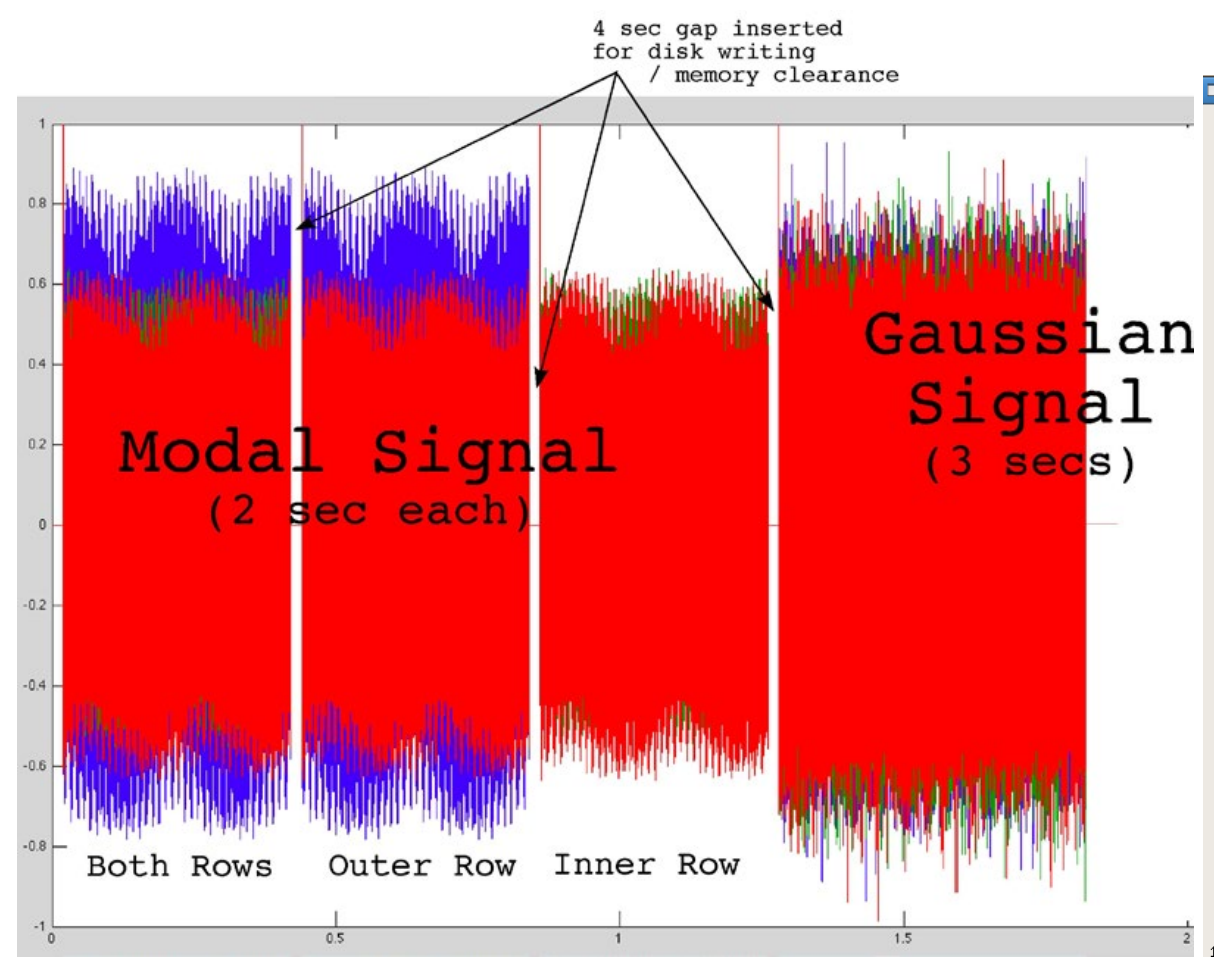

(a)

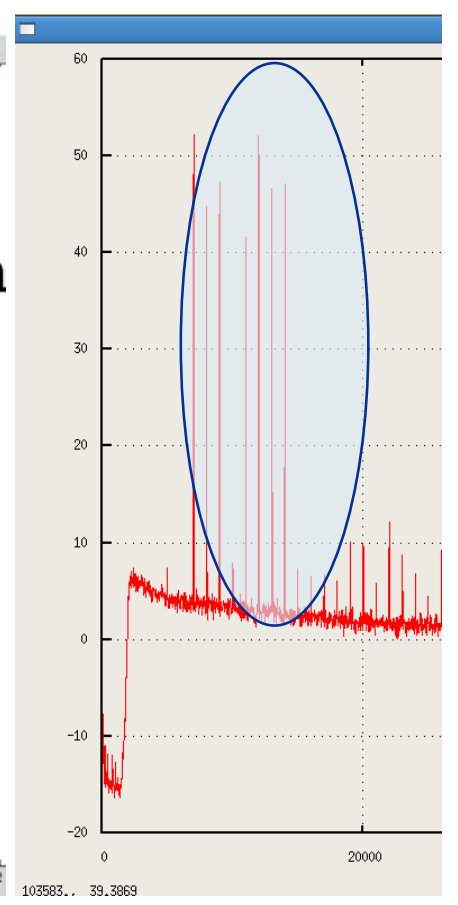

(b)

Figure 11._UCFANS Signature. (a) Illustrative Time History. (b) Spectral Content.

\subsubsection{Signature Validation}

The mode-identification microphone array consists of 72 prepolarized condenser microphones in three rows of 24 each, allowing resolution of circumferential modes up to $|m|=11$. The array is located approximately midway between the actuators and the duct termination, at axial positions that were determined to allow identification of radial orders $n=0,1$ and 2 over the BPF, and part of the $2 \mathrm{xBPF}$ frequency range 7 to $30 \mathrm{kHz}$

The 72 internal microphones, along with the reference signal, were acquired using an AC-coupled $200 \mathrm{kS} / \mathrm{s} \mathrm{A} / \mathrm{D}$ converter with integrated anti-aliasing filters. These time histories were streamed to disk for later analysis. The 72-microphone signals and a reference signal were recorded at $200 \mathrm{kHz}$ sampling rate using simultaneous sampling. The cross-power spectrum of each microphone channel was computed against the reference signal and spectral components corresponding to excitation frequencies were isolated into a "compressed spectrum." The compressed spectrum for each microphone was equalized based on that microphone's calibration curve and then the 24 spectra from each microphone ring were spatially Fourier transformed to recover the complex amplitude of each circumferential mode order $-12<m<12$, with $m=|12|$ measurable, but the direction indeterminate.

For each circumferential mode $m$ of frequency $f$, the radial component composition was estimated by computing the modal cutoff ratios and axial wave numbers

$$
k z_{m, n}=\frac{2 \pi f}{c} \sqrt{1-\left(\frac{f c o_{m, n}}{f}\right)^{2}}
$$

for all radial orders $n=0$ to one above the highest cut on. 
For microphone row $\mathrm{A}, \mathrm{B}$ or $\mathrm{C}$, an axial coordinate $\mathrm{z}$ was established relative to the midway point between rows $\mathrm{A}$ and $\mathrm{C}$. The transfer function from this location to each microphone row $M$ and each propagation mode $(m, n)$ is then

$$
p_{M, m}=\sum_{n} p_{0, m, n} \exp \left(-i k z_{m, n} z_{M}\right)
$$

or, expressed as a transfer matrix function

$$
\left[p_{M}\right]_{m}=\left[H_{M, n}\right]_{m}\left[p_{0, n}\right]_{m}
$$

Since complex circumferential mode amplitudes $p_{M}$ are determined from spatial Fourier transform of the mic data, the matrix $H$ is inverted and multiplied with $p_{M}$ to determine the radial content, $p_{0, n}$ relative to the center of the mic array. This inversion was done using Matlab PINV function, which has the properties:

If rows $=$ columns, inversion is exact

If rows $>$ columns, inversion is the minimum norm solution (fewer modes than mic rows)

If rows $<$ columns, inversion is least squares error solution (more modes than mic rows)

Because each test involved hundreds of far-field microphone array traverse stops, with the same excitation signals applied to the simulator drivers, the modal composition of the excitation was computed for a representative subset of the traverse stops. The results were compared for consistency to ensure repeatability of the radiated sound field.

\subsection{Testing}

\subsection{Configurations}

The general procedure was to first acquire data from the nacelle for each of the isolated (un-shielded) configurations and then repeat the data acquisition for the same geometric positions of the nacelle but with the shield installed. The far field microphone array was traversed at the same set of spatial locations for both shielded and unshielded configurations Thus, each nacelle configuration (exhaust radiationshield with trailing edge, and inlet radiation — shield with leading edge) was tested twice, once unshielded, and subsequently with the shield in place. The key is that the array traverse was always in the same position relative to the edge or shield, or where it would be in the case of isolated nacelle testing.

The acoustic signature used for the results reported in this paper were termed the Code Validation Modes (CVM). These are a set of modes with content limited to the circumferential/radial resolution of the system and with a parametric variation in frequency and modal content intended to provide a database for code validation. Table I lists the frequency/modal content of the first three blocks of the signal; these were followed by the Gaussian 'block'.

The far-field traverses were taken in either horizontal (two) or vertical planes (three). Both horizontal planes were above the model at approximately 7.5 and 10.1 diameters. The vertical planes were on either side of the model, one on the unshielded side, and two in the shielded side ( 6 and 12 diameters). The array spanned 36 in. such that the seventh microphone was centered and tracked the centerline of the model and data were acquired with a 3 in. resolution between traverse stops. The array was then shifted 33 or 66 in. in either the $\pm Y$ directions and another planar sweep acquired, providing a total lateral span of $160 \mathrm{in}$. (due to an overlap of two microphones). The resolution at $Y= \pm 33$ in. was 6 in.; at $Y= \pm 66$ in. it was 12 in. Figure 12 depicts the traverse plane locations relative to the model. Photos of the model installed in the ATL are in Figure 13. 
TABLE I.-CODE VALIDATION MODES

(a) Block 1

\begin{tabular}{|c|c|c|c|}
\hline FREQUENCY & MODES & CUT-0FF RATI0 & AMPLITUDE RATI0 \\
\hline $7 \mathrm{kHz}$ & $(6, \odot)$ & 1.32 & (Outer=1/Inner=1) \\
\hline $8 \mathrm{kHz}$ & $(6, \odot)$ & 1.51 & (Outer=1/Inner=1) \\
\hline $9 \mathrm{kHz}$ & $(6, \odot) /(6,1)$ & $1.70 / 1.08$ & (Outer=1/Inner=1) \\
\hline $11 \mathrm{kHz}$ & $(8, \odot) /(8,1)$ & $1.59 / 1.12$ & (Outer=1/Inner=1) \\
\hline $12 \mathrm{kHz}$ & $(8, \odot) /(8,1)$ & $1.73 / 1.22$ & (Outer=1/Inner=1) \\
\hline $13 \mathrm{kHz}$ & $(2, \odot) /(2,1) /(2,2)$ & $7.17 / 2.07 / 1.08$ & (Outer=1/Inner=1) \\
\hline $14 \mathrm{kHz}$ & $(6, \odot) /(6,1) /(6,2)$ & $2.64 / 1.68 / 1.07$ & \\
\hline
\end{tabular}

(b) Block 2

\begin{tabular}{|c|c|c|c|}
\hline FREQUENCY & MODES & CUT -0FF RATI0 & AMPLITUDE RATI0 \\
\hline $7 \mathrm{kHz}$ & $(8,0)$ & 1.01 & (Outer=1/Inner=1) \\
\hline $8 \mathrm{kHz}$ & $(8,0)$ & 1.15 & (Outer=1/Inner=1) \\
\hline $9 \mathrm{kHz}$ & $(8,0)$ & 1.30 & (Outer=1/Inner=1) \\
\hline $11 \mathrm{kHz}$ & $(8,0) /(8,1)$ & $1.59 / 1.12$ & (Outer=1/Inner $=0$ ) \\
\hline $12 \mathrm{kHz}$ & $(8,0) /(8,1)$ & $1.73 / 1.22$ & (Outer=1/Inner $=0$ ) \\
\hline $13 \mathrm{kHz}$ & $(2,0) /(2,1) /(2,2)$ & $7.17 / 2.07 / 1.08$ & (Outer=1/Inner=0) \\
\hline $14 \mathrm{kHz}$ & $(6,0) /(6,1) /(6,2)$ & $2.64 / 1.68 / 1.07$ & \\
\hline
\end{tabular}

(c) Block 3

\begin{tabular}{|c|c|c|c|}
\hline FREQUENCY & MODES & CUT-OFF RATIO & AMPLITUDE RATIO \\
\hline $7 \mathrm{kHz}$ & $(4,0)$ & 1.95 & (Outer=1/Inner=1) \\
\hline $8 \mathrm{kHz}$ & $(-6,0)$ & 1.51 & (Outer=1/Inner=1) \\
\hline $9 \mathrm{kHz}$ & $(-8,0)$ & 1.30 & (Outer=1/Inner=1) \\
\hline $11 \mathrm{kHz}$ & $(8,0) /(8,1)$ & $1.59 / 1.12$ & (Outer $=\odot /$ Inner $=1$ ) \\
\hline $12 \mathrm{kHz}$ & $(8,0) /(8,1)$ & $1.73 / 1.22$ & (Outer $=\odot /$ Inner $=1$ ) \\
\hline $13 \mathrm{kHz}$ & $(2,0) /(2,1) /(2,2)$ & $7.17 / 2.07 / 1.08$ & (Outer=๑/Inner=1) \\
\hline $14 \mathrm{kHz}$ & $(6,0) /(6,1) /(6,2)$ & $2.64 / 1.68 / 1.07$ & (Outer $=\odot /$ Inner $=1$ ) \\
\hline
\end{tabular}


array is 13 mics; 36" wide; 3 " between mics (perpendicular to paper)

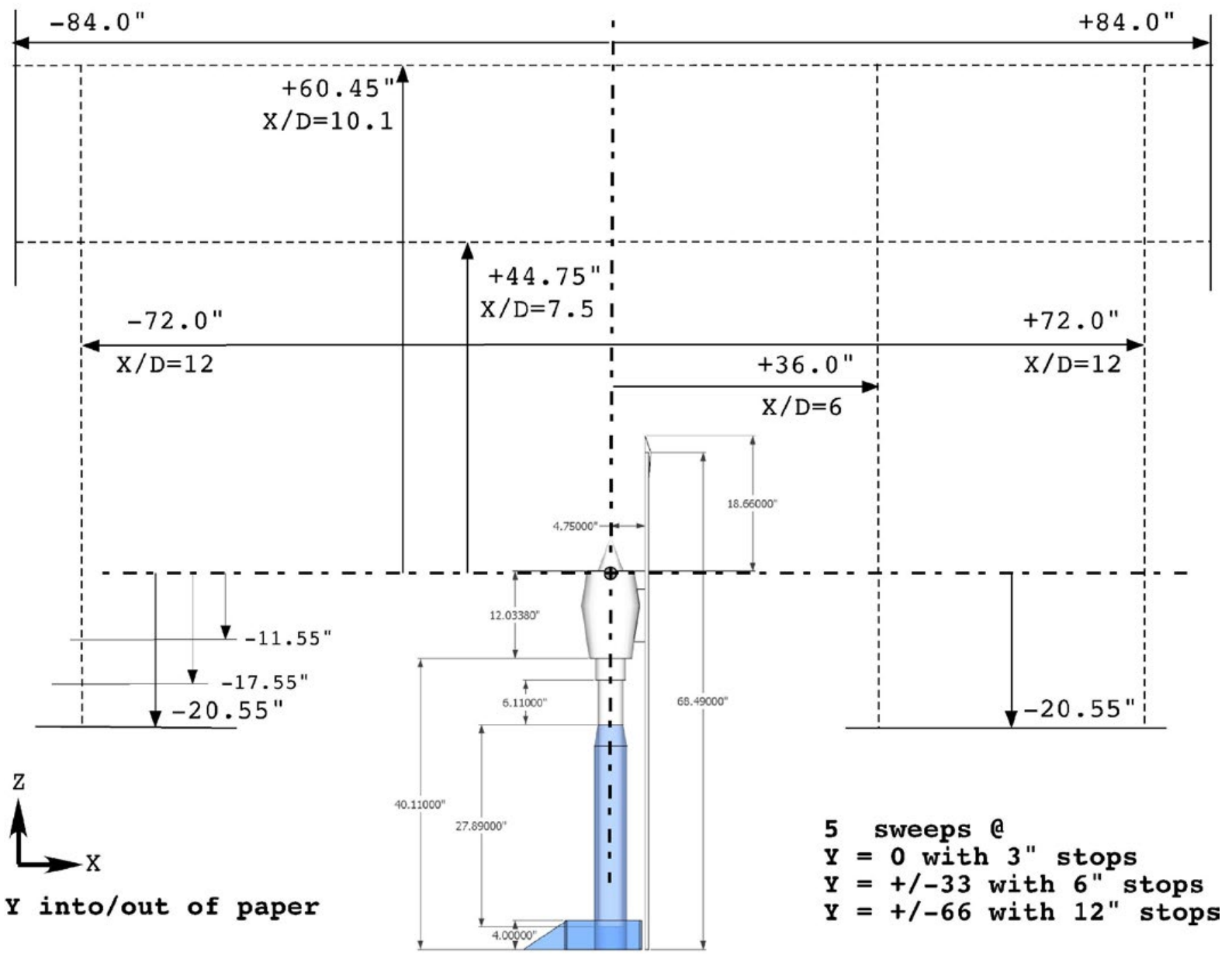

Figure 12.-Traverses for Code Validation Mode Configurations. 


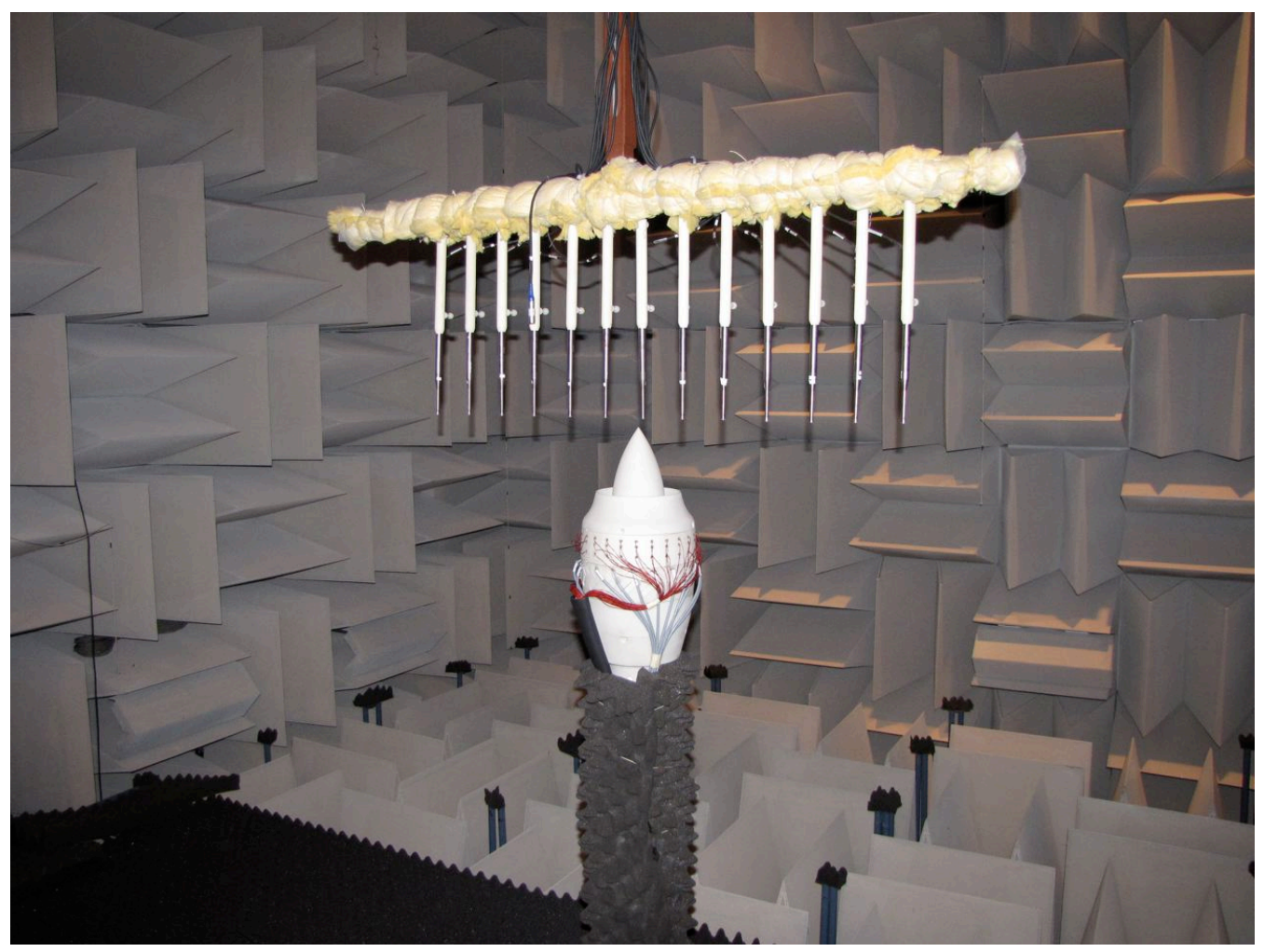

(a)

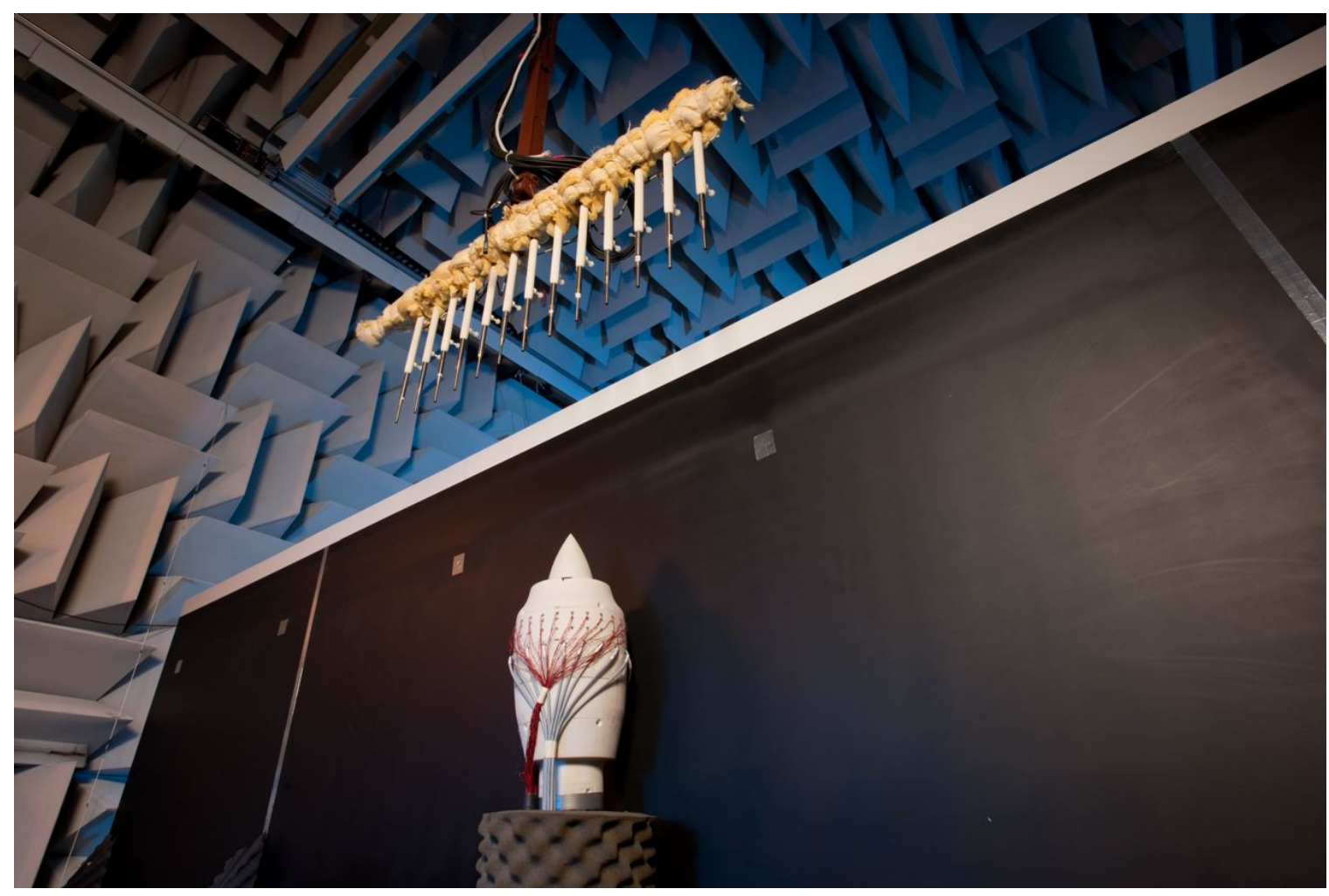

(b)

Figure 13.-(a) Isolated UCFANS Exhaust Configuration Installed in ATL. (b) UCFANS Exhaust Configuration Adjacent to Shield with Trailing Edge Installed in ATL. 


\subsection{Reduced Data}

A significant amount of data was acquired for noise shielding prediction code validation. Reported herein will be a selection of the reduced data, encompassing select changes in the parametric study. The data include the in-duct relative modal decomposition and sound pressure level (SPL) contour plots of the traverse planes. The SPL contour planes were also integrated to obtain noise power level (PWL) (actually partial power to be used for comparison purposes). These are done for both the isolated nacelle and the nacelle with wing (shield) cases. In addition, deltas between the isolated nacelle/nacelle + wall configurations are presented to obtain shielding values. The convention will be to denote a reduction in PWL due to shielding as a negative number (cooler colors on the contour plots). A qualitative analysis is provided herein, as the objective is to assess the character of the system.

\subsubsection{In-Duct Modal Signatures}

Figure 14 and Figure 15show the in-duct modal decomposition for the exhaust nacelle (Figure 14) and for the inlet nacelle (Figure 15). Subplots (a) to (c) show cases where the frequency was held constant at $7 \mathrm{kHz}$ and the single cut-on circumferential mode varied. Subplots (d) to (e) show the cases with frequency held constant at $12 \mathrm{kHz}$ and the circumferential mode $m=8$ with two radials cut-on are being generated. The variation is in the driver row actuation (both, inner, or outer) - in order to cause a differentiation in the radial mode mix. The ratio between the outer/inner driver row signal is varied to qualitatively illustrate radial mode effects. While the mode generation system could infinitely vary the relative magnitude or phase between the two rows, this simple on/off was chosen for evaluation purposes. In theory, a desired radial structure could be selected and generated if a significant number of magnitude/phase variations were generated and measured, then a steering vector matrix determined.

The single mode cases show the dominant mode substantially above the background. The target mode $(4,0)$ was strongly excited with very little spillover. Both the exhaust (Figure 14(a) to (c)) and inlet (Figure 15(a) to (c)) show this clearly. At the higher frequency, $12 \mathrm{kHz}$, with two-radials propagating $(8,0) /(8,1)$ the results are more mixed. For the exhaust configuration, there is clear aliasing to $m=-10$, which is expected due to the driver count. (The aliased mode is the target mode minus the number of drivers, e.g., $8-18=-10$.) The outer drivers (Figure 14(e)) generate a reasonable target mode with moderate spillover, while the inner driver (Figure 14(f)) target mode generation is weak and more spillover. The inlet configuration has generally cleaner mode decomposition. The outer driver (Figure 15(e)) and inner driver (Figure 15(f)) couple nicely to the zeroth and first radials, respectively. The combination of the two rows creates a cancellation that reduces the overall target mode strength, with modest spillover.

The two cases presented were generally representative the range of clarity of the modal decomposition. The majority tended to be closer to the stronger target mode with modest spillover. Imperfections in the compensation curves may account for spillover, and could be corrected in an iterative process.

\subsubsection{Nacelle Radiation to Far-Field Array Contours}

Far-field noise data were acquired to document the possible shielding effect of the HWB and provide data for the development of noise propagation codes. Time series data were recorded at a $200 \mathrm{kHz}$ sample rate. A Kaiser window function ( $2^{14}$ points) was then applied and a Fourier transform used to convert the data to "as measured" spectra. Each spectrum was then corrected on a frequency-by-frequency basis for the individual microphone response and the effect of the grid cap (using calibration curves supplied by the manufacturer). Finally, the data were converted to a lossless condition by correcting for the atmospheric attenuation of propagating sound. Note that the data presented are at the measurement location and include the spherical spreading of sound. At this point, the tones of interest may be extracted from the overall spectrum. 

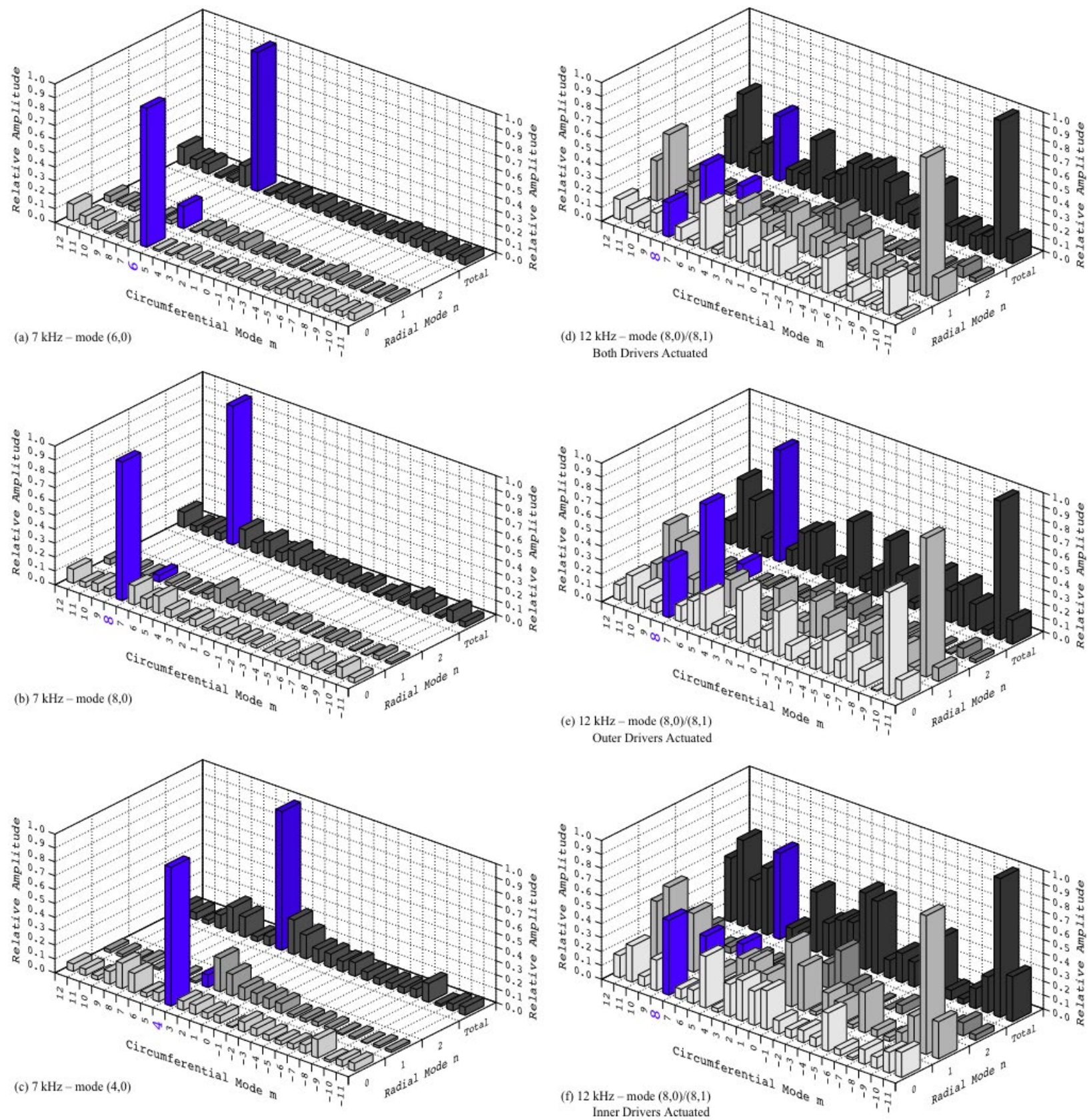

Figure 14.-Relative Modal Decomposition for the Nacelle in the Exhaust Configuration. 

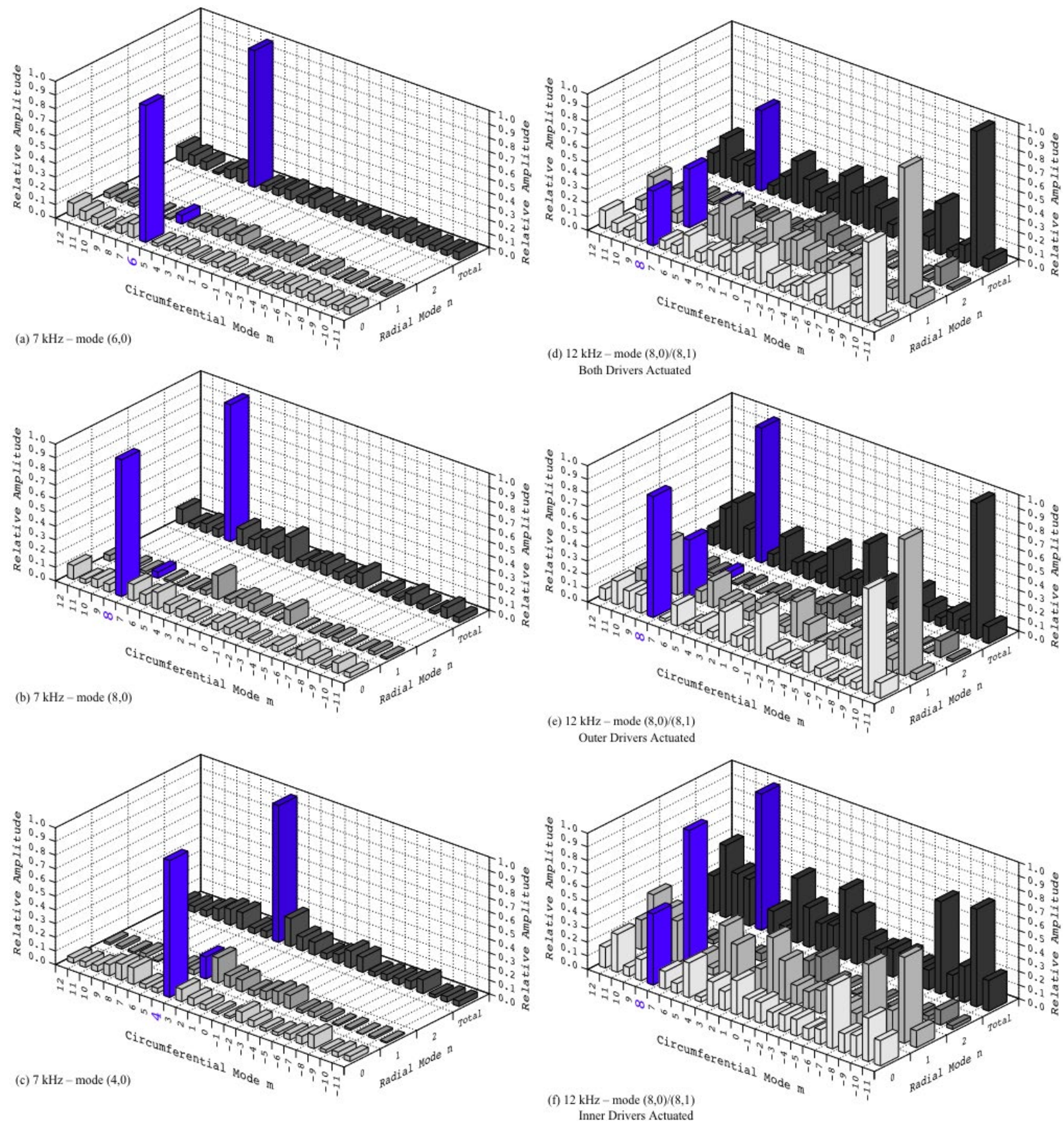

Figure 15.-Relative Modal Decomposition for the Nacelle in the Inlet Configuration. 


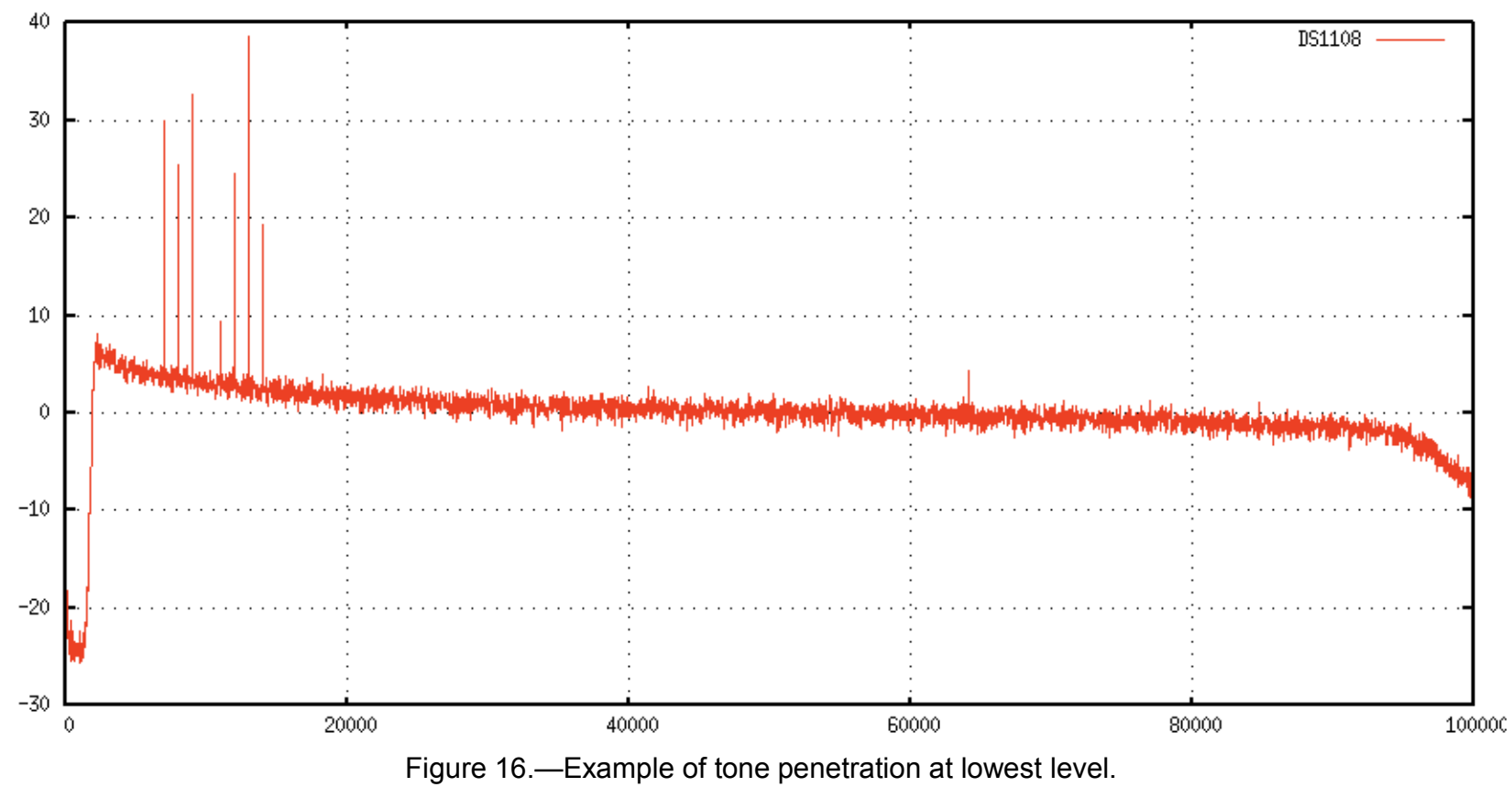

Of particular interest in a shielding study is the background noise level (acoustic or electronic) and the tone penetration to insure that the correct value for shielding is being determined. Figure 16 presents a spectrum from data acquired from the shielded side of the model and represents one of the lowest noise levels measured. It is seen in this figure that the tone penetration is a minimum of $\sim 10 \mathrm{~dB}$ above the background level. It is therefore believed, that all of the measurements made are that of valid tone levels, and that any computed shielding value is not limited by the background noise.

A simple check on repeatability was achieved by repeating the main overhead horizontal sweep. Figure 17 compares the SPL contours taken at the beginning of the day and at the end of the day. The qualitative comparison of the contours is excellent. The computed PWL differences range from -0.3 to $-0.8 \mathrm{~dB}$, depending on the tone frequency, averaging $-0.5 \mathrm{~dB}$. This systematic shift may be due to output drift as a result of temperature or operating time.

The SPL contours for the exhaust nacelle configuration, $7 \mathrm{kHz} m=(4,0)$ are presented in Figure 18 and Figure 19. The results for the two horizontal sweeps above the nacelle alone case are shown on the left side of Figure 18, while the nacelle plus wall case are shown on the right side of the figure. The nacelle alone cases show clear and strong modal structure, spreading out as the radiated distance from the nacelle increases from +44.75 in. (c) to +60.45 in. (a) above the nacelle. The PWL is essentially conserved, with a small amount of leakage outside the measurement plane at the higher distance sweep. The nacelle with wall configuration, shows the reflection to the unshielded side of the nacelle. PWL is essentially conserved as any reduction in sound energy on the shielded side is reflected and mostly captured on the un-shielded side. Figure 19 is the data acquired along the vertical planes (curtains) for the same nacelle configuration. The results obtained along the vertical curtain at $-72.00 \mathrm{in}$. on the unshielded side of the nacelle (i.e., above the aircraft) are shown in Figure 19(a) and (b). The edge of the mode lobe is seen and the wing reflection increases the PWL on this side. The results obtained along the two vertical curtains at +36.00 in., and +72.00 in. on the shielded side of the nacelle (i.e., below the aircraft) are shown in Figure 19(c) to (f). The symmetry in the radiation from the isolated nacelle is seen by comparing Figure 19(a) and (e). The effect of shielding is noted with a reduction in PWL of $14.1 \mathrm{~dB}$ at 36 in. from the shield and $5.6 \mathrm{~dB}$ at $72 \mathrm{in}$., with the higher value achieved closer to the "wing" as would be expected. 

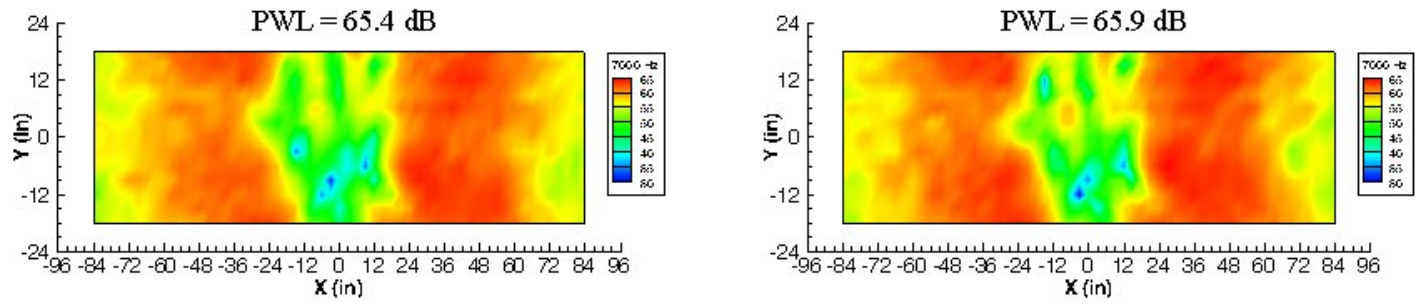

(a) $7 \mathrm{kHz}$ - mode $(6,0)$
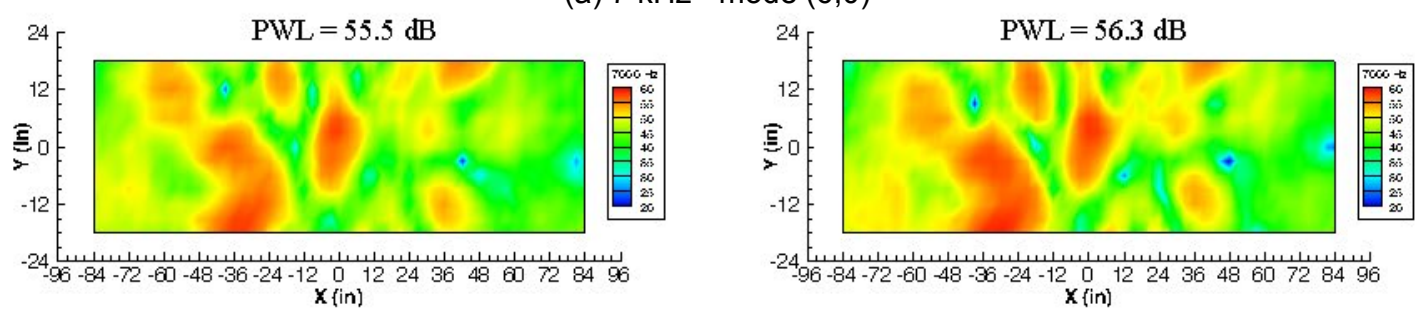

(b) $7 \mathrm{kHz}$ - mode $(8,0)$
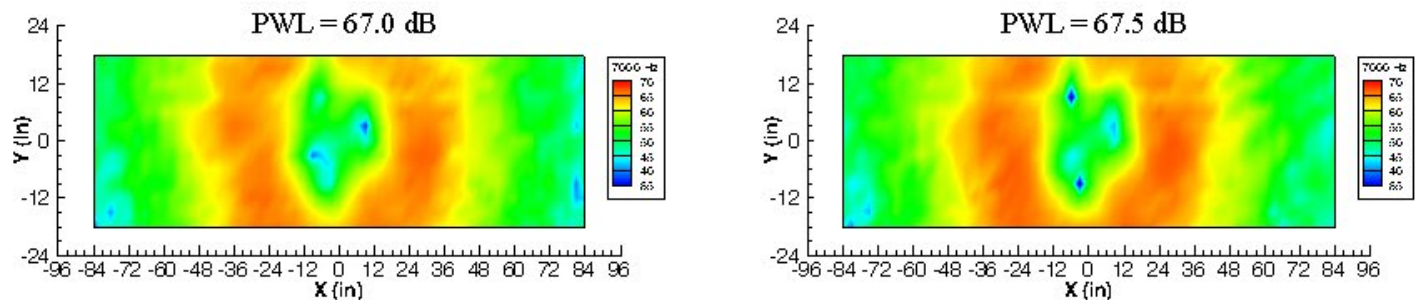

(c) $7 \mathrm{kHz}$ - mode $(4,0)$
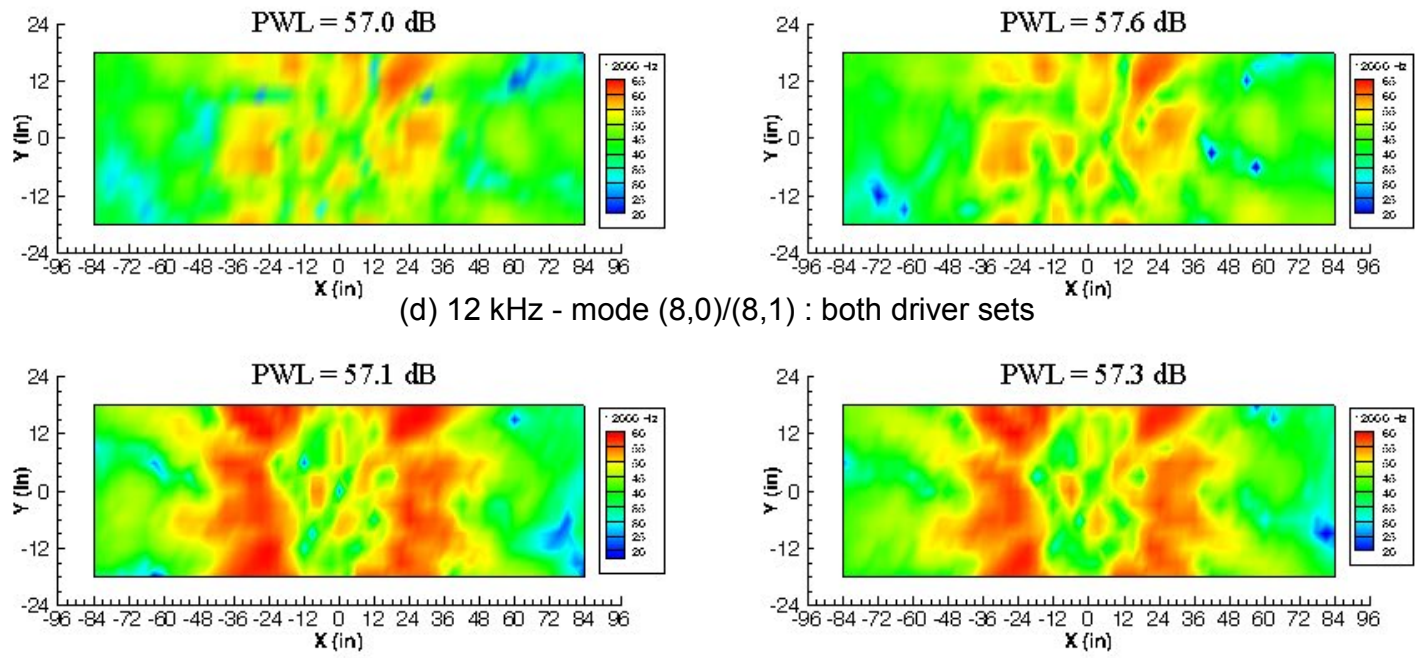

(e) $12 \mathrm{kHz}$ - mode $(8,0) /(8,1)$ : outer driver set
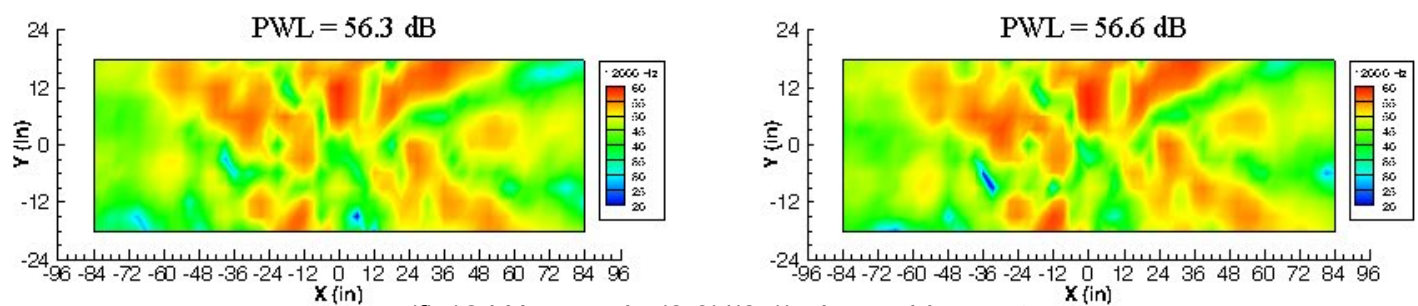

(f) $12 \mathrm{kHz}$ - mode $(8,0) /(8,1)$ : inner driver set

Figure 17.- Repeatability (left column beginning of day / right column end of day). 


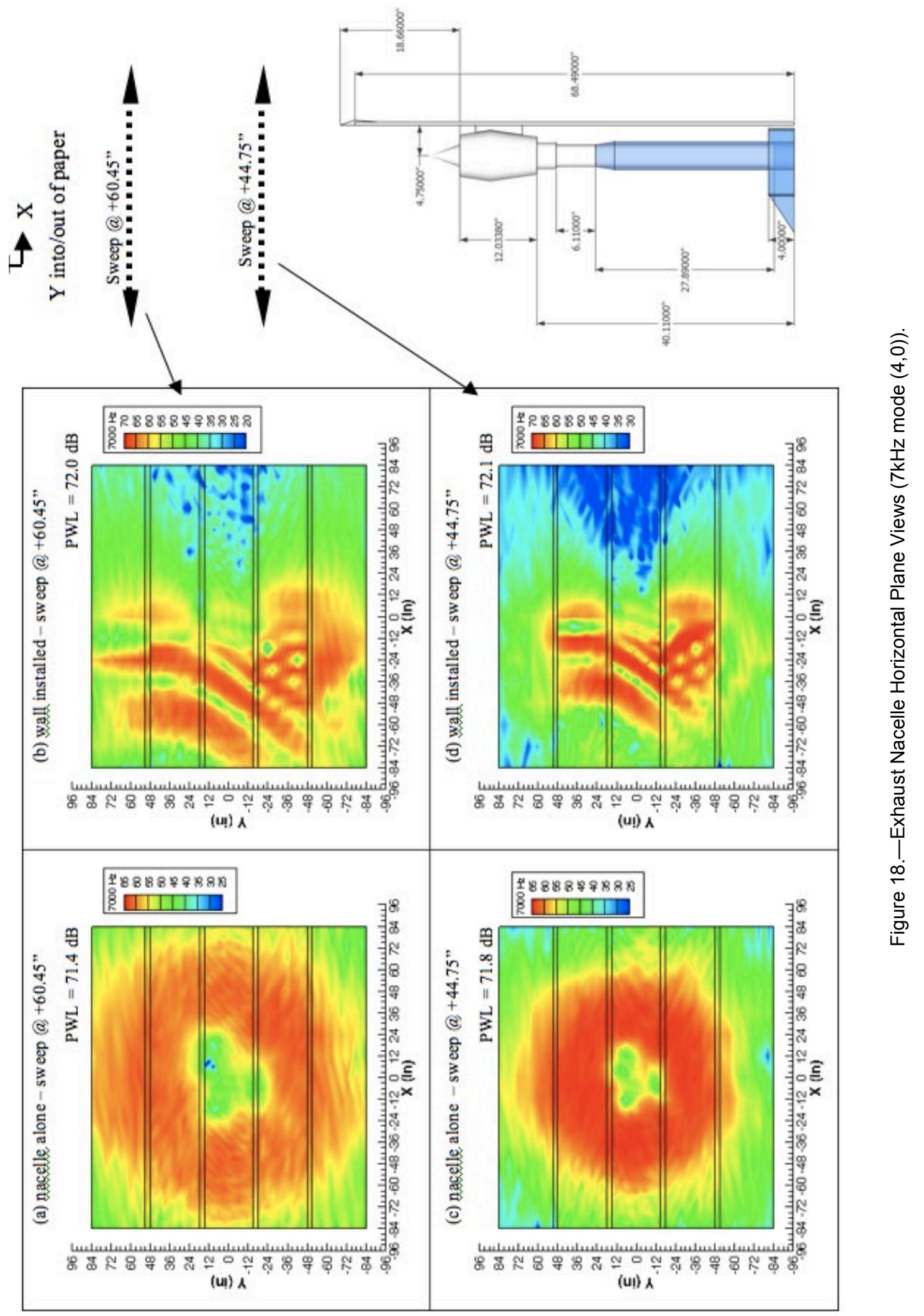




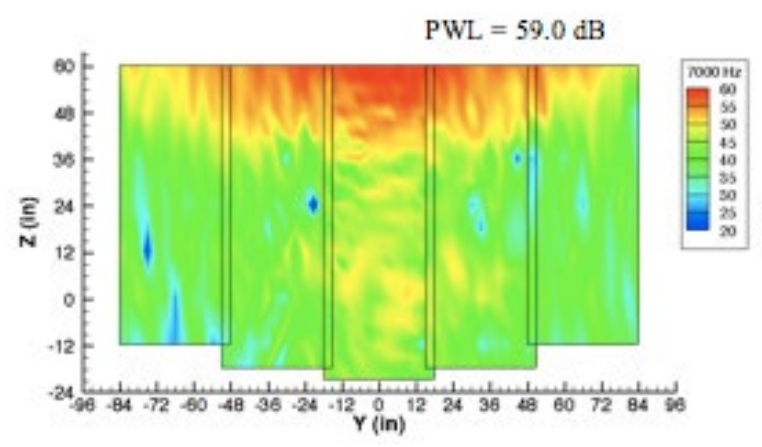

(a) Nacelle alone-Curtain at -72.00 in.

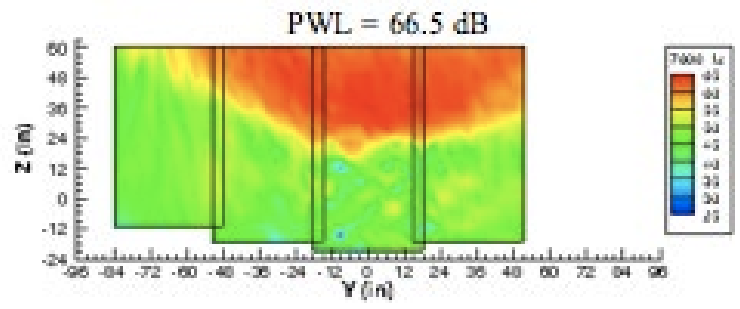

(c) Nacelle alone-Curtain at +36.00 in.

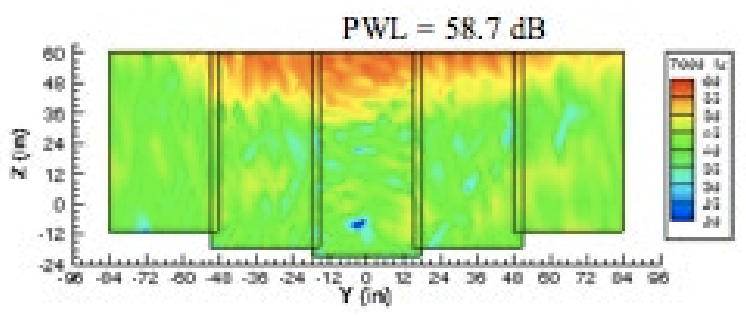

(e) Nacelle alone-Curtain at +72.00 in.

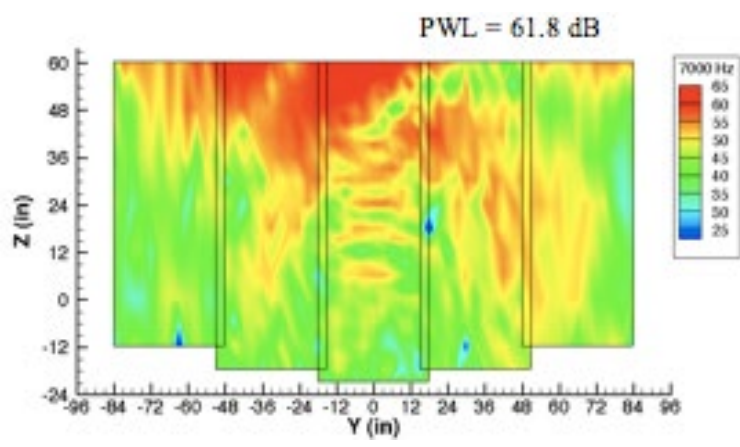

(b) Wall installed-Curtain at -72.00 in.

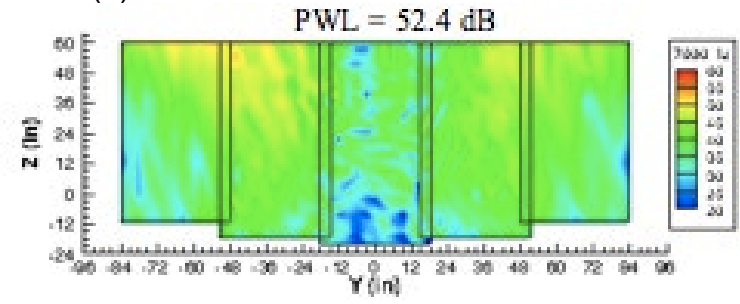

(d) Wall installed-Curtain at +36.00 in.

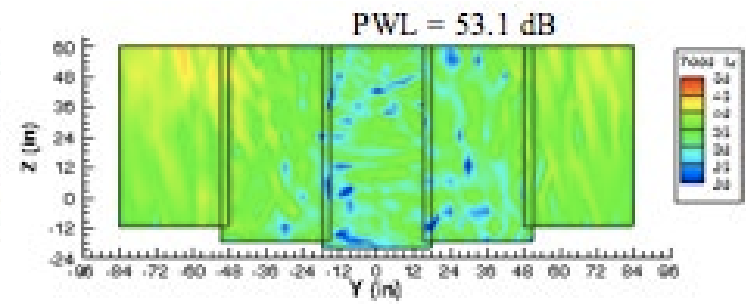

(f) Wall installed-Curtain at +72.00 in.

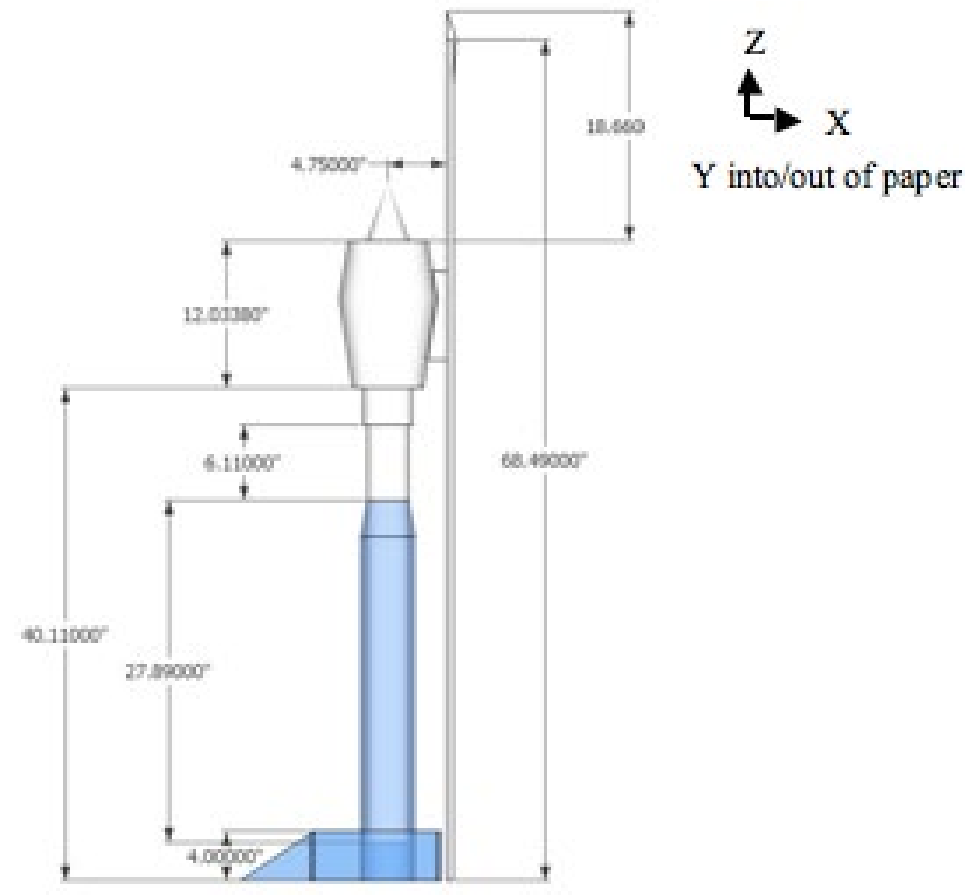

Figure 19.-Exhaust Nacelle Vertical Plane Contours at -72.00 in. (7 kHz mode $(4,0))$. Exhaust Nacelle Vertical Plane Contours at +36.00 in. and +72.00 in. $(7 \mathrm{kHz}$ mode $(4,0))$. 
SPL contours for the exhaust nacelle in the isolated configuration are presented in Figure 20. The frequency is held constant at $7 \mathrm{kHz}$ and the circumferential mode (single radial only) is varied. The results obtained in the horizontal plane at $44.75 \mathrm{in}$. above the model are presented on the left hand side, the vertical curtain at $36.00 \mathrm{in}$. from the model are presented in the right hand side. Integrated PWLs are indicated next to each contour. As the plots are reviewed from the top of the page to the bottom, the circumferential mode number increases, or the cut-off ratio decreases. For the well cut-on mode $(4,0)$ and $\zeta=1.95$, the results shown in Figure 20(a) and (b) the very distinct lobed pattern of a classic mode. It is seen in Figure 20(c) and (d) that as the cut-on ratio decreases the mode becomes more diffuse, until at just above cut-on $(\zeta=1.01$ - Figure $20(\mathrm{e})$ and (f) ) the mode is seen to break down.

The results obtained for the higher frequency case $(12 \mathrm{kHz})$ (also for the isolated exhaust nacelle) are presented in Figure 21. At this frequency two-radials are cut-on; $(8,0)$ and $(8,1)$. The ratio between the outer/inner driver row signal is varied to qualitatively illustrate radial mode effects in the far-field. The azimuthal variation at this frequency is evident due to the spillover noted, especially in the horizontal sweeps. There is a marked far-field effect due to radial variation. With some imagination, one can see that figures (a) and (b) are super-positions of (c) and (e) and (d) and (f), as one might expect as the sources themselves are super-positions. That is the configuration with both rows driven should be a combination of the outer and inner rows individually driven.

Figure 22 ( $f=7 \mathrm{kHz}, m$-mode varies) and Figure $23(12 \mathrm{kHz}, m=8 ; n$ varies) repeat the modal variations with the wall installed next to the exhaust nacelle. The PWL increases in each case on the shielded side. Significant shielding is qualitatively noted (consistent with the other plots, the shielded side is on the right hand side of plots (a), (c), and (e)). PWLs are tabulated for each of the cases.

The $\Delta$-SPL is computed by straight-forward subtraction at each measurement point to obtain the quantitative shielding characteristics. A positive level ("warm" colors) indicate an increase in SPL or PWL, while negative levels ("cool" colors) indicate a decrease in SPL or PWL, or "goodness". The $\Delta$ SPL results are shown in Figure 24 for the $7 \mathrm{kHz}$ circumferential mode variation, and in Figure 25 for the $12 \mathrm{kHz}$ radial mode variation. The computed $\Delta$-PWL is presented on each plot for the corresponding sweep location. For the vertical curtain sweep, the $\Delta$-PWL at the closer location is also indicated on the plot, for comparison.

The results obtained for the isolated inlet nacelle configuration are shown in Figure 26 and Figure 27. The corresponding data acquired with the leading edge 'wing' installed are shown in Figure 28 and Figure 29. The equivalent $\Delta$-SPL plots for the inlet nacelle are shown in Figure 30 and Figure 31. Trends are very similar but subtle differences can be seen when making comparisons to the exhaust nacelle results.

Figure 32 presents a limited sample of the broadband spectra. The spectra of the centerline microphone is plotted at selected 6-in. intervals for the horizontal sweep above the model for the isolated exhaust nacelle (Figure 32(a)) and with the wall installed (Figure 32(b)). For the isolated nacelle, one expects that about $4.3 \mathrm{~dB}$ lower SPL is due to spherical spreading alone and that the rest of the difference is due to the "lobed" nature of broadband directivity in the far-field as a function of radiated angle. A quick glance shows that attenuation in the broadband SPL as the measurements are acquired deeper into the shielded zone, is on the order of 20 to $25 \mathrm{~dB}$ attenuation at the $36.00 \mathrm{in}$. position. Figure 32(c) and (d) show the same isolated nacelle/nacelle plus wall comparison but for the vertical curtain sweep. Figure 32(e) shows the spectra from the traverse point that is at the same geometric position of the two sweeps. The broadband "repeatability" is excellent. 
(a) Horizontal plane at 44.75 in. above

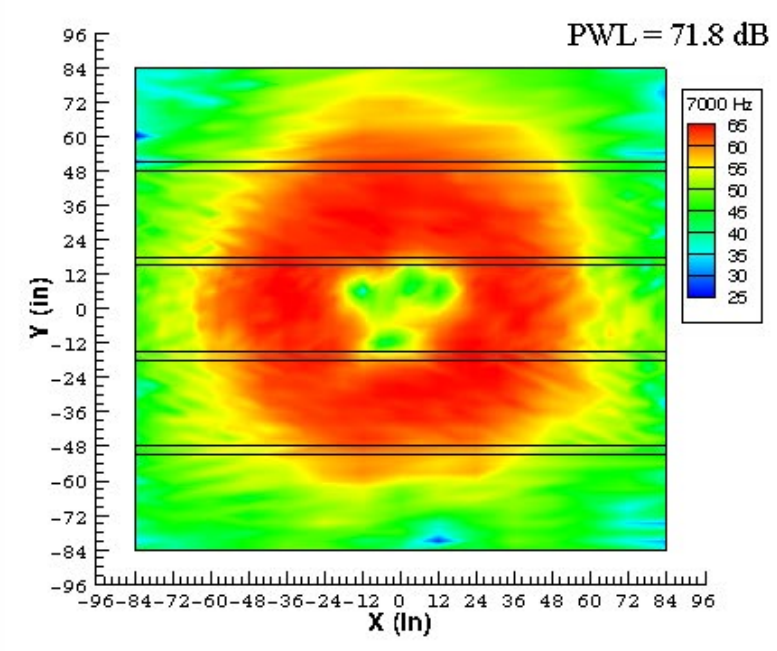

(c) Horizontal plane at 44.75 in. above

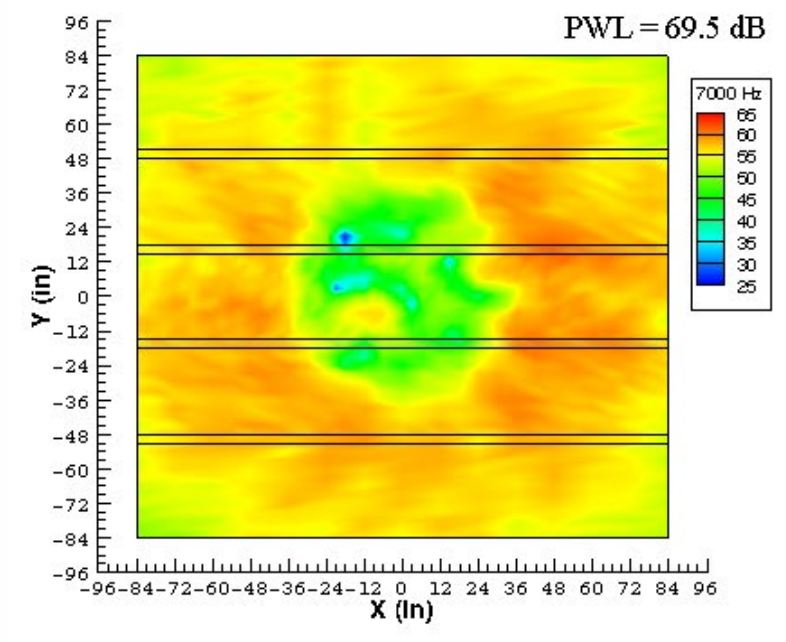

(e) Horizontal plane at 44.75 in. above

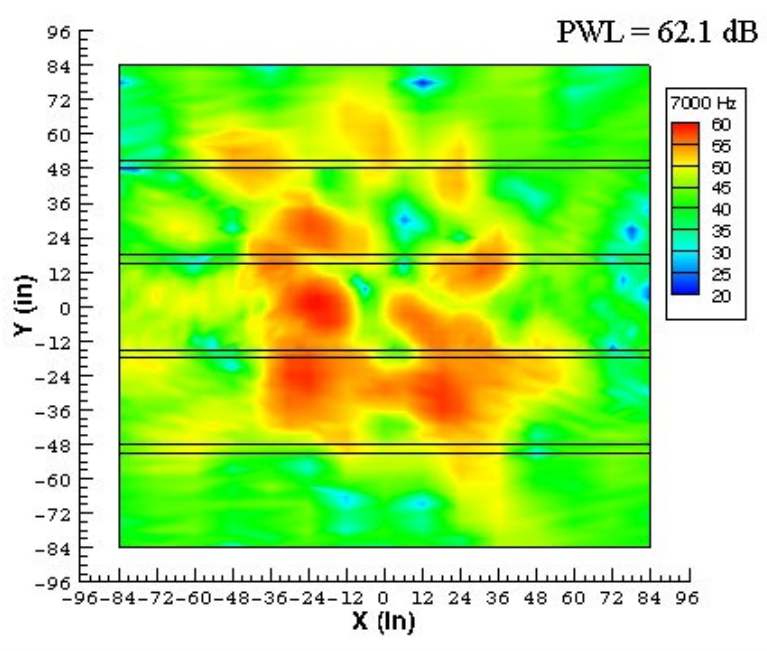

(b) Vertical plane at 72.00 in.

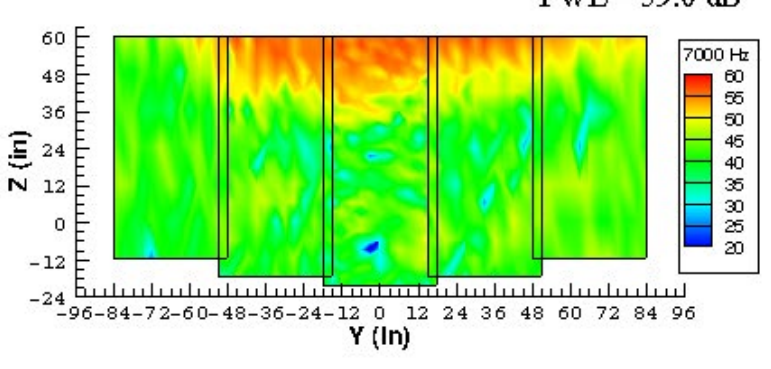

$7 \mathrm{kHz}$ - mode $(4,0)$

$$
\zeta=1.95
$$

(d) Vertical plane at 72.00 in.

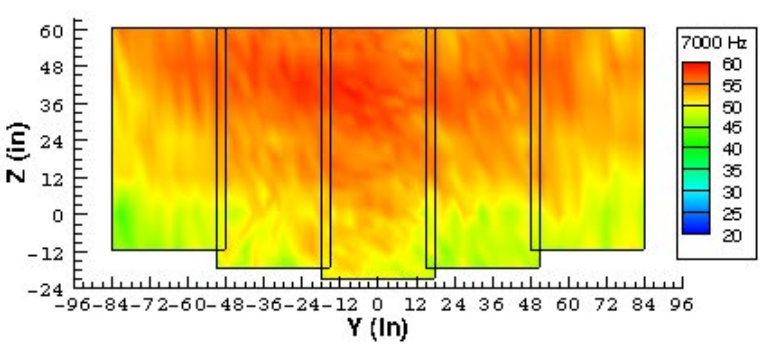

$7 \mathrm{kHz}$ - mode $(6,0)$

$$
\zeta=1.51
$$

(f) Vertical plane at 72.00 in.

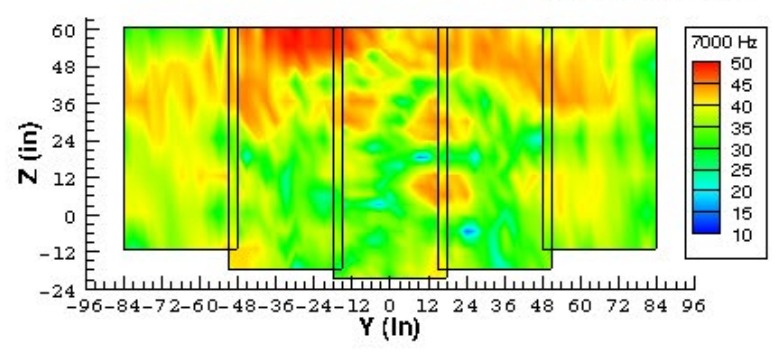

$7 \mathrm{kHz}$ - mode $(8,0)$

$$
\zeta=1.01
$$

Figure 20.-Exhaust Nacelle Alone Contour Plots (Circumferential Mode Variation). 


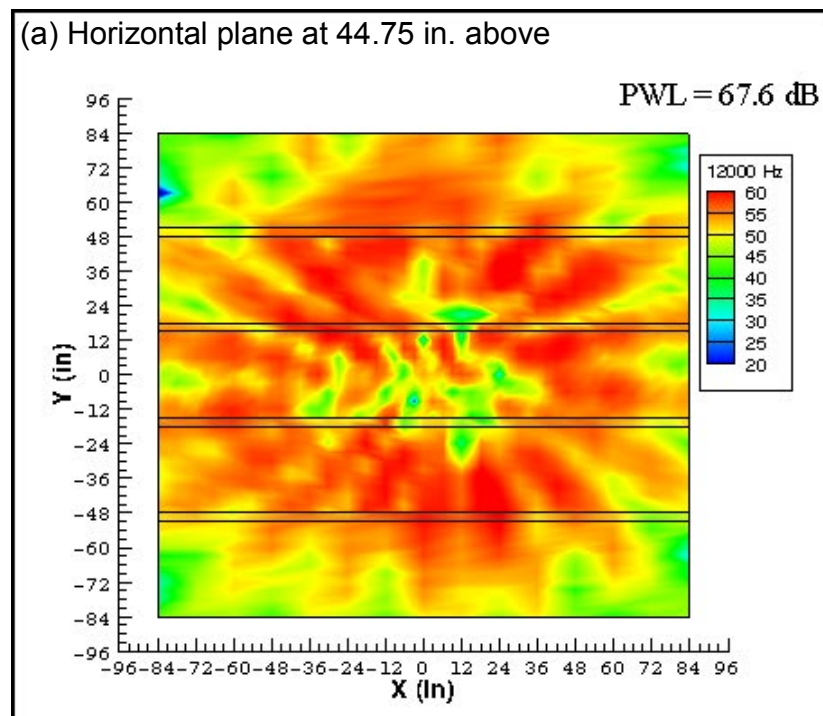

(c) Horizontal plane at 44.75 in. above

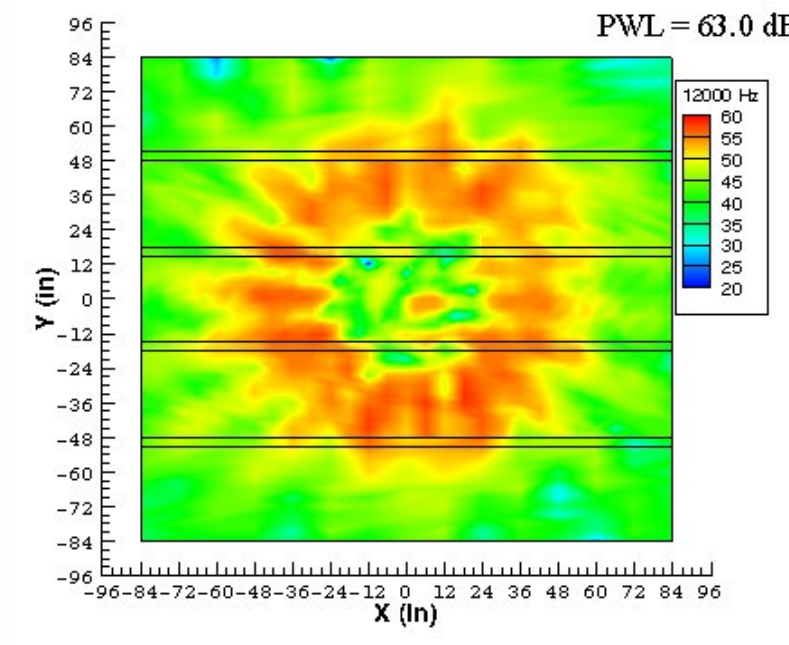

(e) Horizontal plane at 44.75 in. above

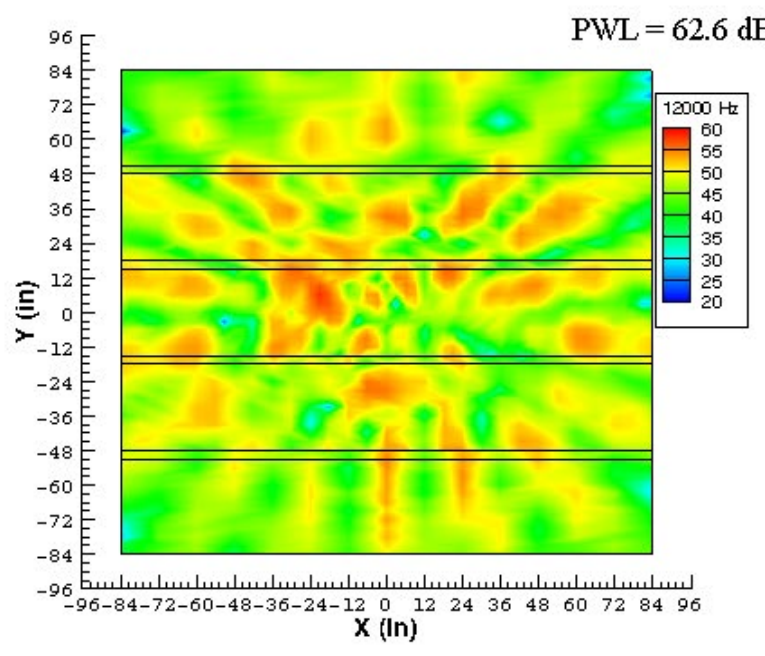

(b) Vertical plane at 72.00 in.

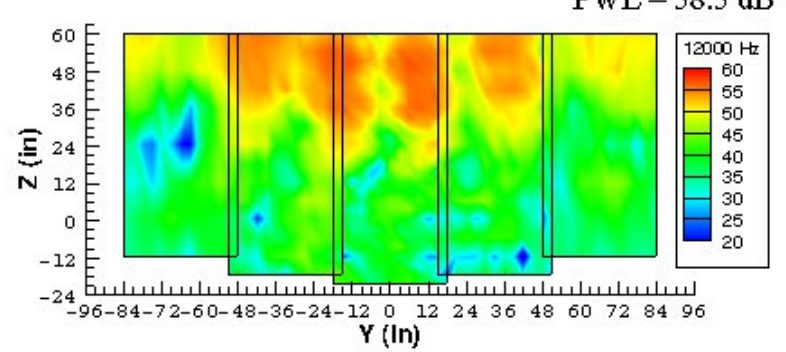

$12 \mathrm{kHz}$ - mode $(8,0) /(8,1)$ both driver sets

(d) Vertical plane at $72.00 \mathrm{in}$.

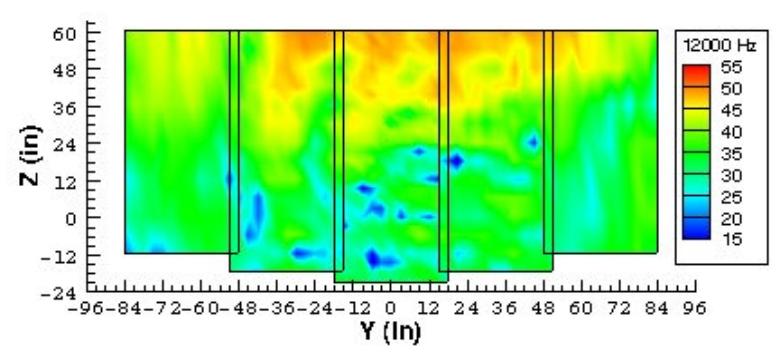

$12 \mathrm{kHz}$ - mode $(8,0) /(8,1)$ outer driver set

(f) Vertical plane at 72.00 in.

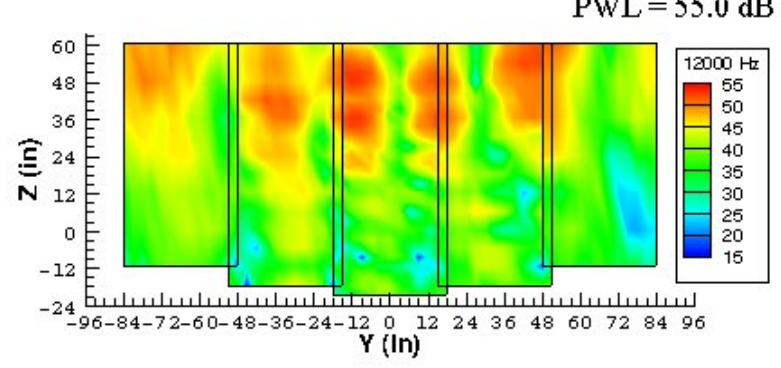

$12 \mathrm{kHz}$ - mode $(8,0) /(8,1)$ inner driver set

Figure 21.-Exhaust Nacelle Alone Contour Plots (Radial Mode Variation). 


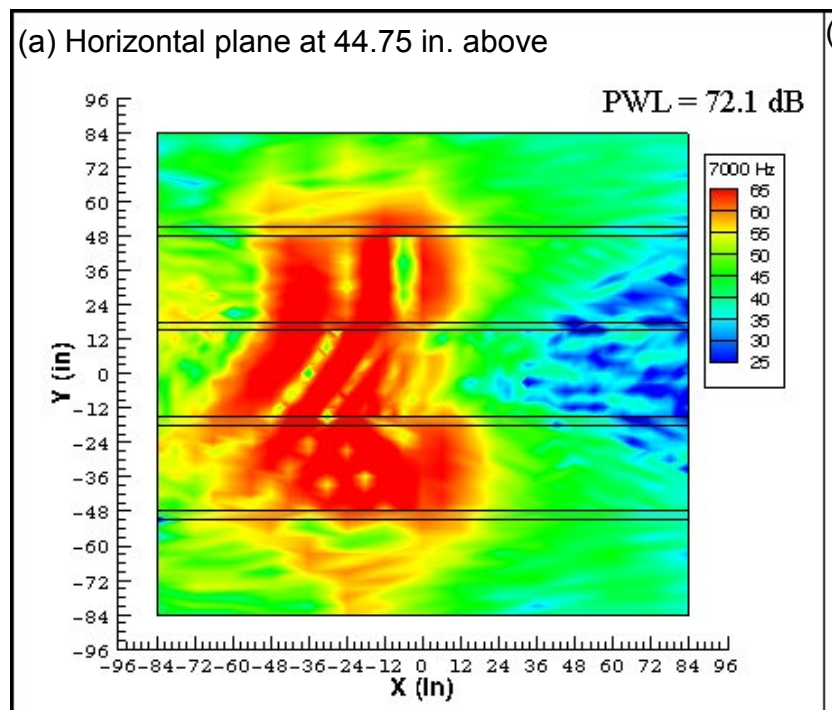

(c) Horizontal plane at 44.75 in. above

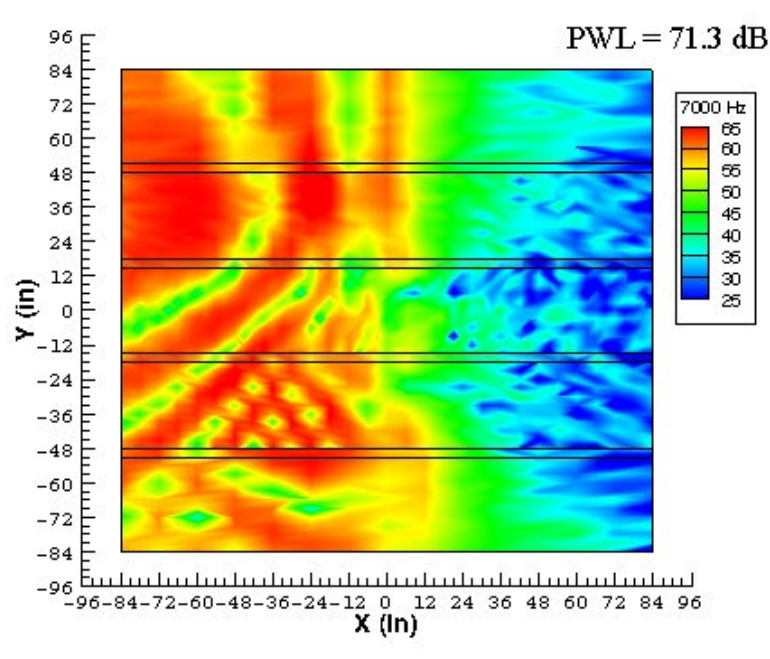

(e) Horizontal plane at 44.75 in. above

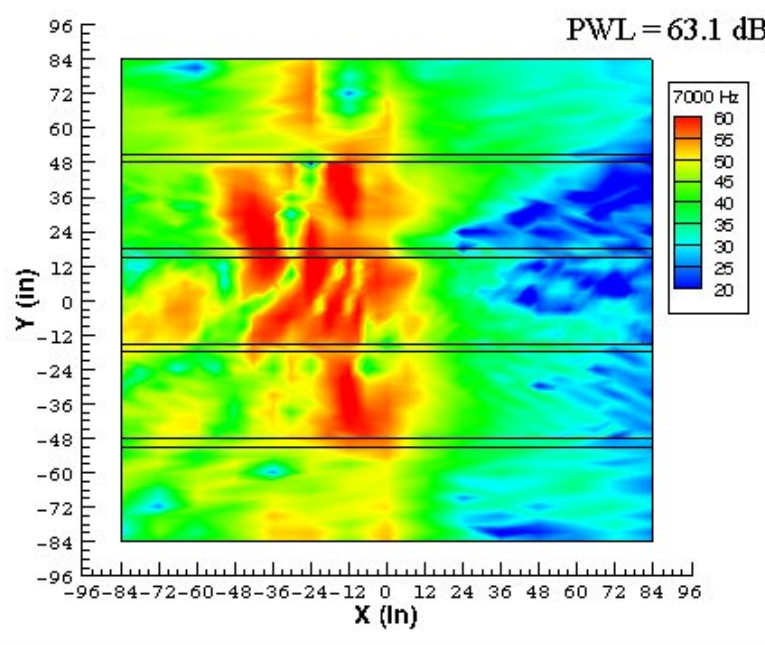

(b) Vertical plane at $72.00 \mathrm{in}$.

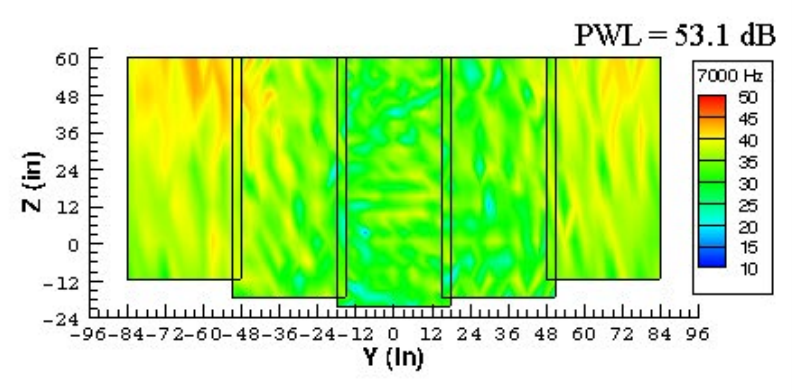

$7 \mathrm{kHz}$ - mode $(4,0)$

$\zeta=1.95$

(d) Vertical plane at 72.00 in.

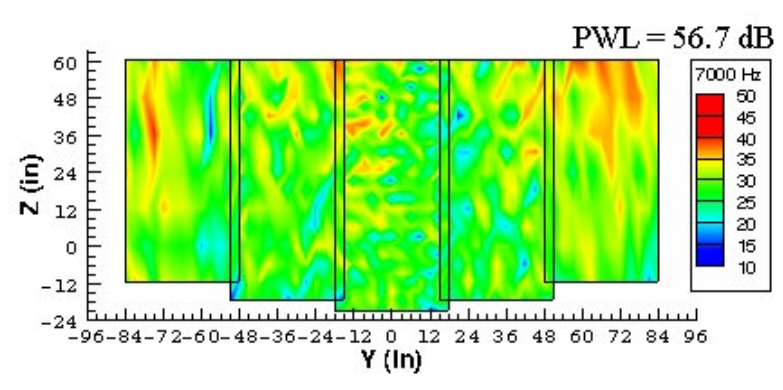

$7 \mathrm{kHz}$ - mode $(6,0)$

$\zeta=1.51$

(f) Vertical plane at 72.00 in.

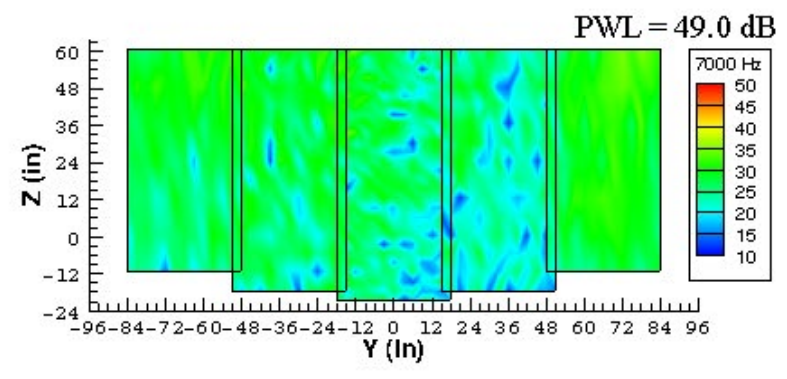

$7 \mathrm{kHz}$ - mode $(8,0)$

$\zeta=1.01$

Figure 22.-Exhaust Nacelle with Wall Installed Contour Plots (Circumferential Mode Variation). 
(a) Horizontal plane at 44.75 in. above

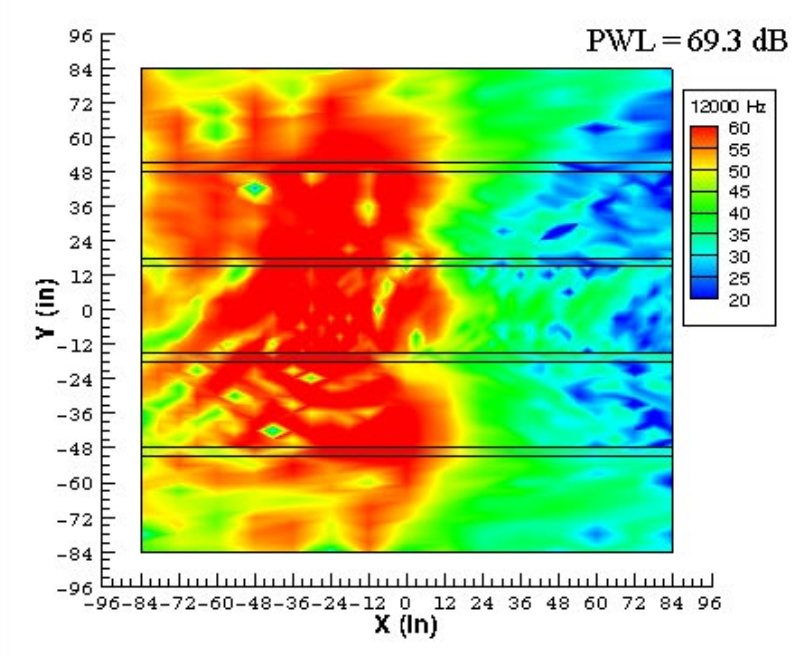

(c) Horizontal plane at 44.75 in. above

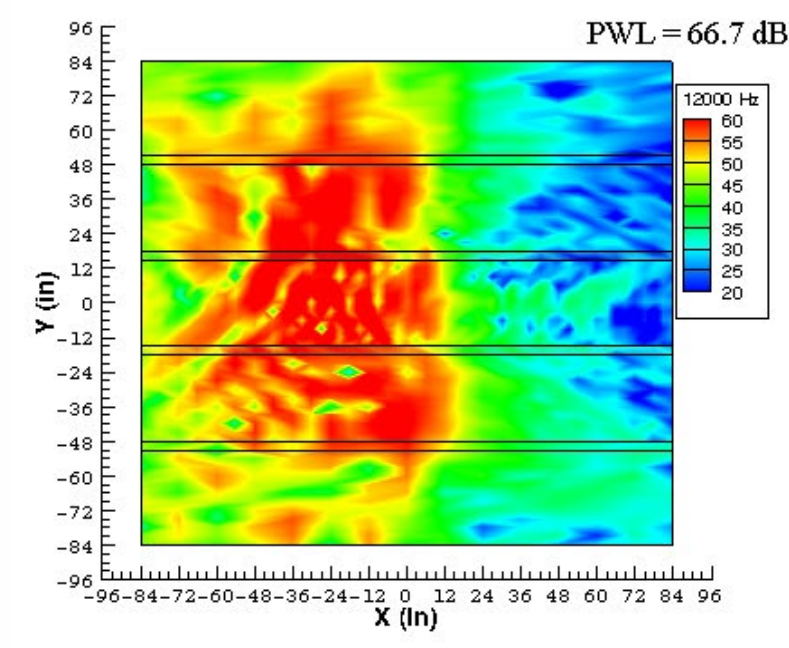

(e) Horizontal plane at 44.75 in. above

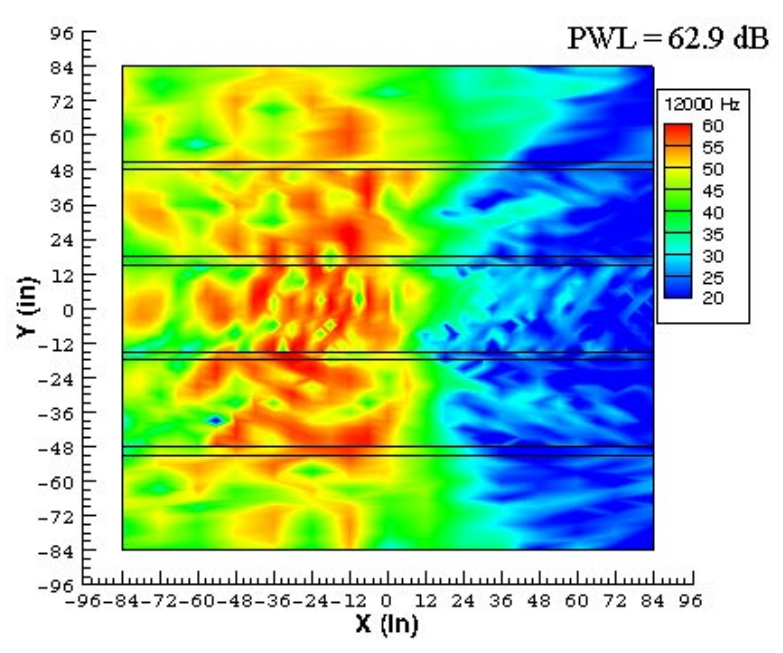

(b) Vertical plane at 72.00 in.

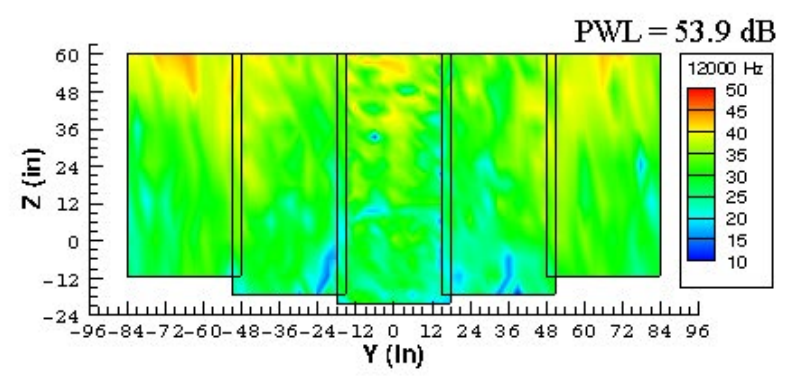

$12 \mathrm{kHz}$ - mode $(8,0) /(8,1)$ both driver sets

(d) Vertical plane at 72.00 in.

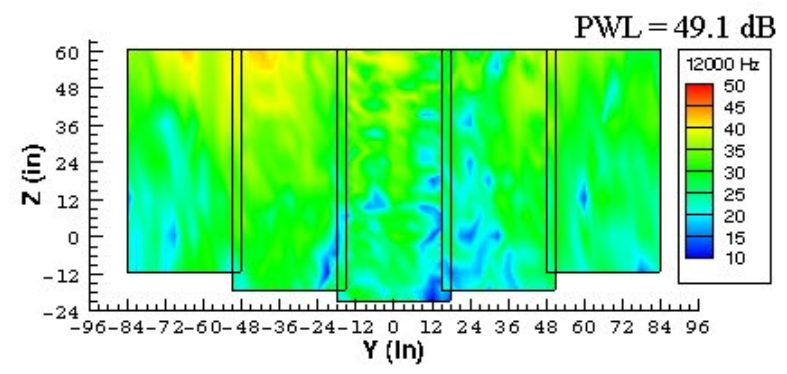

$12 \mathrm{kHz}$ - mode $(8,0) /(8,1)$ outer driver set

(f) Vertical plane at 72.00 in.

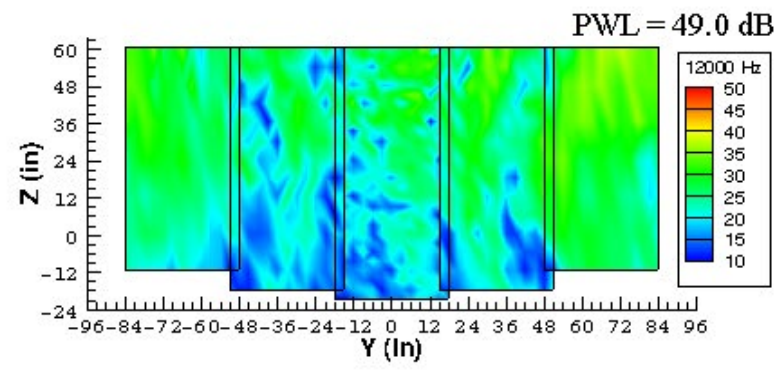

$12 \mathrm{kHz}$ - mode $(8,0) /(8,1)$

imer driver set

Figure 23.-Exhaust Nacelle with Wall Installed Contour Plots (Radial Mode Variation). 


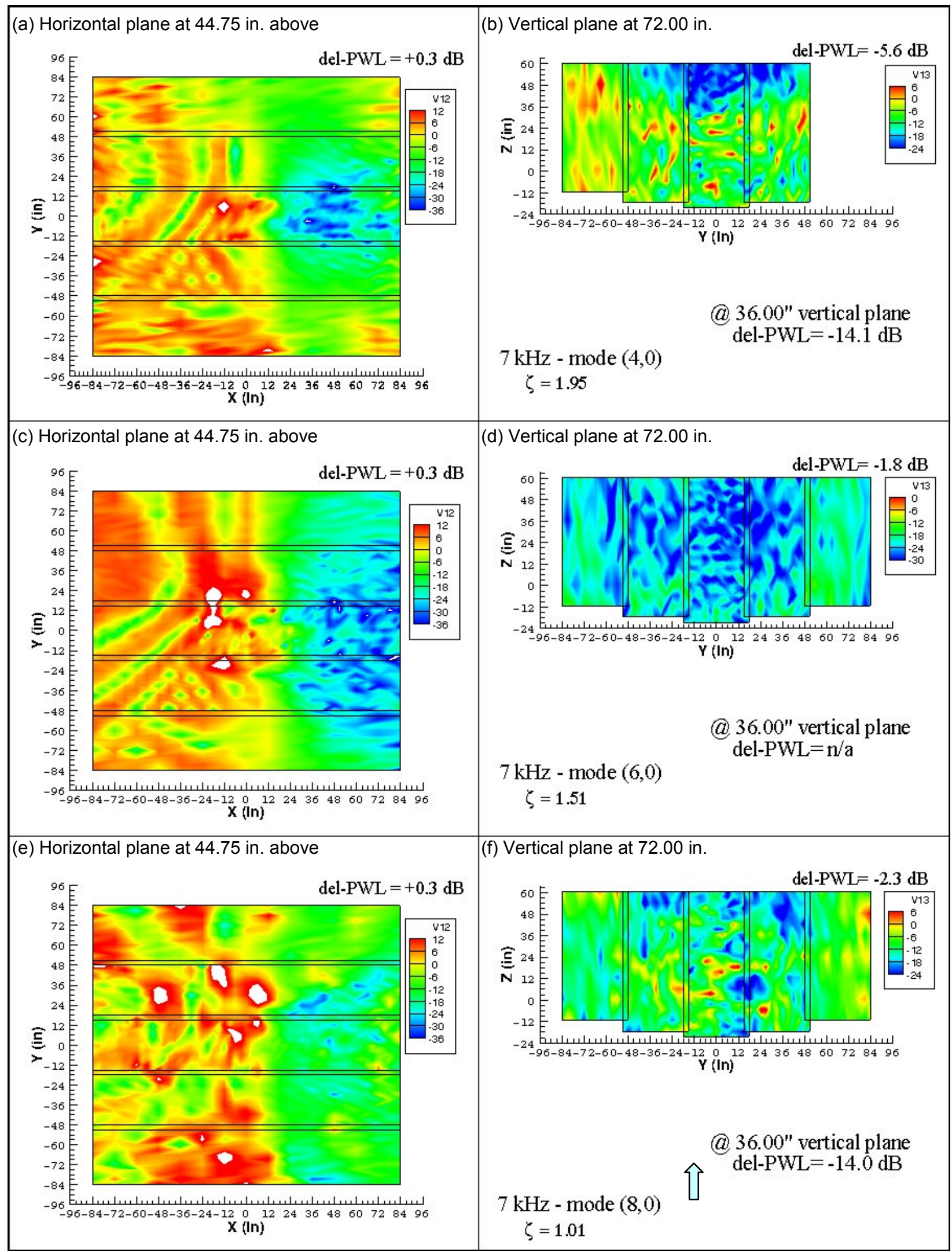

Figure 24.-Exhaust Nacelle Shielding (delta) Contour Plots (Circumferential Mode Variation). 


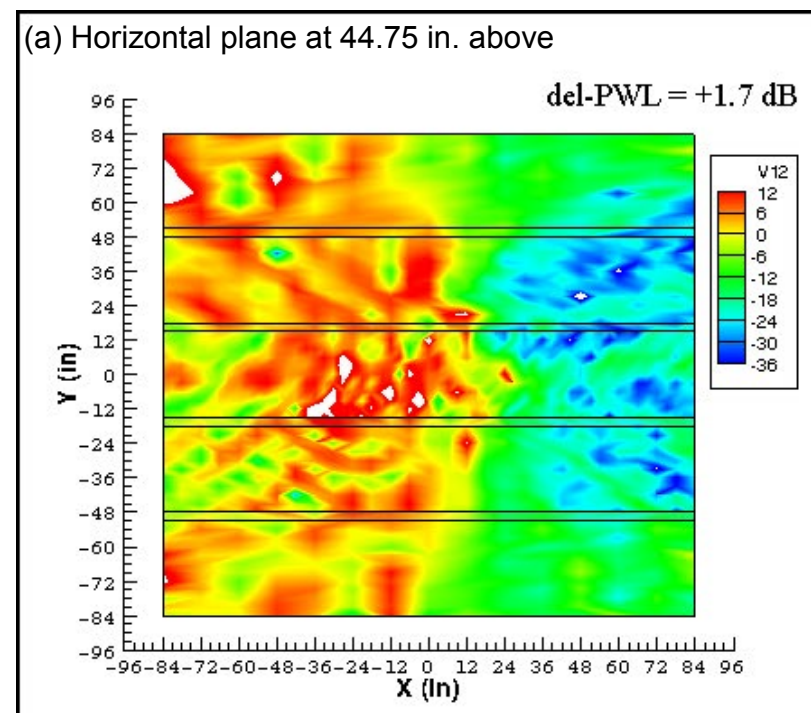

(c) Horizontal plane at 44.75 in. above

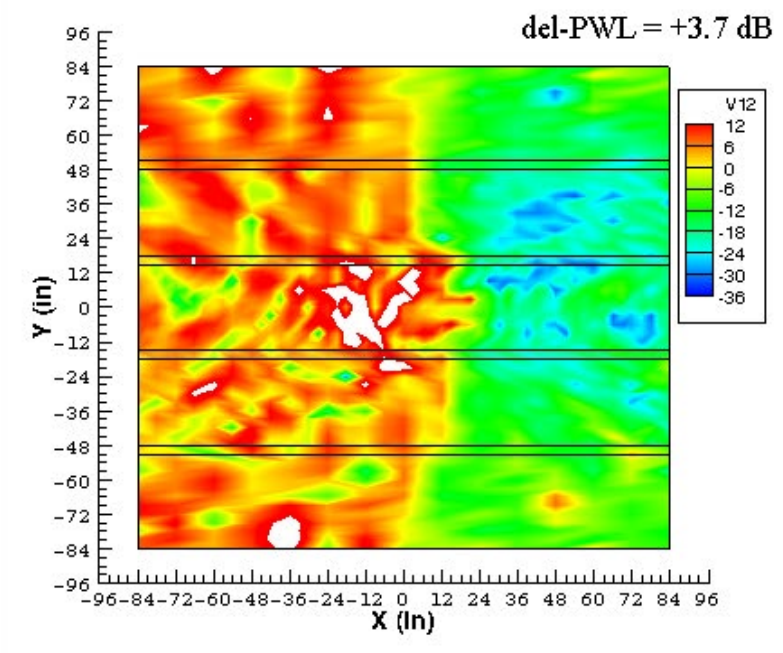

(e) Horizontal plane at 44.75 in. above

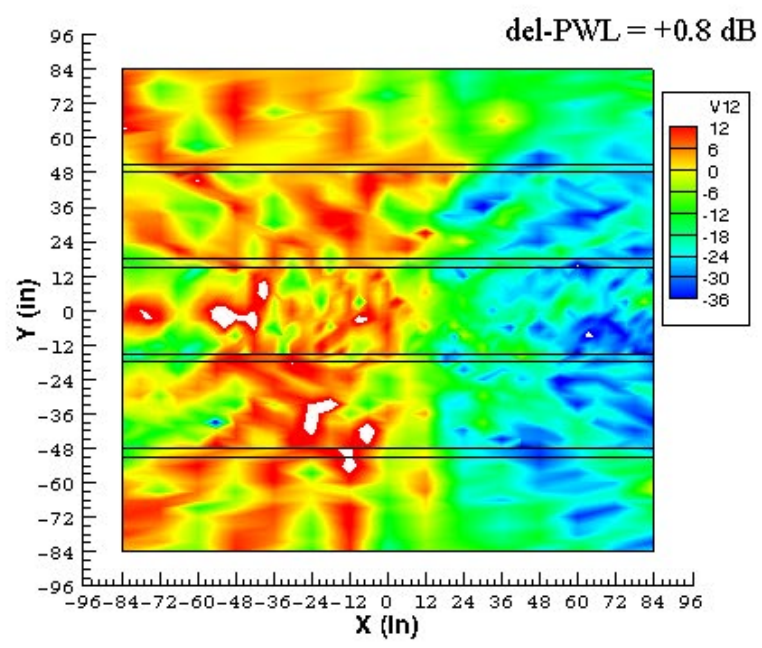

(b) Vertical plane at 72.00 in.

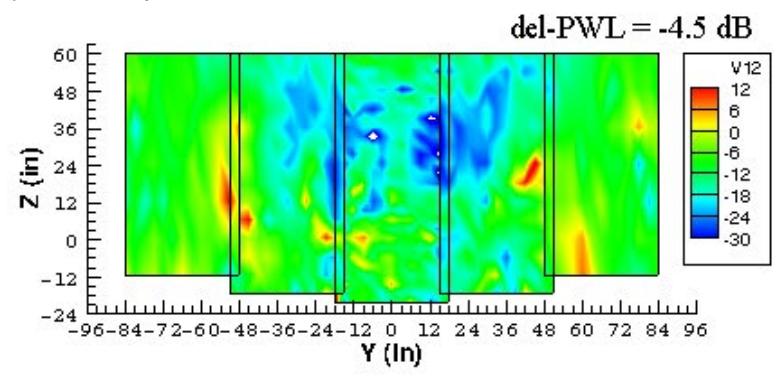

(a) $36.00^{\prime \prime}$ vertical plane del-PWL n/a

$12 \mathrm{kHz}$ - mode $(8,0) /(8,1)$ both driver sets

(d) Vertical plane at 72.00 in.

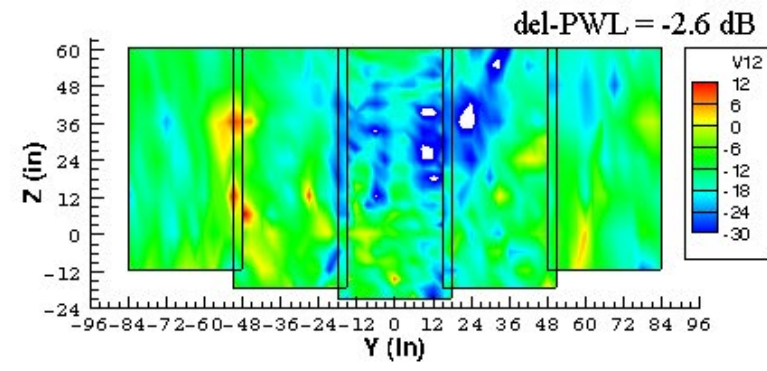

(a) $36.00^{\prime \prime}$ vertical plane del-PWL $=-15.8 \mathrm{~dB}$

$12 \mathrm{kHz}$ - mode $(8,0) /(8,1)$ outer driver set

(f) Vertical plane at 72.00 in.

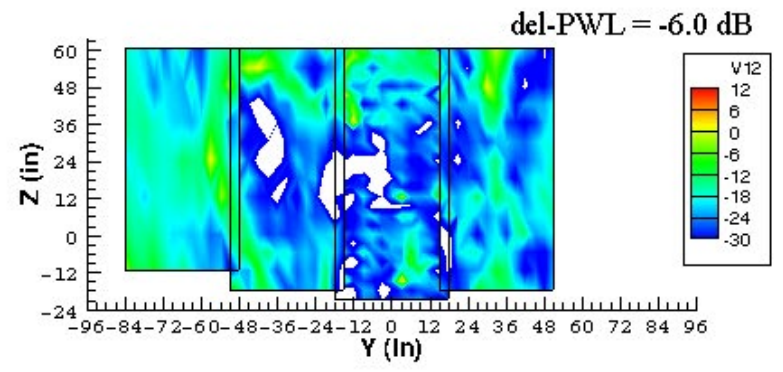

(a) 36.00" vertical plane del-PWL $=-19.8 \mathrm{~dB}$

$12 \mathrm{kHz}$ - mode $(8,0) /(8,1)$ inner driver set

Figure 25.-Exhaust Nacelle Shielding (delta) Contour Plots (Radial Mode Variation). 


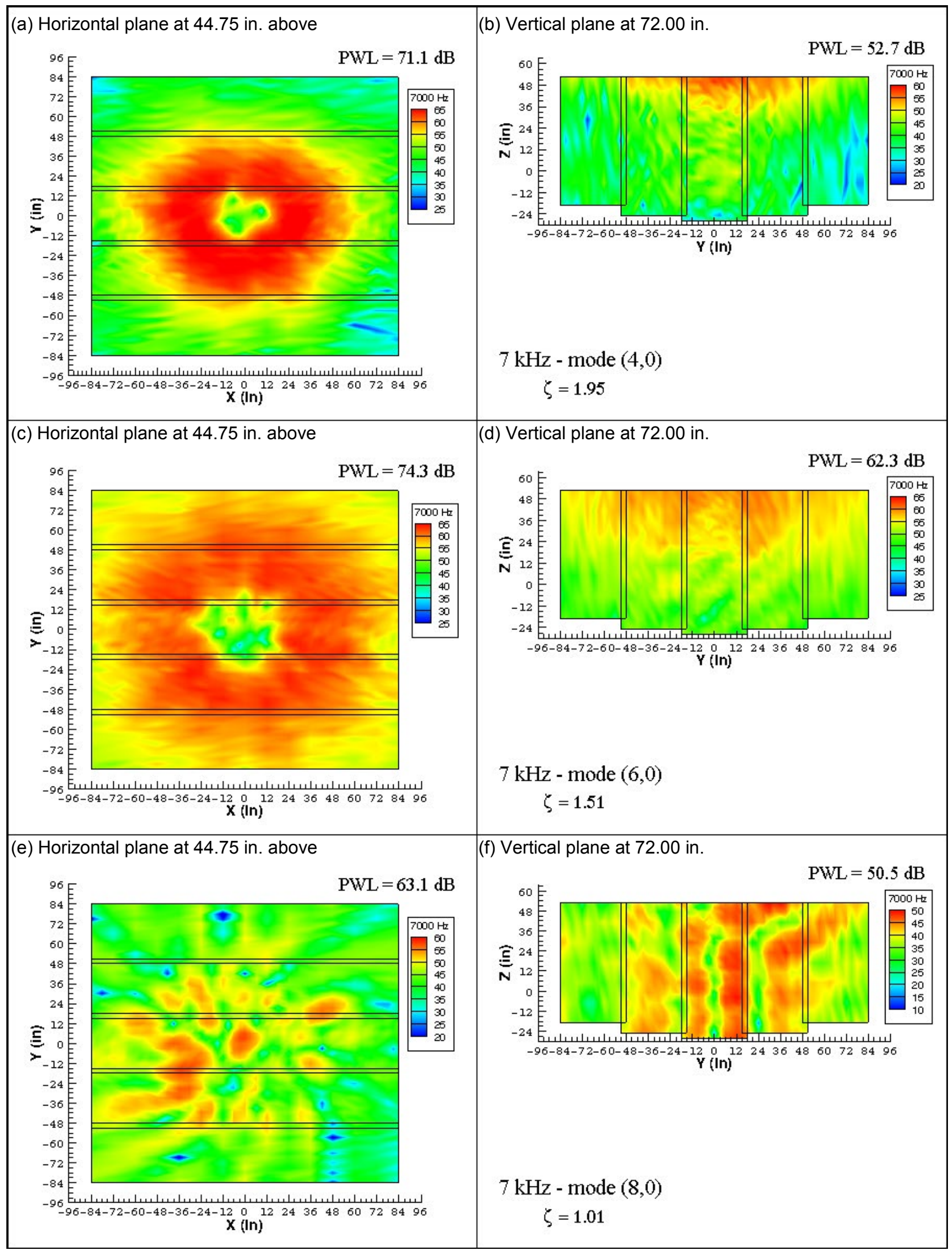

Figure 26.-Inlet Nacelle Alone Contour Plots (Circumferential Mode Variation). 


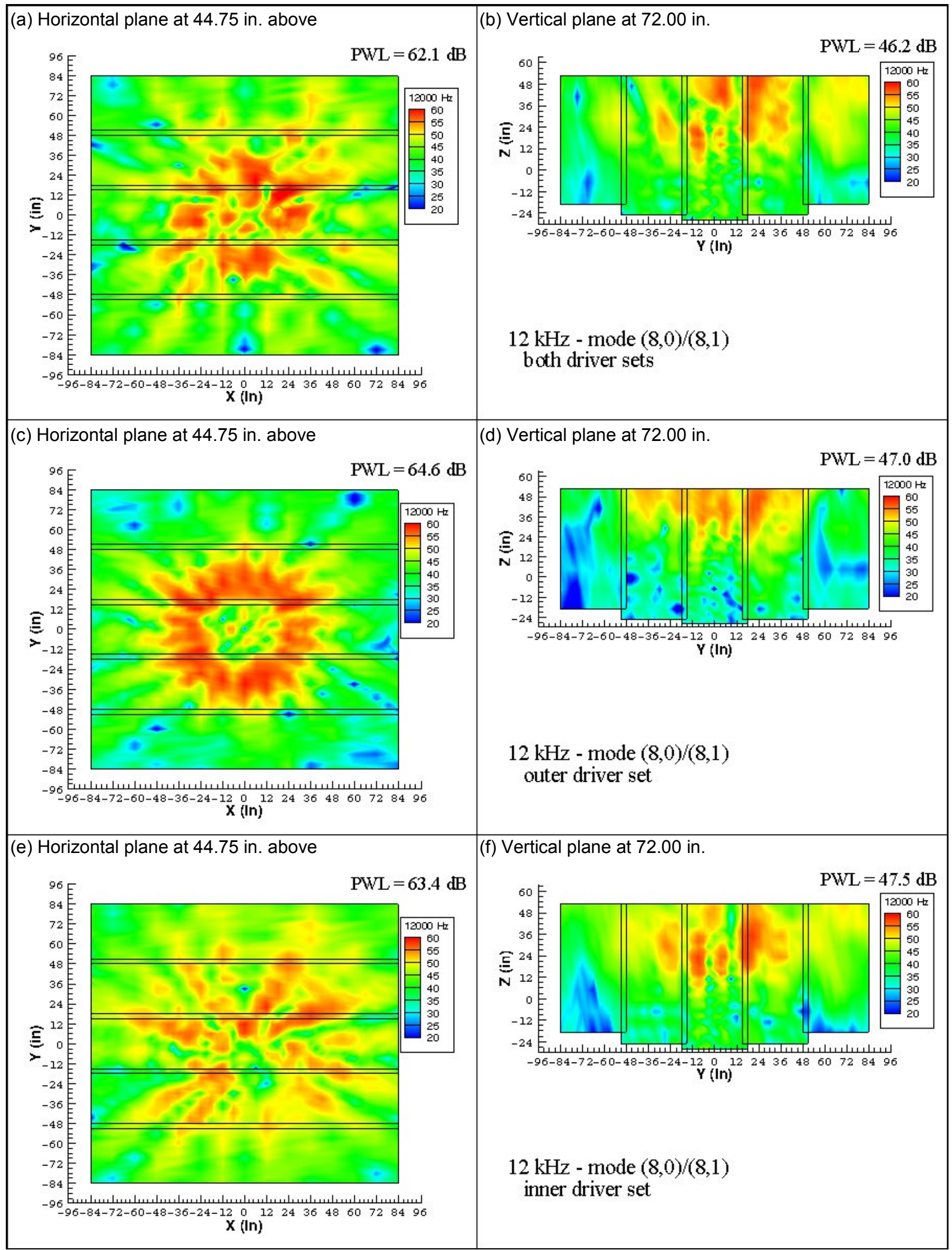

Figure 27.--Inlet Nacelle Alone Contour Plots (Radial Mode Variation). 


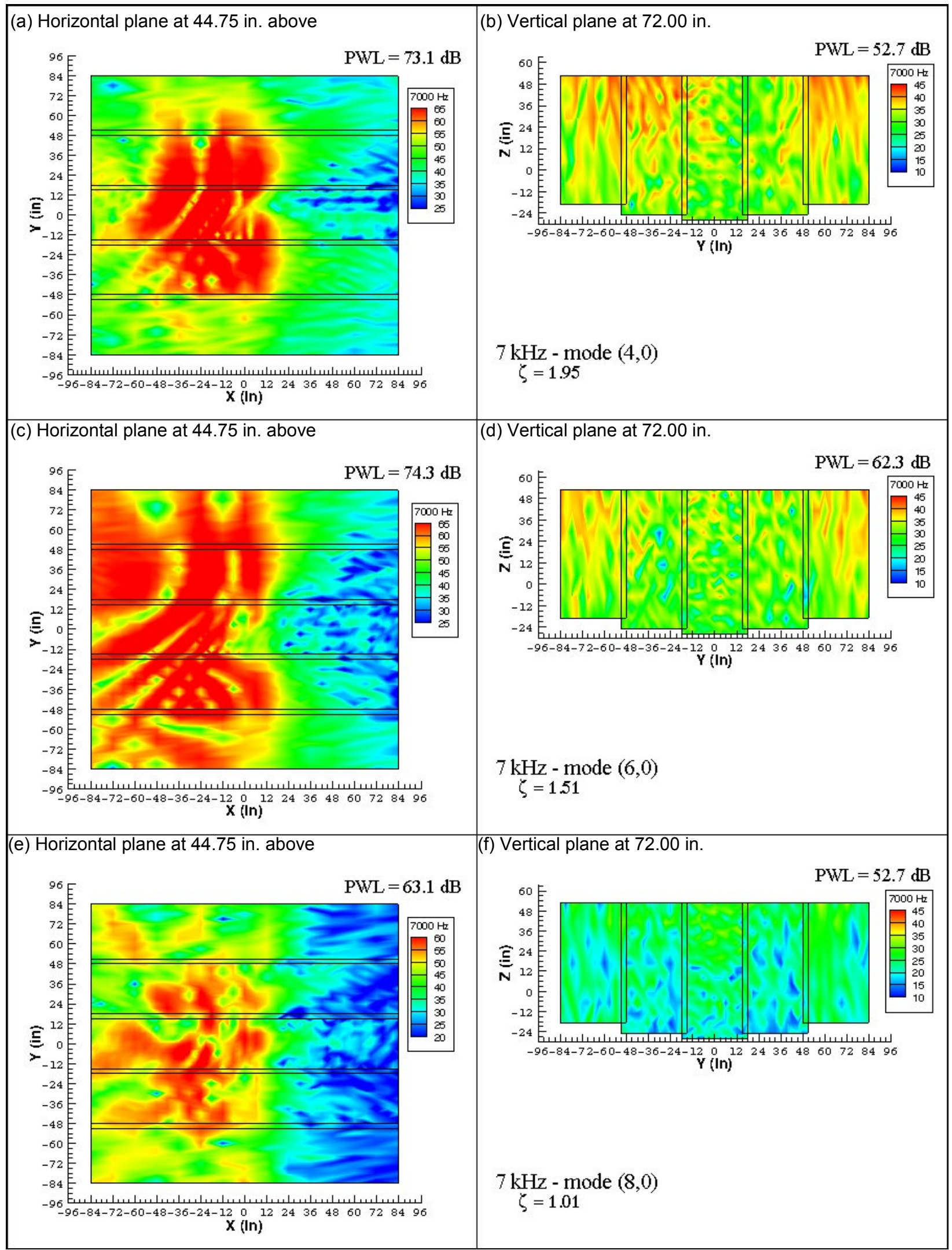

Figure 28.-Inlet Nacelle w/ Wall Installed Contour Plots (Circumferential Mode Variation). 
(a) Horizontal plane at 44.75 in. above

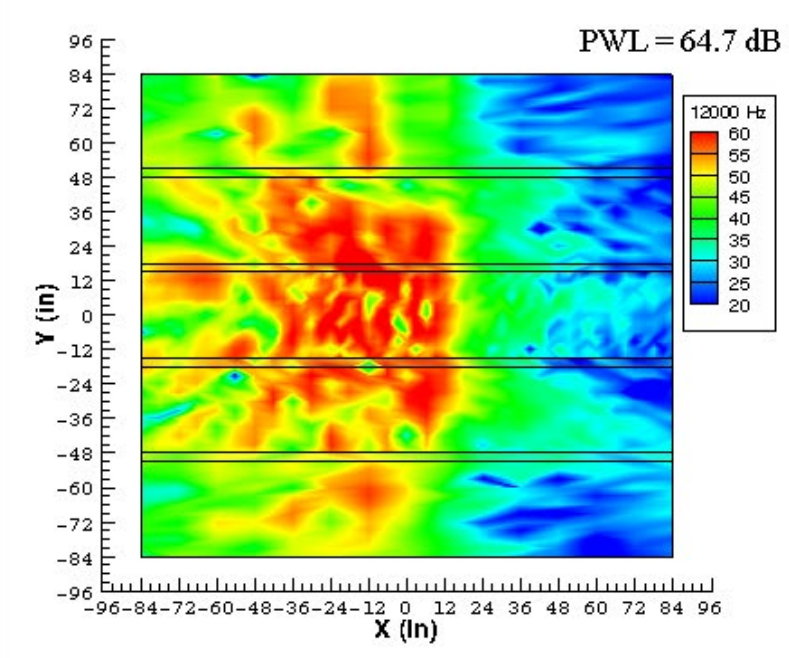

(c) Horizontal plane at 44.75 in. above

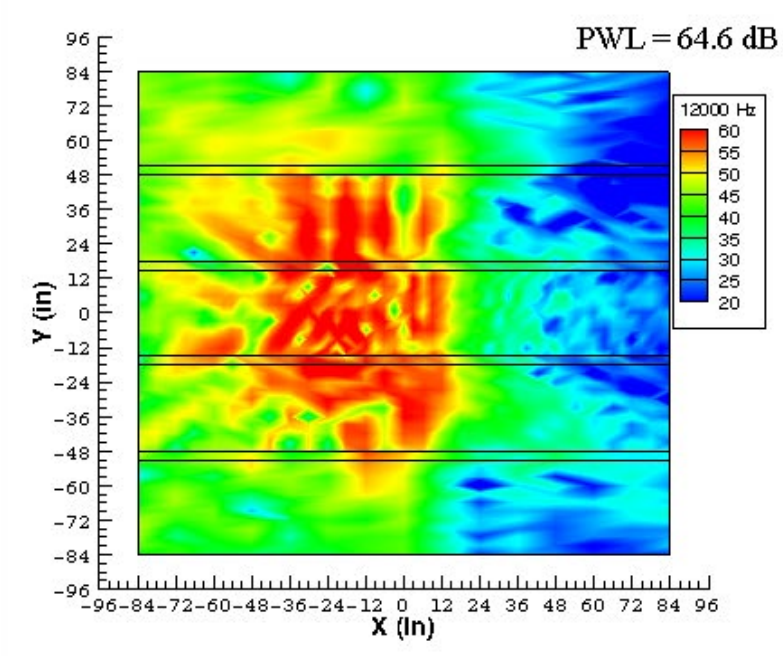

(e) Horizontal plane at 44.75 in. above

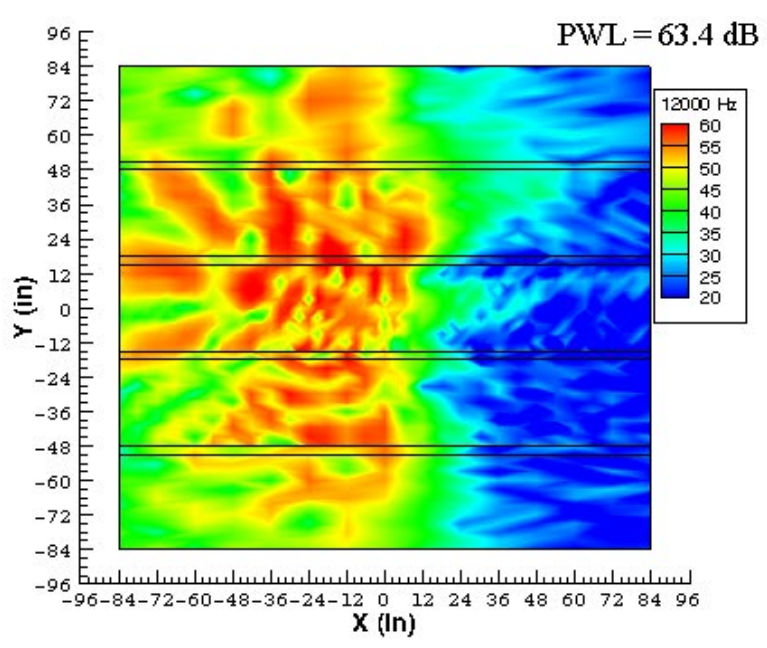

(b) Vertical plane at 72.00 in.

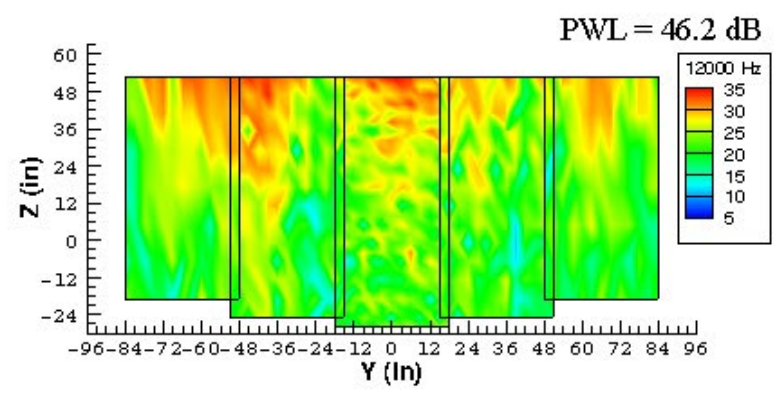

$12 \mathrm{kHz}$ - mode $(8,0) /(8,1)$ both driver sets

(d) Vertical plane at 72.00 in.

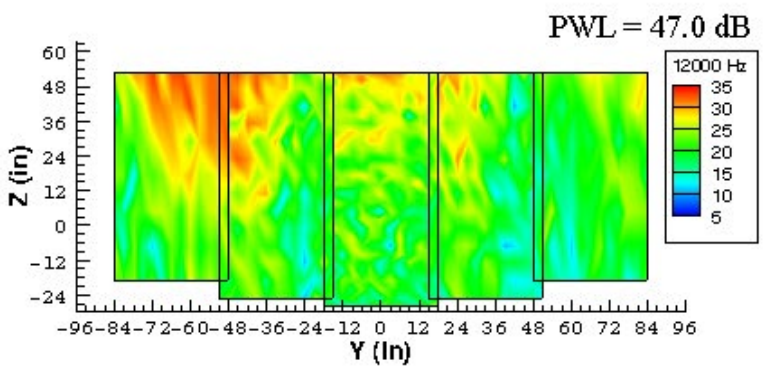

$12 \mathrm{kHz}$ - mode $(8,0) /(8,1)$ outer driver set

(f) Vertical plane at 72.00 in.

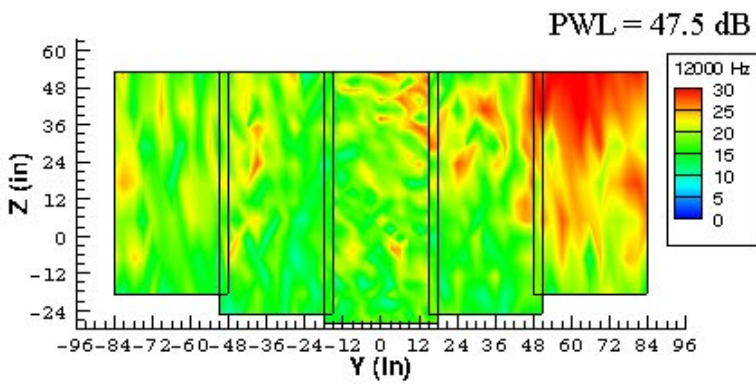

$12 \mathrm{kHz}$ - mode $(8,0) /(8,1)$ inner driver set

Figure 29._-Inlet Nacelle w/ Wall Installed Contour Plots (Radial Mode Variation). 


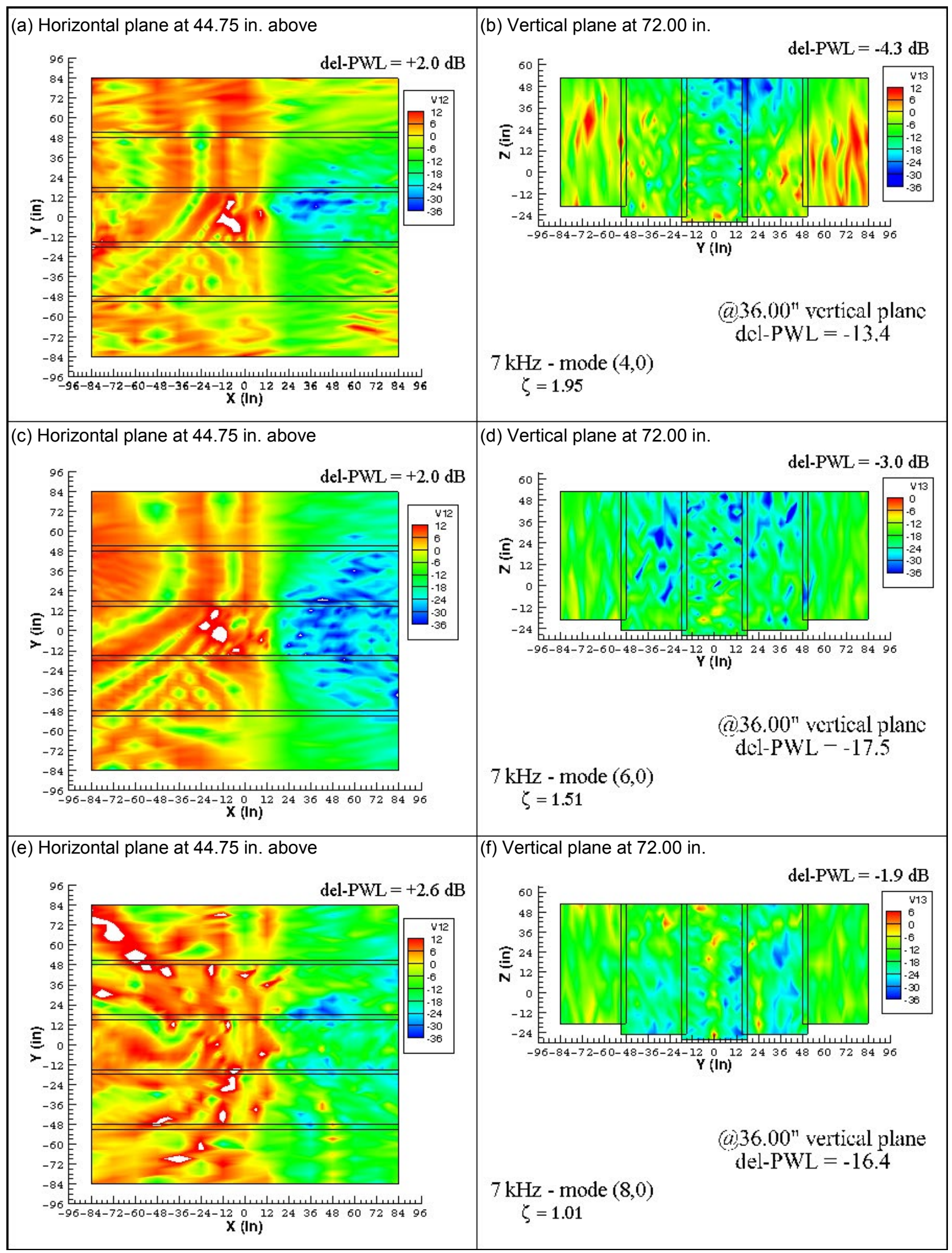

Figure 30.--Inlet Nacelle Shielding (delta) Contour Plots (Circumferential Mode Variation). 
(a) Horizontal plane at 44.75 in. above

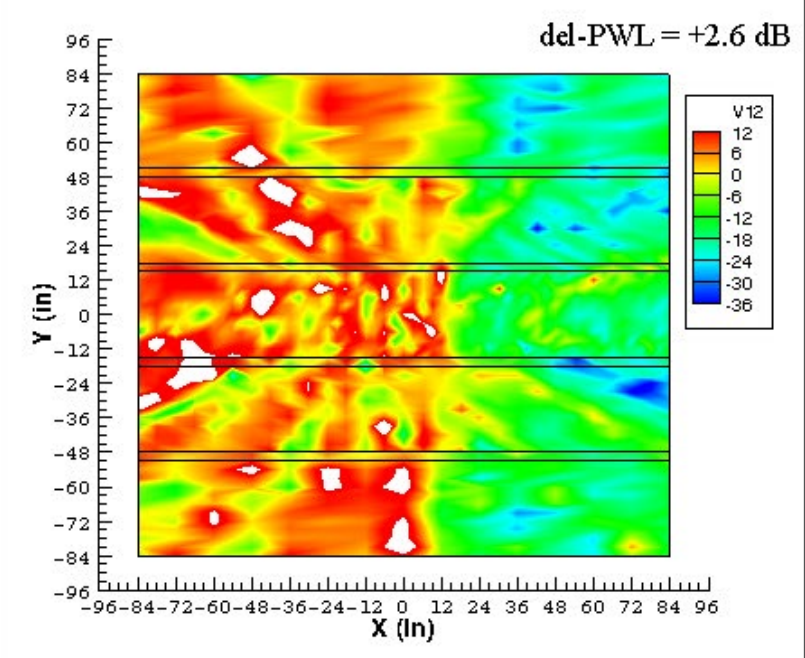

(c) Horizontal plane at 44.75 in. above

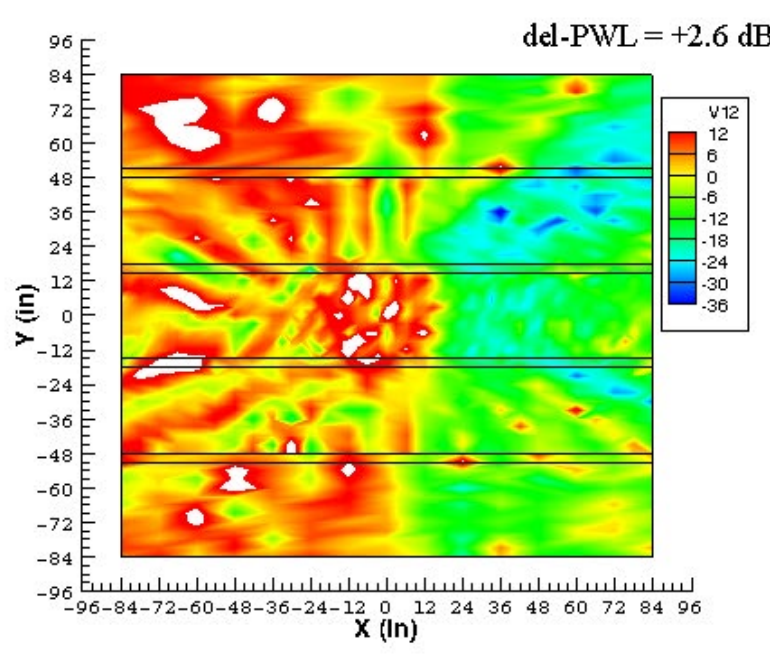

(e) Horizontal plane at 44.75 in. above

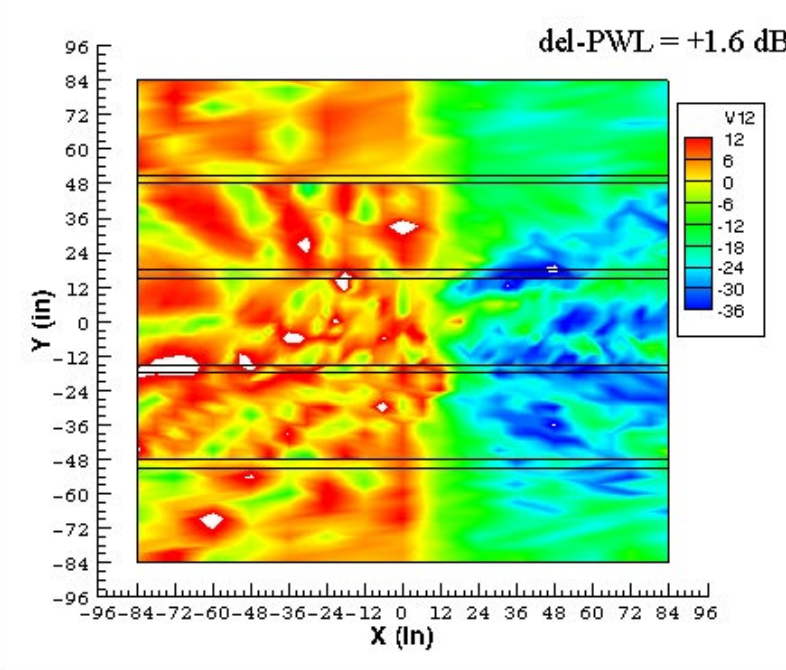

(b) Vertical plane at 72.00 in.

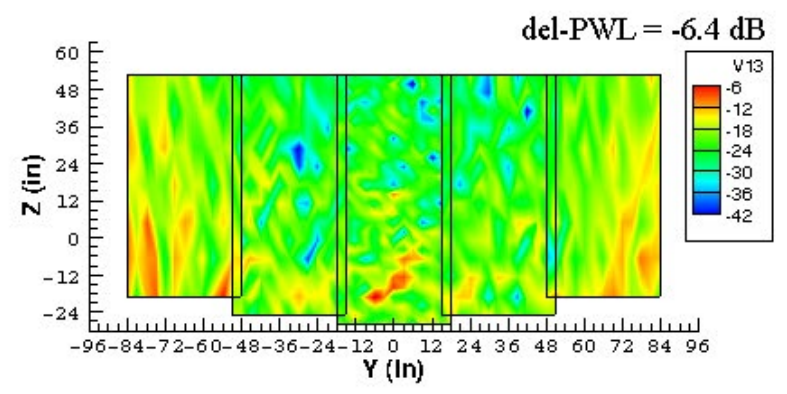

(a) 36.00 vertical plane del-PWL $=-14.6$

$12 \mathrm{kHz}$ - mode $(8,0) /(8,1)$

(d) Vertical plane at $72.00 \mathrm{in}$.

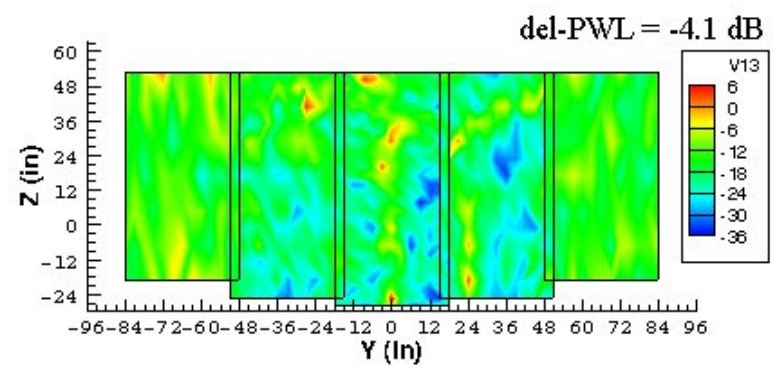

(d36.00 vertical plane del-PWL = -13.8

$12 \mathrm{kHz}$ - mode $(8,0) /(8,1)$

(f) Vertical plane at 72.00 in.

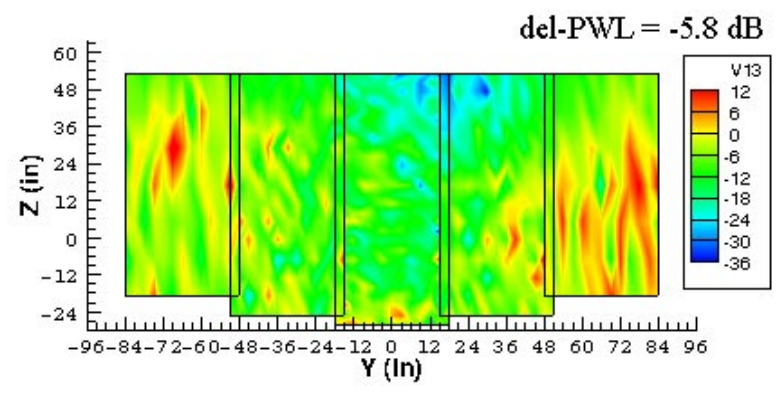

@36.00 vertical plane del-PWL $=-19.8$

$12 \mathrm{kHz}$ - mode $(8,0) /(8,1)$

Figure 31._-Inlet Nacelle Shielding (delta) Contour Plots (Radial Mode Variation). 


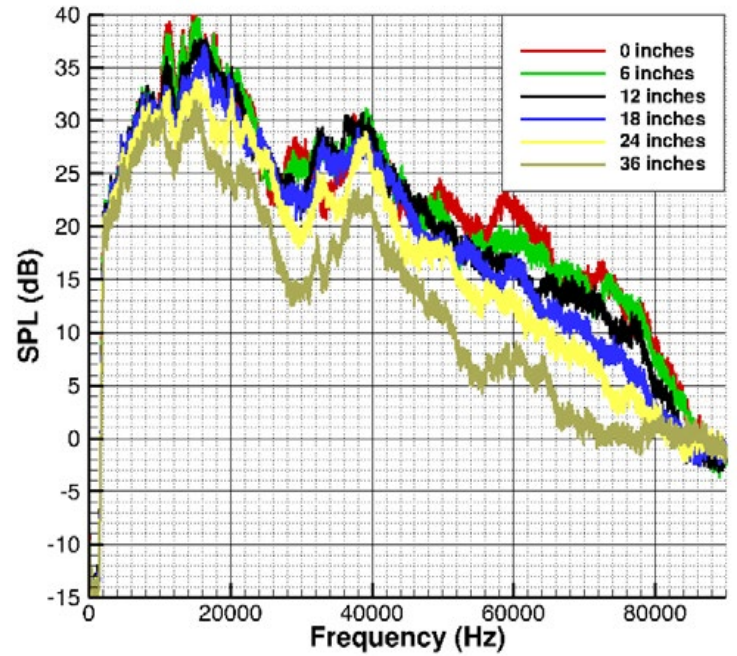

(a) Horizontal plane at 44.75 in. above (no wall)

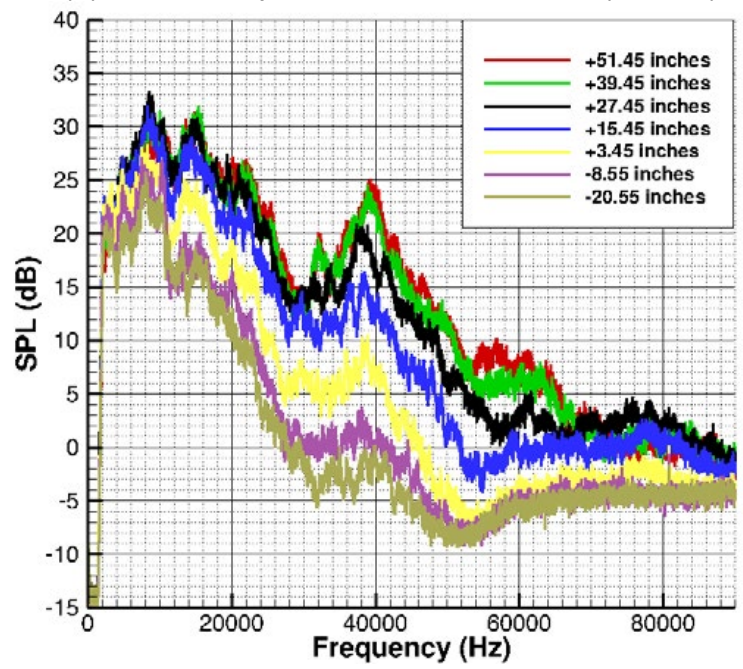

(c) Vertical plane at 36.00 in. (no wall)

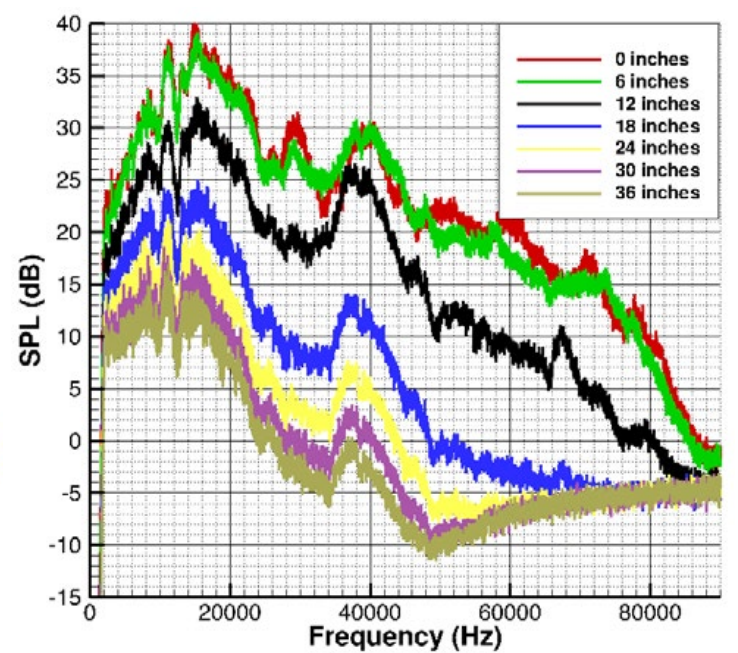

(b) Horizontal plane at 44.75 in. above (wall)

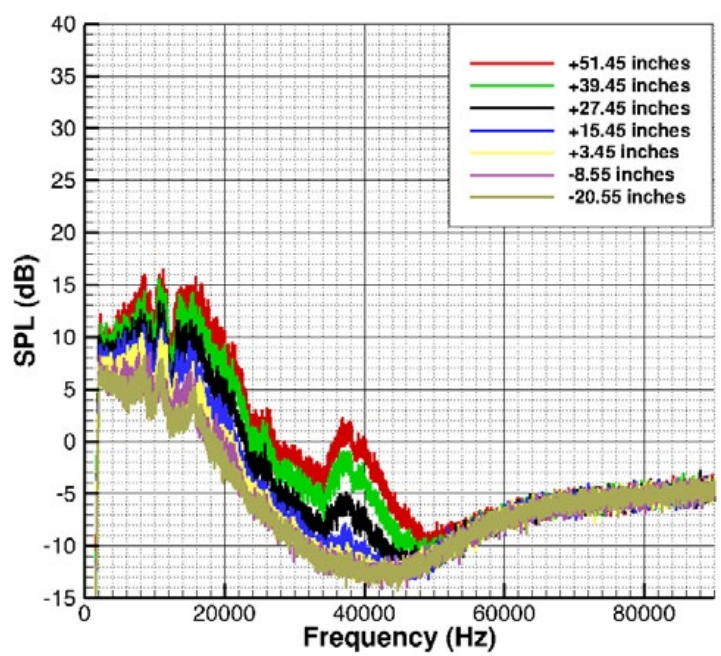

(d) Vertical plane at 36.00 in. (wall)

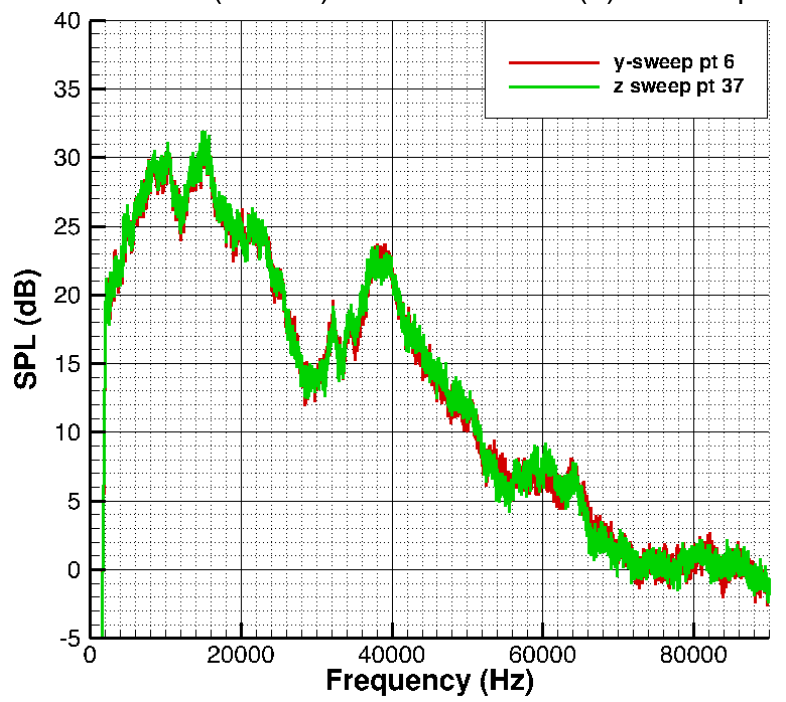

(e) "Intersection point"-Repeat

Figure 32.-Example of Broadband Signature-Exhaust Nacelle. 


\subsection{Conclusion}

The Ultrasonic Configurable Fan Artificial Noise Source (UCFANS) test fixture is a configurable fan-mode simulator for scale model testing of acoustic shielding. A sample subset of data was presented for illustrative purposes representing the range of cases tested. In-duct modal analysis and external radiation patterns confirm that consistent targeted combinations of frequencies and modal structure can be achieved. Qualitatively, the far-field modal and shielding characteristics are as would be intuitively expected and thus suitable for code validation and can be used for first order approximation shielding benefits of fan tone noise for system study purposes.

The frequencies, and hence more complex modal structure, based on the operating points for the Advanced Ducted Propulsor class engines selected for the Hybrid Wing Body aircraft, will be reported in a flow-on paper.

\section{References}

1. Dr. Fay Collier, Eddie Zavala, Dennis Huff, "Fundamental Aeronautics Program Subsonic Fixed Wing Reference Document."

2. HWB N+2 Phase II Final Report, NASA ARMD Subsonic Fixed Wing Project, "Acoustic Prediction Methodology and Test Validation for an Efficient Low-Noise Hybrid Wing Body Subsonic Transport," NASA Contract Number NNL07AA54C, Final Report, February 2011.

3. Beth Cooper, Alan Eckel, Trent Butcher, and David Nelson, "New Acoustical Testing Laboratory at NASA," Sound \& Vibration. Dec. 2000: 10-18.

4. Heidelberg, L.J. and Elliott, D.M., "A Comparison of Measured one Modes for Two Low Noise Propulsion Fans," NASA/TM-2000-210231, AIAA-2000-1989.

5. Schroeder, M.R., Number Theory in Science and Communication, Springer-Verlag 1984.

6. http://www.wildlife-sound.org/equipment/technote/micdesigns/ultrasonic.html, accessed 27-October, 2011. 



\begin{tabular}{|c|c|c|}
\hline \multicolumn{2}{|c|}{ REPORT DOCUMENTATION PAGE } & $\begin{array}{l}\text { Form Approved } \\
\text { OMB No. 0704-0188 }\end{array}$ \\
\hline \multicolumn{3}{|c|}{$\begin{array}{l}\text { The public reporting burden for this collection of information is estimated to average } 1 \text { hour per response, including the time for reviewing instructions, searching existing data sources, gathering and maintaining the } \\
\text { data needed, and completing and reviewing the collection of information. Send comments regarding this burden estimate or any other aspect of this collection of information, including suggestions for reducing this } \\
\text { burden, to Department of Defense, Washington Headquarters Services, Directorate for Information Operations and Reports (0704-0188), } 1215 \text { Jefferson Davis Highway, Suite } 1204 \text {, Arlington, VA } 22222-24302 \text {. } \\
\text { Respondents should be aware that notwithstanding any other provision of law, no person shall be subject to any penalty for failing to comply with a collection of information if it does not display a currently valid OMB } \\
\text { control number. } \\
\text { PLEASE DO NOT RETURN YOUR FORM TO THE ABOVE ADDRESS. }\end{array}$} \\
\hline $\begin{array}{l}\text { 1. REPORT DATE (DD-MM-YYYY) } \\
01-11-2012\end{array}$ & $\begin{array}{l}\text { 2. REPORT TYPE } \\
\text { Technical Memorandum }\end{array}$ & 3. DATES COVERED (From - To) \\
\hline \multirow{3}{*}{\multicolumn{2}{|c|}{$\begin{array}{l}\text { 4. TITLE AND SUBTITLE } \\
\text { Hybrid Wing Body Shielding Studies Using an Ultrasonic Configurable Fan Artificial Noise } \\
\text { Source Generating Simple Modes }\end{array}$}} & 5a. CONTRACT NUMBER \\
\hline & & 5b. GRANT NUMBER \\
\hline & & 5c. PROGRAM ELEMENT NUMBER \\
\hline \multirow{3}{*}{\multicolumn{2}{|c|}{$\begin{array}{l}\text { 6. AUTHOR(S) } \\
\text { Sutliff, Daniel, L.; Brown, Clifford, A; Walker, Bruce, E. }\end{array}$}} & 5d. PROJECT NUMBER \\
\hline & & 5e. TASK NUMBER \\
\hline & & $\begin{array}{l}\text { 5f. WORK UNIT NUMBER } \\
\text { WBS 699959.02.10.03.05 }\end{array}$ \\
\hline \multicolumn{2}{|c|}{$\begin{array}{l}\text { 7. PERFORMING ORGANIZATION NAME(S) AND ADDRESS(ES) } \\
\text { National Aeronautics and Space Administration } \\
\text { John H. Glenn Research Center at Lewis Field } \\
\text { Cleveland, Ohio 44135-3191 }\end{array}$} & $\begin{array}{l}\text { 8. PERFORMING ORGANIZATION } \\
\text { REPORT NUMBER } \\
\text { E-18368 }\end{array}$ \\
\hline \multirow{2}{*}{\multicolumn{2}{|c|}{$\begin{array}{l}\text { 9. SPONSORING/MONITORING AGENCY NAME(S) AND ADDRESS(ES) } \\
\text { National Aeronautics and Space Administration } \\
\text { Washington, DC 20546-0001 }\end{array}$}} & $\begin{array}{l}\text { 10. SPONSORING/MONITOR'S } \\
\text { ACRONYM(S) } \\
\text { NASA }\end{array}$ \\
\hline & & $\begin{array}{l}\text { 11. SPONSORING/MONITORING } \\
\text { REPORT NUMBER } \\
\text { NASA/TM-2012-217685 }\end{array}$ \\
\hline \multicolumn{3}{|c|}{$\begin{array}{l}\text { 12. DISTRIBUTIONIAVAILABILITY STATEMENT } \\
\text { Unclassified-Unlimited } \\
\text { Subject Categories: } 07,09 \text {, and } 71 \\
\text { Available electronically at http://www.sti.nasa.gov } \\
\text { This publication is available from the NASA Center for AeroSpace Information, 443-757-5802 }\end{array}$} \\
\hline
\end{tabular}

\section{SUPPLEMENTARY NOTES}

\section{ABSTRACT}

An Ultrasonic Configurable Fan Artificial Noise Source (UCFANS) was designed, built, and tested in support of the Langley Research Center's 14- by 22-Foot wind tunnel test of the Hybrid Wing Body (HWB) full three-dimensional 5.8 percent scale model. The UCFANS is a 5.8 percent rapid prototype scale model of a high-bypass turbofan engine that can generate the tonal signature of candidate engines using artificial sources (no flow). The purpose of the test was to provide an estimate of the acoustic shielding benefits possible from mounting the engine on the upper surface of an HWB aircraft and to provide a database for shielding code validation. A range of frequencies, and a parametric study of modes were generated from exhaust and inlet nacelle configurations. Radiated acoustic data were acquired from a traversing linear array of 13 microphones, spanning 36 in. Two planes perpendicular to the axis of the nacelle (in its $0^{\circ}$ orientation) and three planes parallel were acquired from the array sweep. In each plane the linear array traversed five sweeps, for a total span of 160 in. acquired. The resolution of the sweep is variable, so that points closer to the model are taken at a higher resolution. Contour plots of Sound Pressure Level, and integrated Power Levels are presented in this paper; as well as the in-duct modal structure.

\section{SUBJECT TERMS}

Fan noise; Test; Ducted fans; Acoustics

\begin{tabular}{|c|c|c|c|c|c|}
\hline \multicolumn{3}{|c|}{ 16. SECURITY CLASSIFICATION OF: } & \multirow{2}{*}{$\begin{array}{l}\text { 17. LIMITATION OF } \\
\text { ABSTRACT } \\
\text { UU }\end{array}$} & \multirow{2}{*}{$\begin{array}{l}\text { 18. NUMBER } \\
\text { OF } \\
\text { PAGES } \\
46\end{array}$} & \multirow{2}{*}{$\begin{array}{l}\text { 19a. NAME OF RESPONSIBLE PERSON } \\
\text { STI Help Desk (email:help@sti.nasa.gov) } \\
\text { 19b. TELEPHONE NUMBER (include area code) } \\
\text { 443-757-5802 }\end{array}$} \\
\hline $\begin{array}{l}\text { a. REPORT } \\
\text { U }\end{array}$ & $\begin{array}{l}\text { b. ABSTRACT } \\
\text { U }\end{array}$ & $\begin{array}{l}\text { c. THIS } \\
\text { PAGE } \\
\text { U }\end{array}$ & & & \\
\hline
\end{tabular}



